\title{
MASER
}

\section{An Assessment of the Once-Through Cooling Alternative for Centra! \\ Steam-Electric Generating Stations}

by

R. A. Paddock and J. D. Ditmars

WATER RESOURCES

RESEARCH PROGRAM

EES

\section{ANL}
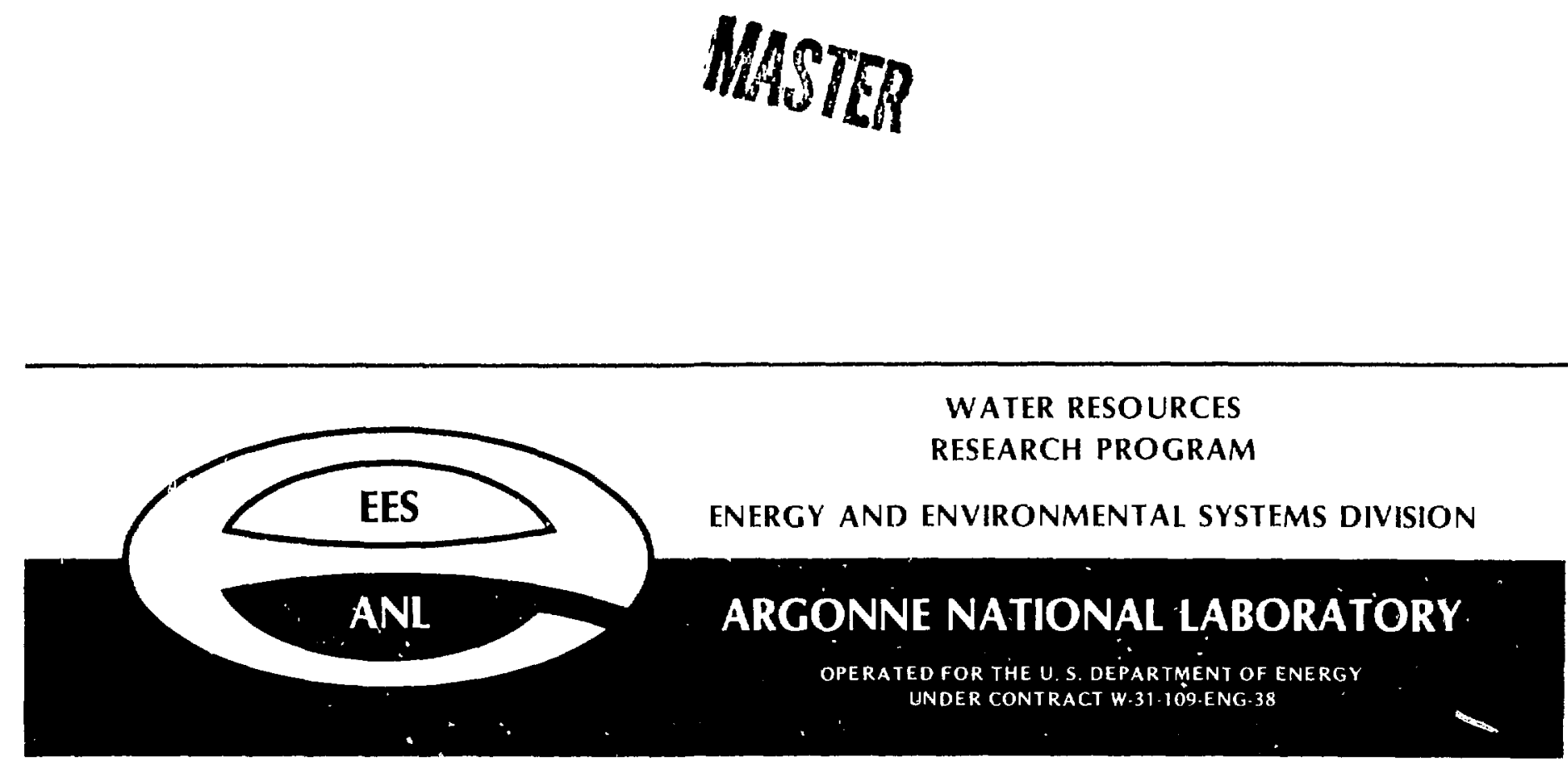
Distribution Categories:

Environmental Control Technology and iarth Sciencts (UC-11)

Heat Rejection and Utilization $(\mathrm{vC}-12)$

iNL/WR-78-5

\begin{abstract}
ARGONNE NATIONAL JABORATORY
9700 South Cass Avenue Argonne, Illinois 60439
\end{abstract}

AN ASSESSMENT OF THE ONCE-THROUGH COOLINC

ALTERNATIVE FOR CENTRAL STEAM-ELEC'T'RIC

GENERATING STATIONS

by

R. A. Paddock and J. D. Ditnars

Energy and Environmenta]. Systems Division

December 1978

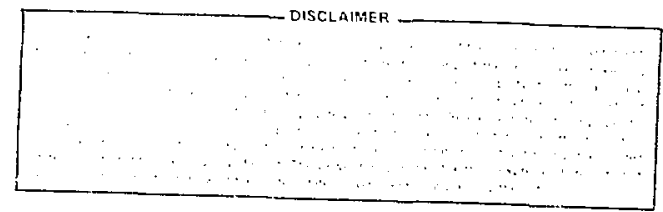

Work Sponsored By

Division of Environmental Control Technology

office of Environment

U.S. Department of Energy 
3.] Waste Heat Disposizl

1.2 Fnvironnental lifiects buce Le once-Through cooling

1.3 Srepe of issestisment of onre-Through cooling

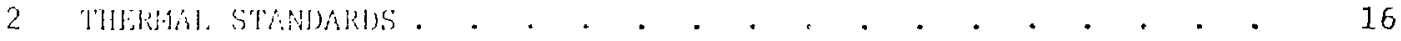

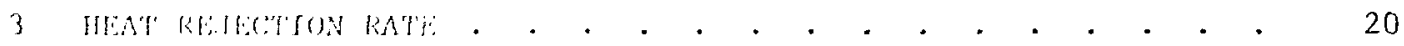

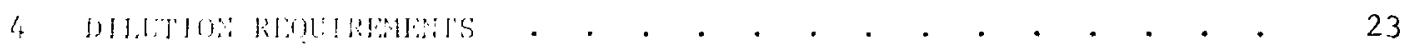

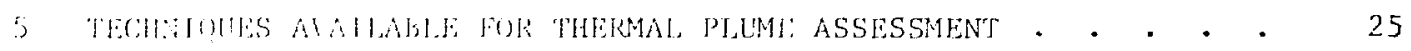

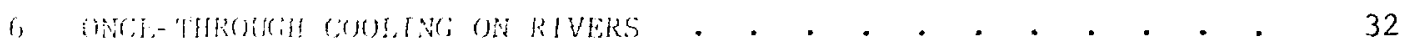

h. lieneral fiegures . . . . . . . . . . . . . . 32

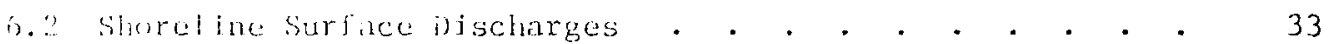

6. 3 Submergerl Multiport diffusers . . . . . . . . . . . . 38

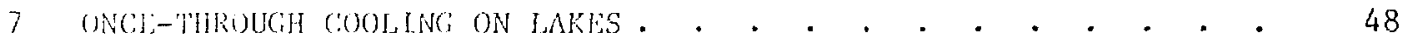

7.1 Ceneral fealures . . . . . . . . . . . . . . 48

7.2 Shoreline Surface Discharges . . . . . . . . . . . . . . 48

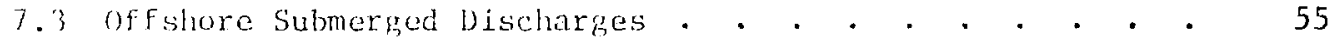

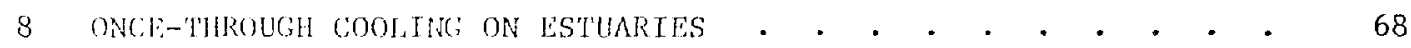

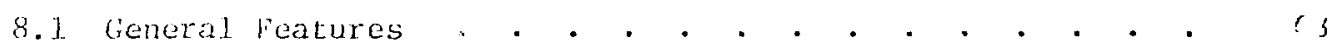

8.? Shoreline Discharges . . . . . . . . . . . . . . . 10

8.3 Submerged Multiport Diffusers . . • . . . . . . . 73

9 ONCE-THROUGH COOLTNG ON OPEN COASTAL WATERS • • • • • • • • • $\quad 88$

9.1 Ceneral Features . . . . . . . . . . . . . . 88

9.2 Shoreline Surface Discharges . • . . . . . . . . . . . 90

9.3 Submerged Mu1tiport Diffusers . . . . . . . . . . . 91

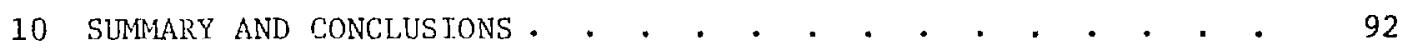
ACENOWLEDGMENTS • • • • • • • • • • • • • • • • • • • • • • REFERENCES • • • • • • • • • • • • • • • • • • • • • • 97 
No.

1. Idealized Shoreline Surface Outfal] and SinglePort Submerged Outfall

2. Submerged Multiport Diffuger Design Concepts . . . . . . 28

3. Comparison of Selected Analytical. Mode] Predictions with Average Results of Field Measurements . . . . . . . . 54

4. Minimum Discharge Densimetric Froude Number Needed for the l'lume from a Single Submerged Round Port to $\Lambda$ ttain a Centerline Di]ution of 6.0 at the Surface vs Relative Water Depth. . . . . . . . . . • . . . . .

5. Iffect of Cross Currents on the Dilution Attained by the Physical Model of the J.A. Fitzpatrick Diffuser. . . . .

6. Minium Discharge Densimetric Froude Number Needed for the Plume from a Single Submerged Round Port to Attain a Centarline Di]ution of 12 at the Surface vs Relative Water Depth.

7. Parametric Representation of the Minimum Surface Dilution Attained by a Staged Diffuser -- Physical Model Results . .

8. Parametric Representation of PLume Surface Area as a runction of Dilution for a Stager Diff. ser . . . . . . 


\section{LIST OF TABLES}

No.

Title

Page

1. Distribution of Use of Various Condenser Ċon]ing

Technologies for Steam-Electric rower llants

Expressed as Percent of Jotal Installed Capacity . . . . . 5

2. Capital Costs of Various Types of Cooling Systens . . . . . 7

3. Ferformance Losses Associated with Various Types of

Cooling Systems

4. Incremental Cost of Closed-Cycle Cooling Towers

over That of a Simple Once-Through cooling System. . . . . 10

5. Typical Excess Temperature (Above Ambient) Stancards

as Recommended by the N'AC . . . . . . . . . . . . 18

6. Typical Large Power Plant Capacities and Assumed

Cooling Water Characteristics . . . . . . . . . .

7. Dilution Requirements for Various keceiving Water

Bodjes Assuming a Typical. Injtial Excess Temperature

of $10.0 \mathrm{C}^{\circ}$

8. Selected Mixing-Zone Data for Shoreline Surface

Discharges on Rivers

9. Estimated Minimum River Flow Rates for Shoreline Surface

Discharges Based on Limiting the Mixing Zone (Dilution

of 3.6) to $25 \%$ of the Cross-Sectional Area of the River . . .

10. Estimated Minimum River Flow Rate Based on Limiting

the Mixing Zone (Dilution of 3.6) to $25 \%$ of the Cross-

Sectional Area of the River, Except as Noted . . . . .

11. Summary of Thermal Plume Surface Area Data Correspond-

ing to a Dilution of 6.0 for Shoreline Surface Discharges:

on Lakes . . . . . . . . . . . . . . .

12. Sumnary of the Discharge Parameters for Four Power

Plants with Shoreline Surface Discharges on Large

\section{Lakes}

13. Estimated Multiport Diffuser Parameters for a Typical

1000-MW Nuclear Power Plant when a Dilution of 6.0

is Required (Quiescent Receiving Water)

14. Estimated Multiport "Tee" Diffuser Parameters for a

Typical 1000-iTw Nuclear Power Plant when a Dilution

of 12 is Required (Quiescent Receiving Water) 


\section{LIST OF TABLES (Contd.)}

No.

Title

Page

15. Estimated Diffuser Length to Attain a Dilution of 12 , Under Stagnant Conditions, for a 1000-MW Nuclear

Power Plant Using an Alternating Diffuser Design . • • • • . 78

16. Estimated Staged Diffuser Length Eor a Typical 1000-MW

Nuclear Power Plant when a Dilution of 12 is Required . . . . 83

17. Estimated Staged Diffuser Length for a Typical. 500-MW

Fossil-Fueled Power Plant when a Dilution of 1.2 is

Required . .

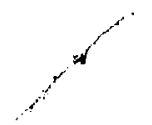




\title{
AN ASSESSMENT OF THE ONCE-THROUGH COOLING \\ ALTERNATIVE FOR CENTRAL STEAM-ELECTRIC \\ GENERATING STATIONS
}

by

R. A. Paddock and J. D. Ditmars

\begin{abstract}
The efficacy of the disposal of waste heat from steamelectric power generation by means of once-through cooling systems was examined in the context of the physical aspects of water quality standards and guidelines for thermal discharges. Typical thermal standards for each of the four classes of water bodies (rivers, lakes, estuaries, and coastal waters) were identified. The mixing and dilution characteristics of various discharge modes ranging from simple, shoreline surface discharges to long, submerged multiport diffusers were examined in terms of the results of prototype measurements, analytical model predictions, and physical model studies. General guidelines were produced that indicate, for a given plant capacity, a given type of receiving water body, and a given discharge mode, the likelihood that once-through cooling can be effected within the restrictions of typical thermal standards.

In general, it was found that shoreline surface discharges would not be adequate for large power plants ( $2500 \mathrm{MW}$ ) at estuarine and marine coastal sites, would be marginally adequate at lake sites, and would be acceptable only at river sites with large currents and river discharges. Submerged multiport diffusers were found to provide the greatest 1ikelihood of meeting thermal standards in all receiving water environments.
\end{abstract}

\section{INTRODUCTION}

The demand for electric power in the United States has doubled every ten years since 1945. This demand is expected to increase steadily in the foreseeable future, although the rate of increase of demand may decrease due to declines in population and industrial growth rates and due to energy conservation policies. Examination of present and near-future energy technologies indicates that most electric power generation will be accomplished at central steam-electric generating plants. For example, in 1974, $84 \%$ of U.S. electric power was produced by steam plants. ${ }^{1}$ Such plants convert thermal energy, derived either from the combustion of fossil fuels or from a nuclear 
reactor, into electric energy with overall thermal efficiencies of $30-40 \%$. As a result of these efficiencies, 1.5-2.3 units of waste heat are produced for each unit of electric energy generated. As significant improvements in thermal efficiency or the introduction of alternative methods of centralstation electric generation are not expected in the near future, the disposal or beneficial utilization of large quantities of waste heat will be an abiding aspect of electric energy generation. The beneficial utilization of low-grade waste heat is in its infancy, and, for the near future, the need for waste heat disposal is expected to continue.

Several alternative technologies exist for the disposal of waste heat from electric power generation: once-through cuoling systems, cooling ponds, spray systems, evaporative cooling towers, and dry towers (or hybrid combinations of these systems). Associated with each disposal technology are economic, energy, and environmental costs. The focus of the present study is one aspect of the environmental control technology for once-through cooling systems -- control of the physical impact on the receiving water body of the thermal plume produced, both in terms of the spatial extent and in terms of the associated excess temperatures. It is the intent of this study to determine, in general terms, the feasibility of effecting once-through cooling within certain physical environmental constraints.

\subsection{WASTE HEAT.DISPOSAL}

Present central-station technology involves removal of the waste (1owgrade) heat from conventinnal steam-electric power cycles by passing large quantities of cooling water through condensers. The heat absorbed by the cooling water must eventually be dissipated to the atmosphere and ultimately outer space, but several technologies exist for the immediate disposal of the heat.

Once-Through Cooling: Cooling water is drawn from a nearby water body (river, lake, reservoir, estuary, or open coastal region), passed through the condensers, and returned directly to the water body at an elevated temperature.

Cooling Ponds: Cooling water is taken from a man-made pond, passed through the condensers, and returned to the pond. The water in the pond is usually thermally stratified, the warmer surface waters dissipate heat to the atmosphere and the cooler deep waters are withdrawn selectively and returned 
to the condensers. Water from nearby natural sources is needed to maintain the pond, and some fraction of the water js usually returned to natural water bodies to reduce the buildup of dissolved solids in the pond.

Spray Systems: Two types of spray systems exist. One is truly closed cycle and operates essentially like a cooling pond except that spray heads are used to increase transfer surfaces and thus increase heat transfer to the atmosphere. The other could be considered open cycle. Conling water is drawn from a nenrby natural water body, passed through the condensers, and then cooled before being returned to the water body. Cooling is accomplished by passage through a network of canals equipped with spray heads.

Evaporative Cooling Towers: Condenser cooling water is recirculated through the tower to transfor the excess heat into the atmosphere, mostly by evaporation. Asain, make-up water from some neaby source is needed to replace evaporative losses, and some water is rominer to the natural water body (blowdown) to decrease the buildup of dissolved solids. Chenical treatment of the water usually is required to prevent biological fouling of the tower elements. Air flow through the tower may be induced by mechanical fans or may be produced naturaliy by the "chinney" effect.

Dry Cooling Towers: Excess heat from the cooling water is dissipated to the atmosphere by conduction without evaporation. Air flowing past pipes containing the flowing condenser cooling water transfers heat directly to the air. Devices such as fins on the pipes increase the heat transfer surface area. Nix flow may be of the mechanically-induced or the latural-draft type.

Each of the cooling methods has its advantages and disadvantages. Oncethrough cooling systems normally have the lowest construction and inaintenance costs. In such systems, incoming cooling water temperatures are typically the lowest practical -- leading to increased thermal efficiency, and cooling water pumping power requirements are generally at a mininum. However, large quantities of water are withdrawn from, heated, and returned to the natural water bodies -- possibly leading to large-scale modifications of the thermal regime of the water body. This may have a direct effect on the erological system of the waterway. Water consumption is minimal, but not ne_+stible, due only to the increased evaporation Erom the water body caused by the elevated temperature. It is estimated that the increase in evaporation rate is equivalent to about 
0.86 of the total cooling water requirement of the plant. 2 For example, a typical 1000-MW nuclear power plant might cause an increase in the evaporation rate of $0.4 \mathrm{~m}^{3} / \mathrm{s}$. Land requirements for once-through cooling systems are negligible relative to other cooling alternatives.

Cooling ponds and spray systems require the dedication of significant land areas and usually do not yield cooling water temperatures as low as those obtained by once-through cooling. For example, a 1000-MW power plant typically would require a cooling pond with a surface of 1000-3000 acres (4-12 $\times$ $10^{6} \mathrm{~m}^{2}$ ), while $100-3.50$ acres $\left(4-6 \times 10^{5} \mathrm{~m}^{2}\right.$ ) would be required for a spray system. ${ }^{3}$ Construction and maintenance costs can be substantial and, in the case of spray systems, there are increased pumping costs. Water consumption is estimated to be 20-50\% higher than for once-through cooling. ${ }^{1,5}$ other than the withdrawal of make-up water and the return of a limited anount of blowdown water, cooling ponds and closed-cycle spray systems have little effect on the $r$ ural water bodies. Although open-cycle spray systems nay not add significant amounts of heat to the natural water bodies, they do divert large quantities of water and may have a considerable effect on the aquatic ccosystem.

Evaporative cooling towers have large construction and maintenance costs. Because cooling capacity depends on the ambient wet-bulb temperature, the resulting cooling water temperatures are generally significantiy higher than thuse of once-through cooling systems and therefore lead to less efficient power plant operation. Pumping power requirements are increased over once-through cooling, and, in the case of mechanical-draft towers, electricai power is required to operate the fan motors. Cooling towers are large devices and can have a degrading effect on the aesthetic value of the land surrounding a power plant, especially in the case of natural draft towers that require large hyperbolic-shaped structures up to $150 \mathrm{~m} \mathrm{high.} \mathrm{Land} \mathrm{use} \mathrm{is} \mathrm{significant}$ but not excessive. A typical 1000-MW plant would require 10-15 acres $\left(4-6 \times 10^{4} \mathrm{mi}^{2}\right)$ for natural-draft towers and 45-68 acres $\left(1.8-2.8 \times 10^{5} \mathrm{~m}^{2}\right)$ for mechanical-draft towers. ${ }^{3}$ Consumptive water use is $60-100 \%$ higher than for once-through cooling. 4,5 The water added to the atmosphere in a localized area by evaporation and drift from the tower may have an adverse effect on the local microclimate. Mechanical-draft towers, with their lower profiles ( $520 \mathrm{~m}$ ), may be particularly troublesome by causing local fogging and icing. As in the case of cooling ponds and spray systems, evaporative towers have little effect 
on the natural water body other than that due to the withdrawal of makeup water and the return of blowdown. Typical systems reject only $1-3 \%$ of the waste heat with the blowdown. ${ }^{6}$

Dry cooling towers have many of the same drawbacks as the evapoiative towers (Iarge construction costs, high cooling-water temperatures, and large visual impact), although consunptive water use and local climate effects are minimal. Cooling water temperatures are limited by the ambient dry-bulb temperature, and therefore these towers must be used with specially designed high-backpressure turbines of lower efficiency. The efficiency of power plants cooled with dry towers is presently about 10-1.5\% less than power plants with once-through or evaporative cooling. ' Dry towers are usually only cost effective where mater supplies aro very 1 imited. Combined evaporative and dry cooling systems, wet/dry towers, may represent a compromise between efficiency and water consumption constraints.

Table 1 shows the extent to which various types of cooling technolozy were used in 1969 and 1974 as reported by the lederal Energy Regulator: Commission. 2 Although the use of closed-cycle cooling is increasing, oncethrough cooling is still used extensively.

Table 1. Distribution of Use of Various Condenser Cooling Technologies for Steam-Electric Power Plants Expressed as Percent of Total Installed Capacity ${ }^{a}$

\begin{tabular}{|c|c|c|}
\hline \multirow[b]{2}{*}{ Type of Cooling } & \multicolumn{2}{|c|}{$\begin{array}{l}\text { Percent of Total } \\
\text { Installed Capacit: }\end{array}$} \\
\hline & 1969 & 1974 \\
\hline \multicolumn{3}{|l|}{ Once-Through } \\
\hline Fresh & 50.5 & 41.1 \\
\hline Saline & 23.5 & 18.9 \\
\hline Total & 74.0 & 60.0 \\
\hline \multicolumn{3}{|l|}{ Closed-Cycle } \\
\hline Ponds & 5.9 & 8.5 \\
\hline Towers & 10.9 & 16.1 \\
\hline Combined Systems & 9.2 & 15.4 \\
\hline \multirow[t]{2}{*}{ Total } & 26.0 & 40.0 \\
\hline & 100.0 & 100.0 \\
\hline
\end{tabular}

From Federal Energy Regulatory Commission Report, Ref. 2. 
Stone and Websler Fis incering Corporation analyzed the results of a survey of over 110 power ;oncrating unjts (representing a total capacity of over 72,500 Mu) to deterninc the capteal costs of various types of cooling system: Resilta were expressed as averaye capital cost per heat dissipation rate. Based on typiral power-plant heat rejection rates discassed in Sec. 3), the cost per rencrating capacity can be calculated. These data were used to determine cosits presented in Table 2 for fossil-fueled and nucleas plants and for new and retrofitted cooling systems. In terms of the capital cost of the cool iny systerti itself, once-thromph cous ing using a simple shorel. ine discharge is the least cxpensive. The other types of systems have average capital costis that are comparable to one another (except cooling ponds, where land acquisition costs were croluded but eruld be large). In any partjcular catie, a site-spectific case study would be nocded to select the most appropriate system on the bass is of cost. Stone and webster also presented estimates of the performance losises associated with the various types of cooling systems, hased on the results of the same survey. These estimates are listed in Tahle 3. The losses are duc to the higher cooling-water temperatures associated with closed-cycle systems, increased pumping-power requirements, and auxiliary power reduirements to operate fans and spray systems. In general, retrofitted systems suffer greater losses because preaxisting turbines that have not been matched to the cooling system must be used. It is djfficult to determine the incromental capital cost of the various closedcycle cooljng systems over that of a simple once-through cooling system from the results of this survey because of the wide range of site-specific factors that enter into the cost at any one site.

United Engineers and Constructors, Inc, prepared a detailed capital. cost analysis of several different hypothetical power plants using various cooling systems at a hypothetical river site. ${ }^{8}$ The power plants considered were: a 1200-MW pressurized water reactor (PWR) nuciear plant, a 1200-MW boiling water reactor (BWR) nuclear plant, a 1200-MN coal (high and low sulfur content) plant, and a 800-MW coal (high and low suifur content) plant. The estimated capital costs, although site dependent, are all calculated on a common basis, in contrast to the Stone and Webster survey results that are based on averages of capital costs reported by many different power plants. 'lhe survey results indicate a significant amount of variation among the different plants surveyed due to site and design differences. 
Table 3. Performance Losses Associated with Various Types of Cooling systoms ${ }^{3}$

\begin{tabular}{|c|c|c|c|c|c|c|c|c|}
\hline \multirow[b]{3}{*}{ Cooling System Type } & \multicolumn{4}{|c|}{ Energy Loss ${ }^{b}$ (Percent) } & \multicolumn{4}{|c|}{ Capability Loss ${ }^{2}$ (Percent) } \\
\hline & \multicolumn{2}{|c|}{ Fossil } & \multicolumn{2}{|c|}{ Nuclear } & \multicolumn{2}{|c|}{ Fossil } & \multicolumn{2}{|c|}{ Nuclear } \\
\hline & New & Retrofit & New & Retrofit & $\mathrm{New}_{\mathrm{H}}$ & Retrofit & New & Rotrotit \\
\hline \multicolumn{9}{|l|}{ Once-Through ${ }^{\mathrm{d}}$} \\
\hline Simple Shoreline Discharge & Base & Base & Base & Base & Base & Base & Base & Base \\
\hline Offshore Diffuser & 0.20 & 0.20 & 0.28 & 0.28 & 0.20 & 0.20 & 0.28 & 0.28 \\
\hline \multicolumn{9}{|l|}{ Closed-Cycle: } \\
\hline Mechanical Draft Towers & 0.7 & $1.3 \pm 1.3$ & $2.2=0.7$ & $4.2=3.1$ & 1.5 & $2.3=1.8$ & $2.9=1.1$ & $4.5 \cdot 2.0$ \\
\hline Natural Draft Towers & 0.6 & $1.0 \pm 0.2$ & $1.9=1.0$ & $3.0 \pm 1.4$ & 1.8 & $2.8 \div 2.0$ & $3.2 \div 1.1$ & $4.9: 1.0$ \\
\hline
\end{tabular}

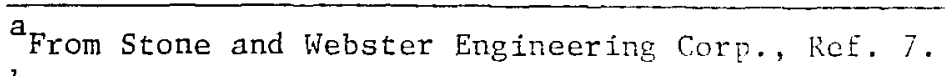

benergy loss includes loss due to increased turbine backpressure and energy recuired to operate cooling system.

${ }^{c}$ Capability loss is loss of peak generating capacity.

${ }^{\mathrm{d}}$ Simple shoreline intake assumed. 


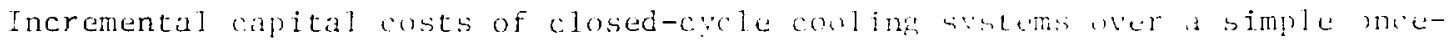

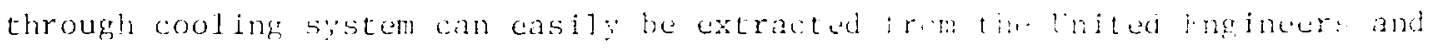

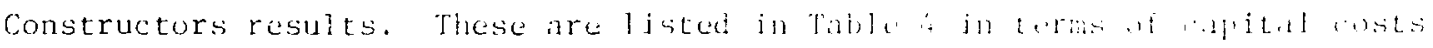

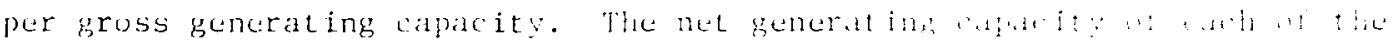

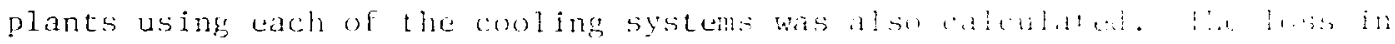

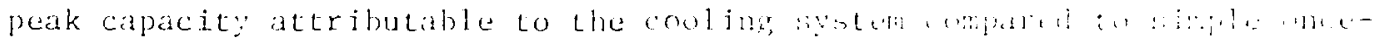

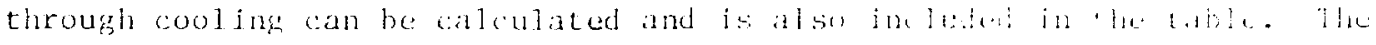

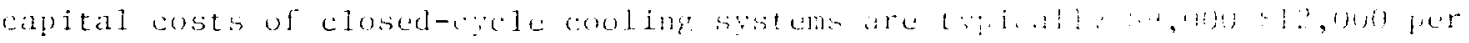

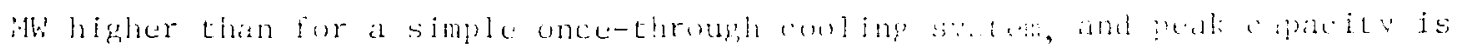
decreasud by about $1-1 / 4 \%$.

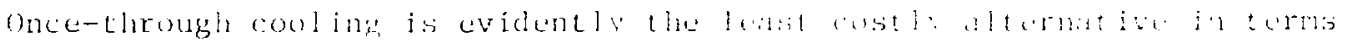

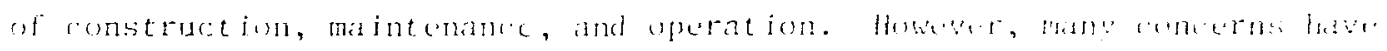

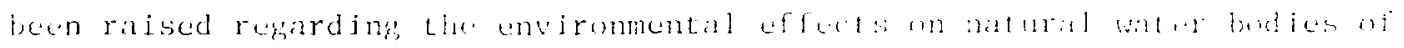

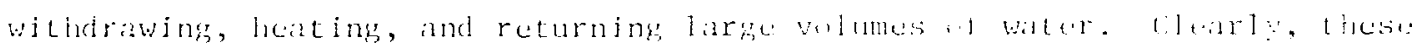

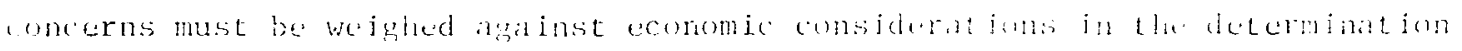

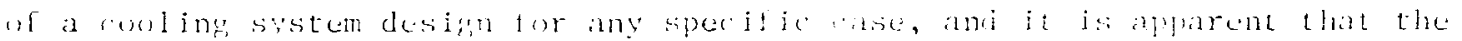

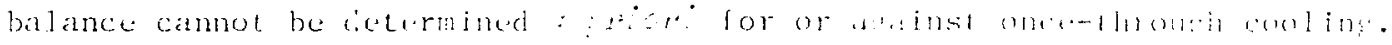

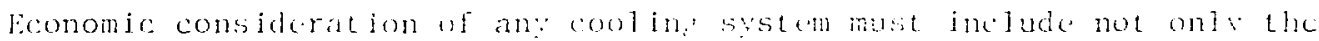
direct costs for the construction, maintenance, and operat ion but al so the energy costs in terms of effect on power-cyche efficioncy and auxiliary prower consumption reguired to operate the cooling system. In fact, it may be most ceonomical to employ a mix of once-through coul ing and evaporative towerts or spray systems to avoid detrimental impact to the aquatic enviroment. Evaporative to ers or spray systeme may be used in the conventional closedcycle mode or they may be used in the "helper" mode to precool the efficuent at times when the environment may be affected adversely by waste heat discharges.

\subsection{ENVIRONMENTAL EFFECTS DUE TO ONCE-THROUGH COOLING}

Within the 48 conterminous states, approximately $30 \%$ ft the mein annual runoff is withdrawn by man from natural bodies for ind.strial, commercial, agricultural, and municipal use. About one-third of thfs usage is for steam-electric power plant cooling, amounting to an average rate of withdrawal of fresh water for cooling water purposes in 1974 of $5623 \mathrm{~m}^{3} / \mathrm{s}$ (equivalent to 
Table 4. 1ncremental Cost of Closed-Cycle Cooling Towers over That of in Simple Once-Through cool ins System ${ }^{\mathrm{a}}$

\begin{tabular}{|c|c|c|}
\hline $\begin{array}{l}\text { Power plant } \\
\text { Cooling System }\end{array}$ & $\begin{array}{l}\text { Tnerementa]. Capital Cost/ } \\
\text { cicuerating Capacity } \\
\text { (bollars/WW) }\end{array}$ & $\begin{array}{c}\text { Capability loss } \\
\text { (percent) }\end{array}$ \\
\hline \multicolumn{3}{|l|}{$1200-\mathrm{MW}$ Nuc: 1 carr (PWR) } \\
\hline Simple Once-through cooling & Base & Baso \\
\hline Mechanical brart Towers & 11,600 & 1.9 \\
\hline Niltural-1)raft Tower & 12,300 & 1.0 \\
\hline \multicolumn{3}{|l|}{ 1.200-MW Nucl car (BWR) } \\
\hline Simple Once-Tlurough Cool ing & Base & Base \\
\hline Mechinical Draft Towers & 1,500 & 2.0 \\
\hline Natural Draft Tower & 11,700 & 1.2 \\
\hline \multicolumn{3}{|l|}{$1200-\mathrm{MW}$ Coal } \\
\hline Simple Once-Through Cooling & Base & Base \\
\hline Mechanical braft lowers & 9,200 & 1.5 \\
\hline Natural Draft Tower & $1.0,600$ & 0.8 \\
\hline \multicolumn{3}{|l|}{ 800-MW Coal } \\
\hline Simple Once-Through Cooling & Base & Base \\
\hline Mechanical Draft Towers & 10,500 & 1.1 \\
\hline Natural Draft Tower & 12,900 & 0.6 \\
\hline
\end{tabular}

arom United Engineers and Constructors, Inc., Ref. 8. ${ }^{b}$ Capability loss is loss of peak generating capacity. 
about $11 \%$ of the mean annual runoff). All but about $2 \%$ of this water is returied to the natural waterway (after accounting for increased evaporation rates due to elevated temperatures). ${ }^{2}$ However, because electric power generation does account for the temporary diversion of a significant portion of the annual runoff, the potential for a considerable impact on the environment exists. The potential impact can be divided into three categories: (1) the direct impact of drawing organisms into the intake, trapping some of them on the screens (impingement), and sending some of them through the pump and condensers (entrainment) back into the water body, (2) the impact on organisms that are entrained into the heated plume without having passed through the plant, and (3) the impact of the raising of the average temperature of a local region of the water body.

The Effects of Passage Through the Power plant: The physical withdrawal of large quantities of water from a natural water body can present a problem in itself. Large fish may avoid the intake, but small fish and other freeswimming species are drawn into the intake, trapped by the screens (impingement) and are eithır directed back to the water body or more often destroyed. Smaller organisms including plankton, fish eggs, and fisl larvae pass through the screens (entrainment) and through the condenser cooling system. These organisms may undergo mechanical damage in the pumps and condenser due to abrasion and pressure changes, thermal shock in the condenser, and chemical shock due to the presence of biocides, other water treatment chemicals, or corrosion products. The damage may not be lethal but may affect an organism's ability to survive once it is returned to the water body. In closed-cycle systems a11 the organisms drawn into the intake are destroyed because the water is not returned directly to the natural waterbody. However, flow rates for closed-cycle systems are much smaller than those for once-through systems as cinly make-up is required, and fewer numbers of organisms are likely to be drawn into the system.

The Effects of Passage Through the Thermal Plume: Organisms can come to live in or pass through the thermal plume in any of several ways. They can have passed through the intake and power plant; they can be carried along with the dilution water entrained into the thermal plume in the mixing process; they can be attracted to the warm water, especially during winter months; or they can be sedentary and exist naturally in the region that happens to be 
occupied by the thermal plume. The effects of living in or passing through the thermal plume are estimated to be far less serious than the effects of passing through the power plant itself. The seriousness of the effect depends on the type of organism, the duration of the exposure, and the temperature elevation encountered. Indeed, the thermal effect can work both ways. Fish that choose to live in the plume may become acclimated to the elevated temperature and upon plant słutdown may undergo deleterious thermal shock. In the case of a narrow waterway, such as a river or estuary, there ts the possibility that the heated plume may serve to block the passage of anadromous species and therefore inhibit their reproduction cycles.

The Erfects of Regional Warming: Tomperature plays a major role in regulating the life cycles of aquatic organisms. Activity, feeding, growth, and reproduction are affected by temperature. Secondary effects such as increased bioaccumulation of toxic materials can also occur. 9 Any change in the normal thermal cy_le of a water body may affect the character and species diversity of organisms living there. The growth of nuisance organisms, such as certain types of algae, may be enlanced with increased temperature, while reproduction of certain cold-water fish can be significantly reduced by elevated temperatures. The effects of regional warming clearly depend on the size and natural characteristics of the water body. Large lakus and open marine coastal waters are flushed by natural currents and tides, while small lakes and rivers with low flows may show notable, persistent temperature alterations.

This brief summary of the types of potential detrimental environmental effects due to once-through cooling systems is of course restrictuve. The magnitude of and, indeed, the presence of the impacts vary from site to site. The assessments of ecosystem impacts (e.g., intake impingement effects on waterbodywide populations) and of mitigating strategies (e.g., fish screens) are themselves often moot issues and the subject of ongoing research. The issues considered in this report are primarily physical in nature, and broader environmental problems are addressed only in part and indirectly. It should be noted, however, that the environmental acceptability of once-through cooling systems at specific sites may well hinge on site-speciffc ecosystem impacts. 


\subsection{SCOPE OF ASSESSMENT OF ONCE-THROUGH COOLING}

Various approaches have been used in the design of existing and proposed oice-through cooling systems for the disposal of waste heat. Systems may use large cooling water flow rates and small. temperature rises or small flow rates and large temperature rises to accommodate waste heat loads. The discharges may have high or low velocities; they may be located at the shoreline or offshore; they may be at the water surface or submerged, or they may have a single port or multiple ports. The approach depends on the type of water body, the size of the plant, and the costs of construction, operation, and maintenance. In addition, environmental constraints are usually imposed and often a judgement nust be made as to which approach will. result in the smallest detrimental impact to the environment.

Large flow rate, low temperature rise cooling systems reduce the temperature elevations experienced by the receiving water but increase the volume of water and, concomitantly, the quantity of organisms that pass through the system. Low-velocity discharges near the surface tend to allow the effluent to float on the surface without much mixing and dilution with ambient water. This enhances the rate of heat transfer to the atmosphere but also increases the magnitude of the plume surface areas associated with large temperature excesses above ambient. High-velocity discharges result in more rapid mixing and thus a reduction in the size of the region affected by high temperatures. However, they also increase the volume of water affected and usually increase the depth to which the plume extends. Surface discharges minimize the effect on organisms that live in shallow, shoreline regions. Generally, multipleport discharges yield larger initial dilutions while single-port discharges confine large temperature excesses to smaller volumes of water. In small water bodies, rapid extensive mixing may not allow sufficient heat transfer to the atmosphere and the overall temperature of the water body may increase. In large water bodies, where natural currents and tides cause flushing, rapid mixing may be desired to make effective use of the flushing.

In the past, electric power utilities chose low-velocity, surface, shoreline, canal discharges because of the relatively lower costs of construction and maintenance and because of the larger initial surface area provided for heat transfer to the atmosphere. Presently, in order to comply with regulatory standards on plume surface areas and temperature elevations, 
high-velocity, submerged, offshore, multiple-port discharges are being used to obtain greater degrees of mixing and reduce the volume of water subjected to higher excess temperatures. Environmental constraints notwithstanding, it is not clear that a single "best" design choice exists for all situations. Both environmental and economic factors must be examined to determine the best design for a specific power-plant site.

Quantification of the costs of the environmental impacts of waste-heat disposal systems, and indeed of the impacts themselves, is of ten elusive. Consequeitty, general conclusions regarding the efficacy of once-through cooling systems in terms of their environmental imapcts are not possible. Environmental assessments of once-through cooling systems are generally made on a case-by-case basis. As mentioned previousiy, the matiers of primary concern in such assessments are the effects of the impingement of organisms on the cooling water intakes, of the entrainment of organisms into the condenser system, of the passage of organisms through the thermal plume created in the receiving water body, and of the local warming of the water body in the vicinity of the discharge. All of these issues are highly dependent on site-specific conditions and intake and discharge designs. However, the two latter concerns are addressed directly in water quality standards and guidelines by means of general restrictions on the temperature elevation above ambient and on the physical extent of such elevations permitted. The intent of this study was to investigate the feasibility of employing once-through cooling systems that do not exceed these restrictions.

In this study restrictions were examined regarding the temperature elevations above ambient water temperatures and on the sizes of mixing zones within which those elevations may be exceeded. The results of that examination are presented in Sec. 2 for the various potential receiving waters for waste heat from once-through cooling: rivers, lakes, estuaries, and marine crastal waters. In Sec. 3, typical cooling water flow rates and power-cycle temperature elevations of cooling water are determined for typical large fossil-fueled and nuclear electric power plants. The general characteristics of once-through-cooling discharge systems and the predictive models and data regarding thermal plume behavior are summarized in Sec. 5. Given the restrictions on plume behavior in the various receiving water types and given the cooling/ water discharge characteristics, analyses were made to determine, in general terms, the feasibility of effecting once-through cooling within the 
physical environmental constraints. Both surface and submerged discharge structures were examined in terms of generalized results based on prototype field measurements augmented by results from physical and mathematical model studies. "The results of measurements from specific plants" or of specific plant designs are given, where appropriate, as examples of site-specific performance and constraints. Guidelines were developed for either the limiting receiving water conditions or the discharge structure size and configuration required to satisfy physical environmental constraints for rivers (Sec. 6), lakes (Sec. 7), estuaries (Sec. 8), and coastal waters (Sec. 9). The thrust of the analyses was the formulation of general conclusions regarding the efficacy" of once-through cooling systems for a variety of water environments, as site specificity precludes detailed conclusions. 


\section{THERMAL STANDARDS}

Concern in the U.S. for the quality of the environment as a whole, and water resources in particular, has increased greatly in the past 20 years. The Federal Water Pollution Control Act wäs passed in 1956, and the Water Quality Act of 1965 amended the original Act and specified that water quality criteria and standards be developed The National Technology Advisory Committee (NTAC) to the Secretary of the Interior developed water quality criteria and published their recommendations in April, 1968.10 In the meantime, individual states instituted, with the approval of the Secretary of the Interior, their own standards for the various aspects of water quality including temperature. In 1970, the duty of overseefing the institution of standards by individual states was transferred to the Administrator of the newly formed U.S. Environmenta1, Protection Agency (U.S. EPA). By 1971, most states had some form of approved standards for maximum temperature and maximum temperature increases" above ambient water temperature. Maximum temperature restrictions ranged from $60.0^{\circ} \mathrm{F}\left(15.6^{\circ} \mathrm{C}\right)$ to $96.8^{\circ} \mathrm{F}\left(36.0^{\circ} \mathrm{C}\right)$ depending upon the state and the type of water body. Maximum allowable temperature increases above ambient ranged from $0-20.0 \mathrm{~F}^{\circ}\left(0-11.1 \mathrm{C}^{\circ}\right)$ depending on the type of water body and its natural temperature.

The NTAC also set forth-recommendations for temperature standards within their water quality sriteria. They recommended a maximum permissitle temperature rise above naturally existing temperatures of $5.0 \mathrm{~F}^{\circ}\left(2.8 \mathrm{C}^{\circ}\right)$ for streams and $3.0 \mathrm{~F}^{\circ}\left(1.7 \mathrm{C}^{\circ}\right)$ for lakes. They also recommended that cold water fisheries (trout and salmon waters) not be disturbed. In marine and estuarine environments, they recommended that monthly maximum daily temperatures at a site not be raised by more than $4.0 \mathrm{~F}^{\circ}\left(2.2 \mathrm{C}^{\circ}\right)$ in the winter (September-May) or more than $1.5 \mathrm{~F}^{\circ}\left(0.8 \mathrm{C}^{\circ}\right)$ in summer (June-August). In addition, the NTAC recommended that mixing zones should be as small as possible and should be determined on a case-by-case basis. A mixing zone is a region near the discharge structure within which the excess temperature standards do not apply (that is, within which standards may be exceeded).

The U.S. Environmental Protection Agency evaluated the state standards and attempted to guide the states in revising their standards so as to be more precise and uniform. The U.S. EPA supported the NTAC recomendations and used them as guidelines in this effort. "As a result, many state standards reflect these recommendations. 
In 1972, Congress adopted the Federal Water Pollution Control Act Amendments (Public Law 92-500). The Act sets the goal of eliminating the discharge of pollutants into navigable waters by 1985 (Section 101); waste heat is specifically included as a pollutant. Section 301 of the Act is concerned with existing sources of pollution and requires the application of the best practicable control techmology currently available by July 1, 1977, and the application of the best available technology econumically achievable (BATEA) by July 1, 1983. Section 306 of the Act states that new sources must employ "the best availeble demonstrated control technology, process, operating methods, or other alternatives, including, where practicable, a standard permittjng no" discharge of pollutants." The EPA interprets "best available technology" for the dissipation of waste heat at large (>25 MW' steam-electric power plants to be closed-cycle evaporative cooling. Section 316(a) of the Act, however, applies specifically, to waste heat and authorizes the Administrator of the EPA to impose alternative effluent limitations on a case-by-case basis such that the "protection and propagation of a balanced indigenous population of shellfish, fish and wildife" in and on the receiving water body can be assur:ed.

The U.S. EPA has developed guidelines for the preparation of documents to support a request for a Section 316 (a) exemption. ${ }^{11}$ Among other things, these guideines essentially require that the physical characteristics of the thermal plume be documented, based on either field measurements in the case of existing discharges or engineering estimates in the case of proposed discharges. A survey conducted by National Economic Research Associates, Inc., ${ }^{7}$ of power plants using or intending to use open-cycle cooling systems as of the end of 1977 showed that $59.3 \%$ (by generating capacity) has appiied for section 316(a) exemptions. Of the exemptions applied"for, $41.5 \%$ (by capacity) had been granted, $57.2 \%$ were pending, and $1.3 \%$ had been denied.

The purpose of this study was an examination of the various types of discharge concepts available for once-through cooling systems to determine the circumstances under which each type might be environmentally acceptable. Because the question of acceptability is clearly site dependent and must be addressed on a case-by-case basis, some general criteria had to be selected and used to determine acceptability. Any such general criteria can only be used as guidelines or for initial screening purposes, because they cannot take 
into account the variability and distribution of aquatic organisms present at a particular site. While not the sole criterion, compliance or lack of compliance with temperature and mixing zone standards is of ten included in the. development and evaluation of arguments concerned with the acceptability of a thermal discharge. Therefore, specific temperature and mixing zone requirements were used in this study to "compare, contrast, and evaluate the performance of various types of discharges in various types of receiving waters.

State water quality standards vary from state to state, and at the present many are undergoing review by the U.S. EPA. As noted above, many are patterned after the recommendations of the NTAC and therefore these temperature standards were selected for use in this study. The maximum allowable temperature rises above ambient outside a mixing zone near the discharge point are summarized in Table 5 f limitations were not specified explicitly by the NTAC but are to be determined, on a case-by-case basis. However, "recommendations to be considered when

establishing mixing zone limitations were set forth. ${ }^{10}$ As a guideline, in the case of streams, the mixing zone should be 1 imited to less than $25 \%$ of the cross-sectional area or of the volume flow of the stream. In "general, the maximum distance, in feet, to the edge of the mixing zone in any direction should not exceed the number obtained by multiplying the numerical value of the square root of the discharge flow rate, in millions of gallons per day,

Table 5. Typical Excess Temperature (Aboye Ambient) Standards as Recommende? by the NTAC

\begin{tabular}{lrc}
\hline Water Body & $\Delta \mathrm{T}_{\max }\left(\mathrm{F}^{\circ}\right)$ & $\Delta \mathrm{T}_{\max }\left(\mathrm{C}^{\circ}\right)$ \\
\hline Streams and Rivers & 5.0 & 2.8 \\
Lakes & 3.0 & 1.7 \\
$\begin{array}{l}\text { Estuaries and Marine } \\
\text { Coastal Waters - } \\
\quad \text { Winter } \\
\quad \text { Summer }\end{array}$ & 4.0 & 2.2 \\
& 1.5 & 0.8 \\
\hline
\end{tabular}


by 200; and in no case to exceed 5,280 ft. In S.I. units, this limit can be expressed as:

$$
\begin{aligned}
L_{m z} & <\sqrt{Q_{p} /\left(1.2 \times 10^{-5} \mathrm{~m} / \mathrm{s}\right)} \text { for } Q_{p}<30 \mathrm{~m}^{3} / \mathrm{s} \text {, and } \\
& <1600 \mathrm{~m} \text { for } Q_{p}>30 \mathrm{~m}^{3} / \mathrm{s}
\end{aligned}
$$

where

$$
\begin{gathered}
\mathrm{L}_{\mathrm{Taz}}=\text { maximum extent of mixing zone, and } \\
Q_{p}=\text { discharge flow rate of the plant. }
\end{gathered}
$$

This recomnendation is considerably moie relaxed than that suggested by many state regulations. In fact, most state regulations specify that the mixing zone be established on a case-by-case basis. When mixing zones are defined, they are often stated in terms of surface areas or areas equivalent to circles of specified radii. The specified radii typically range from $300 \mathrm{ft}$ (91 $\mathrm{m}$ ) to $1000 \mathrm{ft}(305 \mathrm{~m})$. The corresponding surface areas range from 6.5 acres $\left(2.6 \times 1.0^{4} \mathrm{~m}^{2}\right)$ to 72 acres $\left(2.9 \times 10^{5} \mathrm{~m}^{2}\right)$. For purposes of evaluating the various discharge types, two mixing zone surface area restrictions, corresponding to these extremes, were considered in this study.

For the purpose of this study excess temperatures were dealt with, precluding the necessity of defining "ambient temperature." It should be noted, however, that specifications of "ambient" or "natural water temperature" vary and are subject to several interpretations due to temporal and spatial variations in water temperatures in natural water bodies.
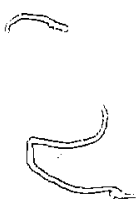


\section{HEAT REJECTION RATE}

Modern steam-electric power plants can be divided into two categories depending on the fuel used -- fossil or nuclear. The basic process for producing electric: power is the same for both types. High-pressure, high-temperature steam is produced in a boiler 1sing heat either from the combustion of rossil fuels or from a controlled nuclear reaction. The steam is passed through a turbine-generator unit that converts thermal energy to mechanical and then electrical energy. The spent low-pressure steam is condensed and returnci to the bojler to coniplete the cycle. The waste heat removed from the low-pressure steam ill a condenser must be disposed of through either a clósed-cycle cooling iystem, such as cooling towers, or an open-cycle system that transfers the hesi to a natural water body. In either case, the heat eventually reaches the atmosphere. Although the basic process is the same for both types of fuels, safety limitations on the operating pressures and temperatures of a nuclear reactor result in lower thermal efficiencies and therefore larger quantities of waste heat per unit of electric power generation for nuclear plants. Therefore, for the purposes of this study, it was necessary to consider power plants in both of "these categories.

In the case of fossil-fueled plants, about $36 \%$ of the energy used by the plant ends up as electric energy, about $15 \%$ of the energy" is lost directly to the atmosphere through the smokestack and within the plant, and the remaining $49 \%$ of the energy ends up in the form of waste heat to be dissipated by the cooling system. As a result, about 1.4 units of waste heat energy are delivered to the cooling water system for each unit of electric energy generated. In a nuclear plant, only about $32 \%$ of the energy used by the plant ends up as electric energy. In-plant losses account for $5 \%$ and the remaining $63 \%$ of the energy must be dissipated as waste heat. Consequently, for each unit of electric euergy generated, about 2.0 units of waste heat are produced. It is evident that nuclear power plants must dispose of about $45 \%$ more waste heat than a fossil-fueled ${ }^{\circ}$ plant of the same generating capacity.

The rate at which waste heat, $\mathrm{dH} / \mathrm{dt}$, is delivered to the cooling water system by the condensers can be related to the cooling-water flow rate, $Q_{p}$, and the resulting tamperature rise, $\Delta \mathrm{T}_{0}$, by:

$$
\frac{d H}{d t}=\rho c_{p} Q_{p} \Delta T_{o}
$$


where:

$$
\begin{aligned}
\rho & =\text { density of water, and } \\
c_{p} & =\text { heat capacity of water. }
\end{aligned}
$$

The heat rejection "rate, dH/dt, is directly related to the plant capacity, $C$, by the factors discussed above ( $1: 4$ for fossil-fueled plants and 2.0 for nuclear plants). The cooling-water flow rate and restiting temperature increase can then be related" to the plant capacity by:

$$
Q_{P} \Delta T_{0}=K C
$$

where:

$$
\begin{aligned}
& K \simeq 0.33 \frac{\left(\mathrm{m}^{3} / \mathrm{s}\right) \mathrm{C}^{\circ}}{\mathrm{MW}} \text { for fossil-Fueled plants, and } \\
& \mathrm{K} \simeq 0.47 \frac{\left(\mathrm{m}^{3} / \mathrm{s}\right) \mathrm{C}^{\circ}}{\mathrm{MW}} \text { for nuclear plants. }
\end{aligned}
$$

The temperature rise, $\Delta T_{\hat{G}}$, experienced by the cooling water in the condensers depends on the particular power plant design. "A survey of over 50 power plants yielded a range for $\Delta \mathrm{T}_{\mathrm{o}}$ of $4.6-17.5 \mathrm{C}^{\circ}$ with an average value of $10.0 \mathrm{C}^{\circ}$. This average value of $10.0 \mathrm{C}^{\circ}$ appears to be somewhat typical of new, large power plants and was used throughout this study as a basis for comparing and contrasting the efficacy of various once-through-cooling-system discharge types.

Over the next 5-10 years, new generating capacity is expected to be made up of an approximately equal mix of nuclear and fossil-fueled plants. New capacity will be primarily made up of large generating units with capacities in the 500-1000 MW range. For the purposes of this study, four typical large generating units were considered -- a 500-MW fossil-fueled plant, a 500-MW nuclear plant, a 1000-MW fossil-fueled plant, and a 1000-MW nuclear plant. If a temperature rise of $10.0 \mathrm{C}^{\circ}$ is assumed, the cooling-water flowrate requirement of each of these plants can be estimated from the previous discussion of heat rejection rates. "These estimated flow rates are listed in Table 6. Although actual flow rates and temperature rises will vary somewhat with plant design, the total heat rejection rates corresponding to the values of $Q_{p}$ and $\Delta T_{o}$ in Table 6 will be approximately correct. 
22

Table 6. Typical Large Power Plant Capacities and Assumed Cooling Water Characteristics

$=$

"4

is

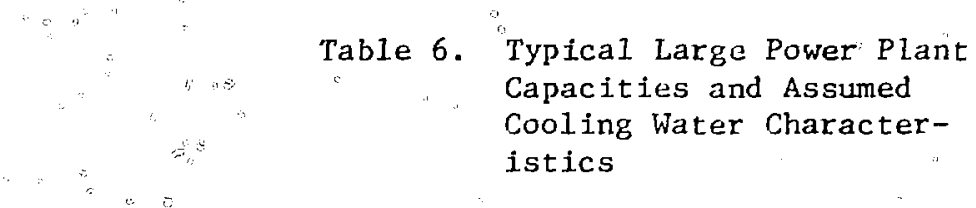

\begin{tabular}{ccc}
\hline Plant & $\Delta \mathrm{T}_{\mathrm{o}}\left(\mathrm{C}^{\circ}\right)$ & $\mathrm{Q}_{\mathrm{p}}\left(\mathrm{m}^{3} / \mathrm{s}\right)$ \\
\hline 500-MW Fossil & 10.0 & 16.5 \\
500-MW Nuclear & 10.0 & 23.5 \\
1000-MW Fossil & 10.0 & 33.0 \\
1000-MW Nuclear & 10.0 & 47.0 \\
\hline
\end{tabular}

is 


\section{DITUTION REQUIREMENTS}

In order that "once-through cooling systems of steam-electric power plants meet the temperature standards discussed in Sec. 2, or indeed any temperature standards, the heated effluent must mix sufficientiy with the ambient receiving water to reduce the excess temperature (above the naturally occurring ambient temperature) below the specified "maximum. In the case of surface discharges, this mixing must occur near the surface within the mixing zone. In the case of submerged discharges, some"mixing with ambient water occurs by the time the heated (buoyant) effluent reaches the surface. The dilution at the point where the effluent reaches the surface (corresponding to the highest excess temperature at the surface) is referred to as the minimom surace dizution. If the excess temperature at this point exceeds the 1 imit set by the appropriate temperature standard, additional mixing must uccur after the effluent has surfaced, within some specified mixing zone."

If it is assumed that the temperature of the ambient receiving water is at approximately the same temperature as the cooling water at the system intake, and that the temperature of the cooling water is raised by about $10.0 \mathrm{C}^{\circ}\left(18.0 \mathrm{~F}^{\circ}\right)$, then the temperature standards impose a lower limit on the dilution that must be achieved. In actuality, cooling water intakes are often designed to withdraw water from below the surface whert cooler temperatures may exist due to natural temperature stratification. This procedura may allow the dilution requirements to be relaxed somewhat because the water is "precooled" compared to natural ambient temperatures at the surface where mixing zone restrictions are often applied. Further, "temperature stratification and the resulting density stratification can inhibit vertical mixing within the ambient recelving water body, markedly reducing the mixing attained by a shallow, surface discharge discharging into a thin surface layer above a shallow thermocline. As water temperature stratification is site-specific and seasonally variable and may aid or Inhibit dilution depeniing on the situation, it was not considered in this study of the efficacy of various types of oncethrough cooling discharges.

For the purposes of this study, the minimum dilution that must be attained was sstimated by the ratio of the temperature risc across the condenser to the maximum temperature rlse allowed by the typical temperature standards. Table 7 lists the minimum dilution requirements for the varlous types of receiving waters and corresponding temperature standards discusseci in Sec. 2. 
Table 7. Dilution Requirements for Various Receiving Water Bodies Assuming a Typical Initial Excess Temperature of $10.0 \mathrm{C}^{\circ}$

\begin{tabular}{lcc} 
Water Body & $\Delta \mathrm{T}_{\max }\left(\mathrm{C}^{\circ}\right)$ & Dilution \\
\hline Streams and Rivers & 2.8 & 3.6 \\
Lakes & 1.7 & 6.0 \\
$\begin{array}{l}\text { Estuaries and Marine } \\
\text { Coastal Waters - } \\
\text { Winter }\end{array}$ & & \\
Summer & 2.2 & 4.5 \\
\hline
\end{tabular}

In this study, it was assumed that these dilutions must be met within a mixing zone that (1) does not have a surface area that exceeds a specific limit, and (2) does not (in the case of streams, rivers, and narrow confined reaches of estuaries) encompass more than $25 \%$ of the cross-sectional area or volume flow of the water passage. The area limit of the first restriction "is usually specified on a case-by-case basis. In this study, two values $\left(2.6 \times 10^{4} \mathrm{~m}^{2}\right.$ and $\left.2.9 \times 10^{5} \mathrm{~m}^{2}\right)$ were considered, corresponding to the lower and upper limits of the range of mixing zone surface areas usually specified. 
5 TECHNIQUES AVAILABLE FOR THERMAL PLUME ASSESSMEN]

There are almost as many types of once-through-cooling discharge designs as there are power plants, and several techniques are available for the prediction of the behavior of thermal plumes from such discharges. Intake and discharge configurations are usually developed for each power plant site to meet the requirements of local shoreline and bottom topography and naturally occurring currents and tidal flows. However, the various discharge designs that have been utilized can be divided into three basic categories: shoreline surface discharges, single-port submerged discharges, and submerged multiport diffusers.

Shoreline surface discharges have long been used by power plants to return the heated effluent to the natural water body. Besides having a low capital cost, this type of outfall is easily maintained. "The idealized surface discharge ( $\mathrm{Fig} .1$ ) is an open rectangular channel terminating at the shoreline, however, a great deal of variation in actual configurations exists. The outfall may consist of a concrete or steel channel with a rectangular cross section or it may consist of a dredged channel with an irregular cross section. The flow may be directed perpendicular to the shoreline, or it may be directed at an angle to take advantage of natural currents, as in the case of rivers. The channel may end at the shoreline or it may extend some distance into the water body. Discharge velocities are usually low $(\simeq 0.5 \mathrm{~m} / \mathrm{s})$ but may be as high as several meters a "second. Many mathematical models have been developed to describe and predict the behavior of surface discharges, and several of the more often cited models include those of "Pritchard, 12,13 Stolzenbach and Harleman, ${ }^{14}$ and Shirazi and Davis. ${ }^{15}$ These and many others have been discussed in Refs. 16-19. Attempts at verification of these models have met with limited success. No single mathematical model has been demonstrated to be generally applicable to the wide spectrum of discharge configurations and receiving water conditions encountered in practice.

In recent years more stringent thermal standards and a change in the philosophy of disposing of waste heat have brought about increased use of submerged discharges. Submerged discharges are usually designed to have higher outfall velocities than surface discharges. Such submerged discharges are often used for ocean sewage outfalls where high dilution is achieved by jet-induced entrainment. Construction costs generally make this alternative 
SHORELINE SURFACE OUTFALL

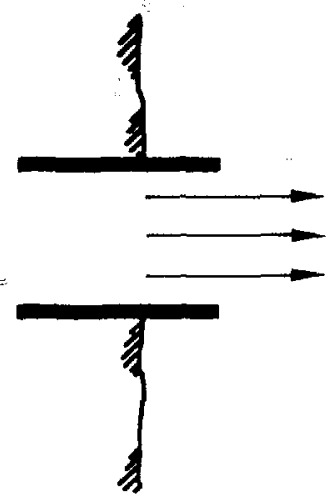

PLAN

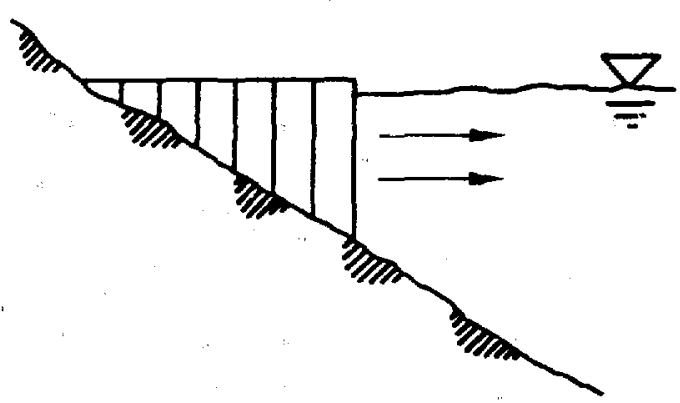

ELEVATION

\section{SINGLE-PORT SUBMERGED SURFACE}

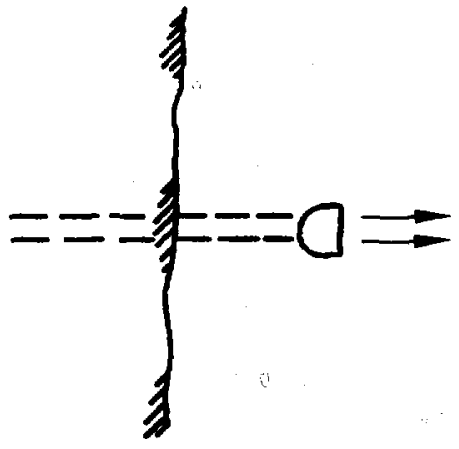

PLAN

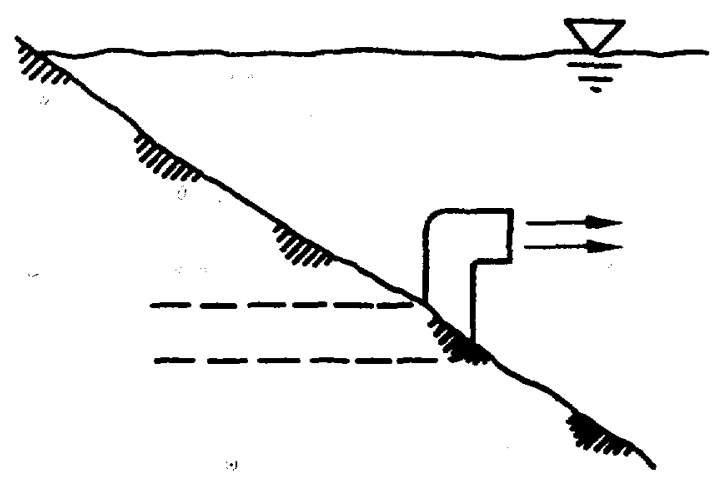

ELEVATION

Fig. 1. Idealized Shoreline Surface Outfall and SinglePort Submerged Outfall 
more expensive than a"surface discharge, but submerged discharges may yield higher initial dilutions, thus enabling thermal standards to be met without resorting to closed-cycle cooling systems. Submerged discharges can be divided into two categories - single-port discharges and multiport diffusers.

The idealized single-port submerged discharge (Fig. 1) is an open round pipe located in deep water so that boundaries, including the bottom and surface, lave $1 \mathrm{itt}$ ]e influence on the behavior of the erfluent. In practice, the depth at which the outfall can be placed is 1 imited by the bottom topography of the receiving water body, construction costs to reach a given depth, and operating costs to pump the cooling water to that offshore location. Further, the outfall may not necessintily be a single round port, it may be made up of one or more closely spaced ports of arbitrary shape that do not necessarily discharge in a unidirectional manner. Tf, however, the port separation becomes large with respect to the port size and the overall length of the discharge structure becones large with respect to the depth of the receiving water, the discharge is referred to as a submerged multiport diffuser. Many investigators, such as Fan and Brooks, ${ }^{20}$ Hirst, 2 Koh and Fan, 22 and Shirazi and Davis, ${ }^{23}$ have developed and applied mathematical models that describe the behavior of single submerged jets under simplified and approximate situations that make the resulting equations tractable. Application of any one of these models to an actual discharge site requires that the limitations of the model be carefully examined in light of the conditions that actually exist at the site.

The idealized submerged multiport diffuser consists of many round ports spaced uniformly along a long pipe (the diffuser pipe) located at the bottom of the receiving water body. The cooling water flows from the power plant to the diffuser pipe through a feeder pipe buried under the botton. Again, many variations exist. The individual discharge ports may be directed vertically or horizontal1y; they all may be directed in the same direction or they may be directed in alternate directions. The ports may be spaced sufficiently far apart so that they behave as individual submerged ports or they may be close enough together so that the jets quickly merge and behave like a single long slot. The ports may be directed at right angles to the diffuser pipe or parallel to it; the diffuser pipe may be oriented parallel to the dominant natural current or it may be at right angles to it. The particular design 
depends on the currents, tidal flows, depth, and other characterfstics of the recefving water and the dilutions that must be attained. Four general types of multiport diffusers that are often consfdered are depicted in Fig. 2. The co-flowing diffuser has the diffuser pipe oriented perpendicular to the dominant ambient current direction, and the individual ports are directed in the same direction as the ambient flow. The "tee" diffuser has the diffuser pipe oriented parallel to the shore and the individual ports are directed in the offshore direction. A flow of ambient water is induced over the diffuser by the momentum of the effluent. The alternating diffuser directs the effluent in both directions perpendicular to the diffuser pipe, resulting in the introduction of no net horizontal. momentum. Under stagnant receiving water conditions, this type of diffuser depends primarlly on buoyancy-driven flows to disperse the heated effluent. The diffuser pipe of a staged diffuser is oriented perpendicular to the shore and the individual ports are directed in

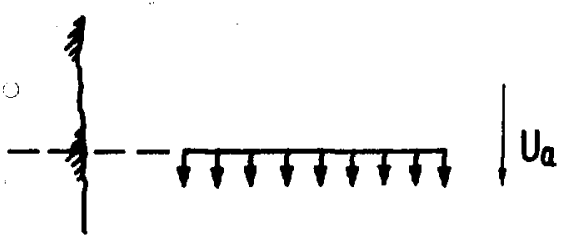

CO-FLOWING

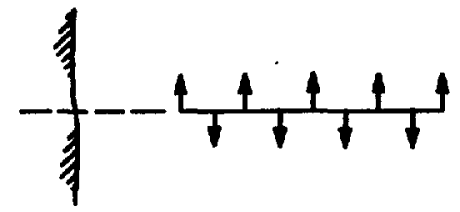

ALTERMATING

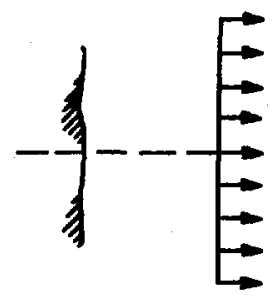

"TEE"

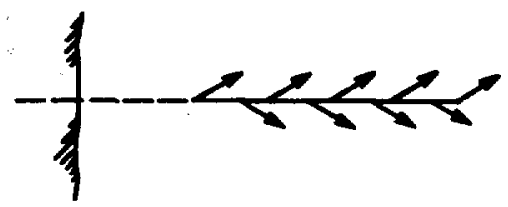

STAGED

Fig. 2. Submerged Multiport Diffuser Design Concepts 
the offshore direction. A general analysis of the behavior of such multiport diffusers does not exist. For multiport diffusers in deep water, Shirazi and Davis $^{23}$ employed the results of integral analyses to prepare a compilation of plume characteristics. They used single round port results until adjacent jets merged and then applied the results of long single-slot analyses. In the case of long multiport diffusers in shallow water, analyses such as those by Adams, ${ }^{24}$ Jirka and Harleman, ${ }^{25}$ and Almquist and Stolzenbach ${ }^{26}$ have been used.

Mathematical models such as those mentioned above, that attempt to predict the behavior of the effluent from a once-through-cooling system discharge, can be relied on to give only general estimates of plume characteristics and dilutions. These models require simplifying approximations and assumptions in order to allow a solution to be obtained with a reasonable amount of computational effort. Usually ambient currents must be assumed to be uniform in space and time. Ambient current shear that often exists due to wind-induced surface currents and periodically varying currents that exist at estuarine sites are neglected. Shoreline and bottom topography must be simplified or. even entirely omitted from consideration. Outfall geometry usually has to be schematized in some manner to fit the assumptions of the model. Stratification in the receiving water often must be neglected or, at most, approximated by some simple function. The detailed effects of winds, solar radiation, surface heat exchange, and other less direct influences on the plume are often neglected. The temperature and velocity structures within the discharge jet usually are approximated by some convenient analytical distribution that often does not allow for asymmetries. The flow establishment region just beyond the outfall is often dealt with by means of a simple semi-empirical treatment. The important physical phenomena themselves, such as entrainment and interaction with the ambient current, must be modeled in an approximate way that often involves coefficients that must be determined from experiment or data fitting. Entrainment is often described in terms of a simple entrainment coefficient or spreading rate. Interaction with the ambient current is usually treated in analogy to form drag on a solid body using a drag coefficient. All of these simplifications and approximations used in developing predictive mathematical models make it essential that specific predictions be used with caution unless the model has been verified under similar circumstances by comparison with experimental data. 
Laboratory-scale physical modeling is an additional predictive tool for the design of once-through-cooling discharge systems and for the assessment of thermal plume behavior. Physical or hydraulic models of heated water discharges often provide the means of investigating site-specific features and complex discharge geometries that may not be presently amenable to mathematical modeling. In fact, physical modeling is one of the principal stateof-the-art tools employed in the design of submerged diffuser systems. While permitting the inclusion of many site-specific aspects of both the receiving water and the discharge, physical models are not without their limitations. Application of hydrodynamic scaling laws is required for the proper simulation of plume and ambient water beilavior at reduced geometric scales. For nearfield or near-discharge plume behavior, experience has indicated that scaling by means of the densimetric Froude number is appropriate. For the intermediatefield and far-field regions of the plume, ambient turbulence and interfacial mixing processes are more important than jet-induced mixing, and different scaling laws may be appropriate. Thus, in most cases, it is difficult to model exactly the entire thermal plume or receiving water region affected by the plume in a single physical model. This problem is sometimes solved in part by the use of more than one physical model or a combination of physical and mathematical models for the different regions of interest. The physical size of the model may be a constraint on the region modeled, and heat buildup or exchange at mode1 boundaries can present problems. Wind effects cannot be modeled well, and surface heat exchange in the laboratory is different than in the prototype and must be corrected for. Ambient currents and density stratification are usually handled in a schematic fashion in physical models.

Despite the limitations inherent in physical modeling, careful interpretation of the results from well-designed, laboratory-scale models provides an important predictive tool. Because many of the thermal standards require that substantial mixing occur in the near-field region, the results of physical modeling are particularly helpful. Although most physical model studies are designed for specific sites, some studies provide data on generic discharge types that are more generally applicable.

The results of field measurements of thermal plumes of prototype scales at existing power plants are less numerous than mathematical or physical model results. While such measurements do incorporate many of the factors omitted 
or poorly represented in mathematical and physical models (such as winds, complex ambient currents, etc.), they suffer from the limitations of site specificity and of relatively uncontrolled experimental conditions. The fact that prototype measurements include all of the complexities of the "real environment" is a double-edged sword: on one side, the effects of many variables are difficult to disaggregate to provide meaningful generalizations, and, on the other, prototype measurements are the only source of data that reflect the aggregate effect of the processes at work. Cognizance of the effects of the variability of receiving water conditions on plume measurements ${ }^{27}$ and selective application of the results to similar cases allow some generalizations to be gleaned from prototype data. In this report, prototype data are examined and used, where available and appropriate, to provide estimates of the ranges of cooling water discharge performance. 
6 ONCE-THROUGH COOLING ON RIVERS

\subsection{GENERAL FEATURES}

The major characteristics of a river that are important in assessing its effectiveness as a receiving water body for the purposes of once-through cooling are (1) limited lateral" extent, (2) essentiaily unidirectional flow, and (3) limited flow rate. Limited lateral extent implies that both banks of a river may influence the behavior of the thermal effluent, although the degree of influence clearly depends on the size of the thermal discharge and the flow characteristics and geometry of the river. For a sufficiently small thermal discharge or a sufficiently large river, this influence may be minimal, but, in general, the width of the receiving water must be taken into consideration. This is particularly true in terms of the mixing zone requirements that generally limit the extent of the mixing zone to 1 ess $s_{i ;}$ than $25 \%$ of the cross-sectional area or volume flow of the river. The flow in a river is generally unidirectional, but the volume flux may vary significantly, especially with the season. River flows are often controlled by dams that form run-of-the-river reservoirs. These dams may serve hydroelectric generating facilities that act as "peaking" units. River flow rates may then vary significantly with daily and hourly fluctuations in electric power demands. During periods of extremely low flow, the effluent from a once-through cooling system may actually extend upstream on the surface if spreading due to buoyancy exceeds the effect of the downstream momentum of the river flow. Availability of river flow for dilution can clearly be a limiting factor in regard to. the use of once-through cooling systems. Other factors that may affect the position, extent, and dispersal of a thermal plume in a river are: channel geometry, lateral and vertical variations in river velocity, temperature stratification, and ambient turbulence.

The water available for the dilution of the thermal effluent from a power plant on a river is limited by the finite flow rate of the river, placing an upper limit on the capacity. of a power plant with once-through cooling that can be supported and still meet the temperature standards discussed in Sec. 2. Conversely, for a given capacity, a lower limit on river flow rate exists. If the waste heat is fully mixed with the entire flow of the river, the lower limit on the river flow rate, $Q_{R}$, that will still meet the excess temperature standard $\Delta \mathrm{T}_{\max }$ for a plant of capacity $\mathrm{C}$ is given by 


$$
\mathrm{Q}_{\mathrm{R}} \geq \frac{\mathrm{KC}}{\Delta \mathrm{T}_{\max }}
$$

where:

$$
\begin{aligned}
& K \simeq 0.33 \frac{\left(\mathrm{m}^{3} / \mathrm{s}\right) \mathrm{C}^{\circ}}{\mathrm{MW}} \text { for fossil-fueled plants, and } \\
& K \simeq 0.47 \frac{\left(\mathrm{m}^{3} / \mathrm{s}\right) \mathrm{C}^{\circ}}{\mathrm{MW}} \text { for nuclear plants. }
\end{aligned}
$$

For a maximum temperature excess of $5.0 \mathrm{~F}^{\circ}\left(2.8 \mathrm{C}^{\circ}\right)$ as suggested by the NTAC for streams and rivers, a 500-MW fossil-fueled plant would require a river flow rate of at least $59 \mathrm{~m}^{3} / \mathrm{s}$, a $500-M W$ nuclear plant $85 \mathrm{~m}^{3} / \mathrm{s}$, a 1000-MW fossilfueled plant $119 \mathrm{~m}^{3} / \mathrm{s}$, and a 1000-MW nuclear plant $169 \mathrm{~m}^{3} / \mathrm{s}$. In practice, complete mixing is not attained nor allowed, and larger river flow rates are needed. This example, however, indicates that river discharge ill be an important factor in determining when once-through cooling may be appropriate.

\subsection{SHORELINE SURFACE RISCHARGES}

Shoreline surface discharges have been used by power plants along many rivers, especially in the southeastern U.S. Many of these discharges were designed and built before thermal standards such as outlined in Sec. 2 were promulgated, and the principal concerrn of the designers of these discharges was the avoidance of recirculation of the heated effluent into the cooling water intakes. To accomplish this, wide, shallow, low-velocity outfali channels are used to confine the heated effluent to the near-surface region with minimal vertical mixing. Skimmer walls are of ten employed in front of the intakes to effect selective withdrawall of deep, cool water. Field measurements at several of these power plant sites carried out by Vanderbilt University ${ }^{28,29}$ showed that, in most cases, surface plumes extended well beyond the limits of mixing zones that have since been recommended. In fact, the boundaries of the plumes often extended beyond the limits of the field surveys. Three surveys at the " Widows Creek Steam Plant, however, did yield sufficient data to determine the extent of the mixing zone defined in terms of a dilution of 3.6 (typical dilution required on rivers, see Sec. 4).

TVA's Widows Creek plant has a capacity of $1750 \mathrm{MW}$ and is located near Stevenson, Alabama, on the Tennessee River. The average width of the river at that point is about $350 \mathrm{~m}$ and the average depth, about $6 \mathrm{~m}$. The outfall canal is located on one bank of the river and is about $75 \mathrm{~m}$ wide and $1.8 \mathrm{~m}$ 
deep. From data on plume surface areas within specific isothermal contours, 28 an estinate can be made of the surface area of the zone required to reach a dilution of 3.6. These areas, denoted $A_{3.6}$, are tabulated in Table 8 ass are river flow" rate, $Q_{R}$, and average river velocity, $U_{R}$, during these surveys.

The Vermont Yankee Nuclear Power Station is located in Vernon, Vermont, along the Connecticut River. It consists of a single 514-MW untt originally designed for once-through cooling. The river is about $490 \mathrm{~m}$ wide with an average depth of about $4.5 \mathrm{~m}$. Except during spring runoff, river flow is controlled by hydroelectric stations about $1 \mathrm{~km}$ downstream. The outfall structure is about $32 \mathrm{~m}$ wide and consists of a ramp-like structure. The slope is such that the discharge velocity is about $1.8 \mathrm{~m} / \mathrm{s}$ for all reasónable discharge flow rates. At the normal discharge flow rate of $23 \mathrm{~m}^{3} / \mathrm{s}$, the depth at the point of discharge is $0.4 \mathrm{~m}$, resulting in a very shallow plume. The plant was retrofitted with cooling towers and presently operates in a closed-cycle cooling mode. However, in 1974, many surveys of the thermal plume were carried out under various discharge and iver-flow conditions. 30 The cooling towers were used to dissipate part of the waste heat so that the plume could be studied

Table 8. Selected Mixing-Zone Data for Shoreline Surface Discharges on Rivers

\begin{tabular}{lcccc}
\hline Power Plant & $Q_{p}\left(\mathrm{~m}^{3} / \mathrm{s}\right)$ & $Q_{R}\left(\mathrm{~m}^{3} / \mathrm{s}\right)$ & $U_{R}(\mathrm{~m} / \mathrm{s})$ & $A_{3.6}\left(\mathrm{~m}^{2}\right)$ \\
\hline Widows Creek & 67 & 741 & 0.33 & $3.3 \times 10^{5}$ \\
& 52 & 741 & 0.33 & $2.7 \times 10^{5}$ \\
& 62 & 1331 & 0.61 & $2.7 \times 10^{5}$ \\
Vermont Yankee & 6.7 & 412 & 0.19 & $1.2 \times 10^{4}$ \\
& 10.4 & 307 & 0.14 & $1.5 \times 10^{4}$ \\
& 15.1 & 349 & 0.16 & $2.0 \times 10^{4}$ \\
& 17.3 & 691 & 0.31 & $2.5 \times 10^{4}$ \\
& 16.5 & 1825 & 0.83 & $2.1 \times 10^{4}$ \\
Monticello & 17.5 & 400 & 1.67 & $3.4 \times 10^{3}$ \\
& 16.0 & 208 & 1.22 & $1.0 \times 10^{4}$ \\
& 16.0 & 105 & 0.88 & $1.5 \times 10^{5}$ \\
& 16.8 & 66 & 0.70 & $1.4 \times 10^{5}$ \\
\hline
\end{tabular}


under various cooling water flow rates. The data were reduced in terms of surface area within isothermal contours and were compiled into five groups by cooling water flow rate and river flow rate. The average area of the mixing zone associated with a dilution of $3 / 6$ for each of the five groups is given in Table 8 along with the average plant discharge flow rate and the average river velocity (estimated from the river discharge), the river width, and the average river depth.

The Monticello Nuclear Power Generating Station is located on the Mississippi River near Monticello, Minnesota. It consists of a single unit with a capacity of $545 \mathrm{MW}$. A combination of mechanical draft towers and once-through cooling is used. During 1971-1973, 32 temperature surveys were conducted by power company personnel downstream of the power plant under various river flow rates. These data were analyzed by Stefan et al. ${ }^{31}$ and divided into four groups by river flow rate. The river is about $145 \mathrm{~m}$ wide at this point with an average depth of 0.6-1.7 m for the river flows studied. The average width and depth of the outfall from the surface shoreline discharge canal varies markedly with river flow rate. For the river flow rates studied, the width varied from $25-45 \mathrm{~m}$ and the depth from $0.5-1.5 \mathrm{~m}$. The depth of the outfall is just slightly less than the average depth of the river. The average surface area of the mixing zone for a dilution of 3.6 for each of the four data groups mentioned above are reported in Table 8 . The plant discharge flow rate was relatively constant, whereas the average river velocity varied substantially. The two cases for low river velocity $(0.70$ and $0.88 \mathrm{~m} / \mathrm{s}$ ) correspond to very shallow average river depths $(0.65$ and $0.83 \mathrm{~m})$. The shallowness may have placed a significant limitation on vertical mixing and therefore resulted in the large mixing zone surface areas observed.

In order to use the results of these field measurements to estimate conditions under which a typical power plant using a shoreline discharge on a river will meet the temperature standards and mixing zone requirements established in Sec. 2, a scheme should be developed to parameterize the data so that the results can be interpolated or extrapolated to the discharge conditions of the four typical plants considered in this study. First, the important parameter or parameters that characterize the surface discharge itself have to be established. For a typical low-velocity, shoreline surface outfall, the most important parameter (in terms of governing the gross behavior of the 
effluent) is the discharge flow rate, $Q_{p}$. The discharge velocity and the geometry of the outfall are of secondary importance. If the plant is to meet the thermal standards set forth in Sec. 2, the mixing zone will probably not extend across the entire river. The surface area of the mixing zone will be primarily influenced by the cross-sectionally averaged river velocity, $U_{R}$. The vertical and horizontal velocfty and depth profiles of the river also affect the size and shape of the mixing zone. These parameters are site dependent and probably of secondary importance in determining the approximate mixing zone area.

The 1imited data avallable in Table 8 and probably the simplictty of the relation sought do not allow a general correlation of mixing zone area, $A_{3.6}$, as a function of plant discharge flow rate, $Q_{p}$, and average river velocity, $\mathrm{U}_{\mathrm{R}}$, to be developed with much confidence. However, the data appear to suggest that in order to meet the more restrictive mixing zone surface area requirement of $2.6 \times 10^{4} \mathrm{~m}^{2}$ (area equivalent to a circle of $300 \mathrm{ft}$ radius), a 500-MW fossil-fueled plant $\left(Q_{p}=16.5 \mathrm{~m}^{3} / \mathrm{s}, \Delta \mathrm{T}_{\mathrm{o}}=10.0 \mathrm{C}^{\circ}\right)$ would require a river velocity of about $0.1-0.4 \mathrm{~m} / \mathrm{s}$ and a $1000-\mathrm{MW}$ nuclear plant $\left(Q_{\mathrm{p}}=47.0 \mathrm{~m}^{3} / \mathrm{s}\right.$, $\Delta \mathrm{T}_{0}=10.0 \mathrm{C}^{\circ}$ ) would require a river velocity of about $1.4-1.6 \mathrm{~m} / \mathrm{s}$. It also appears that the less restrictive mixing zone requirement of $2.9 \times 10^{5} \mathrm{~m}^{2}$ (area equivalent to a circle of $1000 \mathrm{ft}$ radius) could easily be met by a 500-MW fossil-fueled plant for a river velocity less than but on the order of $0.1 \mathrm{~m} / \mathrm{s}$, wh1le a 1000-MW nuclear plant would require a river velocity of less than but on the order of $0.3 \mathrm{~m} / \mathrm{s}$.

In a river, the cross-sectlonal area of the mixing zone is often restrfcted to less than $25 \%$ of the cross-sectional area of the river. By the time a dilution of 3.6 is reached, the flow velocity in the plume will be essentially that of the river, $U_{R}$. If the water within the plume were fully mixed to a dilution of 3.6, the cross-sectional area of the mixing zone would be given by $3.6 Q_{p} / U_{R}$. Because the water in the plume will not be fully mixed in practice, the cross-sectional area will be somewhat smaller. In some of the fleld surveys mentioned above, enough information was presented to make an estimate of the cross-sectlonal area of the mixing zone. On the average, the cross-sectional area of the mixing zone was approximately 2.8 $Q_{p} / U_{R^{*}}$ If it is required that this area be less than $25 \%$ of the total crosssectional area of the river, a restriction is placed on the total flow rate 
of the river, $Q_{R}$. In particular, the flow rate of the river must be at least about 11.2 times the discharge flow rate of the plant. This river flow rate is about three times that which would be required if rapld, complete mixing with the entire river were allowed. "The minimum river flow rates required by this computation for the four typical power plants discussed in Sec. 3 to meet the "25\% restriction" are Iisted in Table 9. Only the major river systems of the U.S. have flow rates that are consistently this large. For example, the monthly, 20-year low flow exceeds $340 \mathrm{~m}^{3} / \mathrm{s}(12,000 \mathrm{cfs})$ only in the Mississippi, Missour1, Ohio, and Tennessee Rivers, the Columbia and Snake Rivers, and the St. Lawrence, Niagara, Detroit, St. Clair and St. Mary's Rivers. ". The Mobile and Alabama Rivers, the Apalachicola $\mathrm{Aver}$, and the Sacramento River can be added to this list if rivers with monthly, 20-year low flows greater than $170 \mathrm{~m}^{3} / \mathrm{s}(6000 \mathrm{cfs})$ are considered. Clearly, surface discharges, in the general sense discussed here, have limited efficacy as a once-through cooling water control technology on rivers.

Table 9. Estimated Minimum River Flow Rates for Shoreline Surface Discharges Based on Limiting the Mixing Zone (Dilution of 3.6 ) to $25 \%$ of the Cross-Sectional Area of the River

\begin{tabular}{lcc}
\hline $\begin{array}{c}\text { Power Plant } \\
\mathrm{Q}_{\mathrm{p}}\left(\mathrm{m}^{3} / \mathrm{s}\right)\end{array}$ & $\mathrm{Q}_{\mathrm{R}}\left(\mathrm{m}^{3} / \mathrm{s}\right)^{\mathrm{a}}$ \\
\hline 500-MW Fossil & 16.5 & 185 \\
500-MW Nuclear & 23.5 & 263 \\
1000-MW Fossil & 33.0 & 370 \\
1000-MW Nuclear & 47.0 & 526 \\
\hline aequired minimum river flow rate is 11.2 \\
times the plant discharge flow rate.
\end{tabular}




\subsection{SUBMERGED MULTIPORT DIFFUSERS}

Submerged multiport diffusers provide an opportunity for more rapid mixing than can be attained by a shoreline surface discharge. Smaller river flows may be required, therefore, to meet the same thermal standards. Typically, a submerged multiport diffuser in a river consists of a pipe extending into the river, along the bottom, perpendicular to the direction of flow. The cooling water is discharged at a relatively high velocity through many ports along the pipe, usually in the downstream direction. If a diffuser could be built across the entire width of a river so that essentially the full flow of the river passed over the diffuser and if the diffuser could be designed to produce rapid, full mixing with the entire river flow, then the minimum river flow required to meet the temperature standards discussed in Sec. 2 would be 3.6 times the flow rate of the plant, $Q_{p}$. If mixing is sufficiently rapid, the surface area restrictions on the mixing zone would probably not be a limitation. A river flow rate as much as four times larger than this might be needed due to the additional restriction that less than $25 \%$ of the crosssectional area and volume flow of the river be blocked by the mixing zone. Mixing with a portion of the river is addressed later after the conditions necessary for rapid, full mixing with the entire river are discussed.

Argue and Sayre 32 have studied, in "the laboratory, the mixing characterIstics of submerged mult \pm port diffusers that extend across the entire channel. Their results for discharges inclined slightly $\left(20^{\circ}\right)$ upward suggest that full mixing over the vertical will occur when

$$
F_{s}^{2}\left(\frac{Q_{p}}{Q_{R}-Q_{p}}\right)^{3} \geq 15
$$

where:

$$
\begin{aligned}
& \mathrm{F}_{\mathrm{s}}=\frac{\mathrm{U}_{\mathrm{o}}}{\sqrt{\frac{\Delta \rho_{\mathrm{o}}}{\rho_{\mathrm{a}}} \mathrm{B}_{\mathrm{o}}}}=\text { discharge densimetric Froude number of equivalent } \\
& Q_{p}=\text { discharge flow rate of plant, } \\
& Q_{R}=\text { river flow rate, } \\
& \mathrm{U}_{\mathrm{O}}=\text { discharge velocity, } \\
& \Delta p_{0}=\text { inttial density difference at point of discharge, } \\
& \rho_{a}=\text { ambient receiving water density, }
\end{aligned}
$$


$g=$ acceleration due to gravity,

$\mathrm{B}_{\mathrm{o}}=\mathrm{Q}_{\mathrm{p}} / \mathrm{U}_{\mathrm{O}} \mathrm{L}=$ equivalent slot height, and

$\mathrm{L}=$ length of diffusert.

If full mixing is sought when the river flow rate is at the minimum value that will result in a dilution of 3.6 (i.e., $Q_{R}=3.6 Q_{p}$ ), the restriction for full mixing becomes

$$
F_{S} \geq 16
$$

Using the definition of the equivalent slot Froude number, the restriction can" be "rewritten as:

$$
\mathrm{U}_{\mathrm{o}} \geq\left(16^{2} \frac{\Delta \rho_{\mathrm{o}}}{\rho_{\mathrm{a}}} \mathrm{g} \frac{\mathrm{Q}_{\mathrm{R}}}{3.6 \mathrm{~L}}\right)^{1 / 3}
$$

If it is assumed that the diffuser extends across the entire river and if an initial density difference corresponding to an initial excess temperature of $10.0 \mathrm{C}^{\circ}$ (see Sec.3) and an ambient temperature of $15.0^{\circ} \mathrm{C}$ is assumed, the restriction becomes:

$$
\mathrm{U}_{\mathrm{O}} \geq\left(1.48 \mathrm{~m} / \mathrm{s}^{2} \mathrm{HU}_{\mathrm{R}}\right)^{1 / 3}=\left(1.48 \mathrm{~m} / \mathrm{s}^{2} \mathrm{Q}_{\mathrm{R}} / \mathrm{L}\right)^{1 / 3}
$$

where:

$$
\begin{aligned}
\mathrm{H} & =\text { average depth of river, } \\
\mathrm{U}_{\mathrm{R}} & =\text { average river velocity, and } \\
\mathrm{L} & =\text { length of diffuser (width of river in this case). }
\end{aligned}
$$

This restriction does not present a strong constraint on the design of a multiport diffuser. "For example, for a typlcal 1000-MW nuclear plant $\left(Q_{p}=47.0 \mathrm{~m}^{3} / \mathrm{s}\right)$ on a river of $10-\mathrm{m}$ width, the discharge velocity must be greater than $3 \mathrm{~m} / \mathrm{s}$. The river postulated is unreasonably narrow, and the restriction would be much less for more reasonable widths. In any case, submerged multiport diffusers typically have discharge velocities of $3-5 \mathrm{~m} / \mathrm{s}$ and, therefore, it should be possible to design a diffuser that produces full mixing at minimum river flow rates.

Once full mixing has been achieved, the river velocity must be sufficiently large to assure that the mixed water will be pushed downstream so that heated water does not build up in the vicinity of the discharge. Jirka and Harleman ${ }^{25}$ suggest that the appropriate criterion to assure this is that the densimetric Froude number of the mixed flow is greater than unity. The restriction can be written as: 


$$
F_{m f}=\frac{U_{R}}{\sqrt{\frac{\Delta \rho_{m}}{\rho_{a}} g H_{H}^{H}}} \geqslant 1
$$

where:

$$
\begin{aligned}
E_{m f}= & \text { densimetric Froude number of the mixed flow, and } \\
\Delta \rho_{m}= & \begin{array}{l}
\text { density difference of mixed water with respect to ambient river } \\
\text { water. }
\end{array}
\end{aligned}
$$

The density difference of the mixed water will be approximately $1 / 3.6$ that of the initial density difference if the river flow is such that the required dilution of 3.6 is attained. The restriction then can be written as:

$$
\mathrm{U}_{\mathrm{R}} \geqslant\left(\frac{\Delta \rho_{\mathrm{o}}}{\rho_{\mathrm{a}}} \frac{1}{3.6} \mathrm{~g} \mathrm{H}\right)^{1 / 2}
$$

Using, the initial density difference used previously corresponding to an initial excess temperature of $10.0 \mathrm{C}^{\circ}$, this becomes:

$$
\mathrm{U}_{\mathrm{R}} \geq\left(0.0056 \mathrm{~m} / \mathrm{s}^{2} \mathrm{H}\right)^{1 / 2}
$$

This restriction is for rivers where flow rate is just sufficient to produce the required dilution upon full mixing with the power plant effluent. It is a restriction on the natural characteristics of the river and cannot be met through manipulation of the discharge design. For a river with a depth of $3 \mathrm{~m}$, the minimum river velocity required to counter upstream spreading is $0.13 \mathrm{~m} / \mathrm{s}$ and for a 10-m deep river, the minimum river velocity is $0.24 \mathrm{~m} / \mathrm{s}$. It is difficult to determine, in general, whether this restriction will be a limitation in practice, because it is entirely site specific. However, it appears that it could be a real limitation at some sites. Variation of river velocity across the cross section of the river could result in regions where heated water builds up at the surface even though the average river velocity exceeds this restriction.

The preceding discussion suggests that the achievement of rapid, full . mixing in a river with a submerged multiport diffuser is possible and usually practical. However, the additional restriction that the mixing zone block less than $25 \%$ of the cross-sectional area and of the volume flow of the river must also be considered. In most cases, this restriction would mean that the diffuser could occupy only $1 / 4$ of the width of the river. The diffuser 
would no longer be laterally confined by the channel boundaries. The case of a long diffuser in a shallow co-flowing water body without the presence of confining walls has been studied by Adams. ${ }^{24}$ He observed a contraction of the flow downstream of the diffuser. The momentum of the diffuser discharge disturbs the uniform flow field in such a way that upstream water that would pass beyond the ends of the diffuser if the diffuser were not present is drawn over the diffuser and increases the dilution. Through the application of Bernoulli's theorem and conservation of momentum, Adams developed an expression for the dilution, $S$, downstream of the diffuser where the dilution flow and the discharge flow become fully mixed over the depth. The resulting expression for the dilution can be written:

$$
S=\frac{1}{2} \cdot \frac{U_{a} H}{U_{0} B_{0}}+\frac{1}{2}\left[\left(\frac{U_{a} H}{U_{0} B_{0}}\right)^{2}+2 \frac{H}{B_{0}}\right]^{1 / 2}
$$

where:

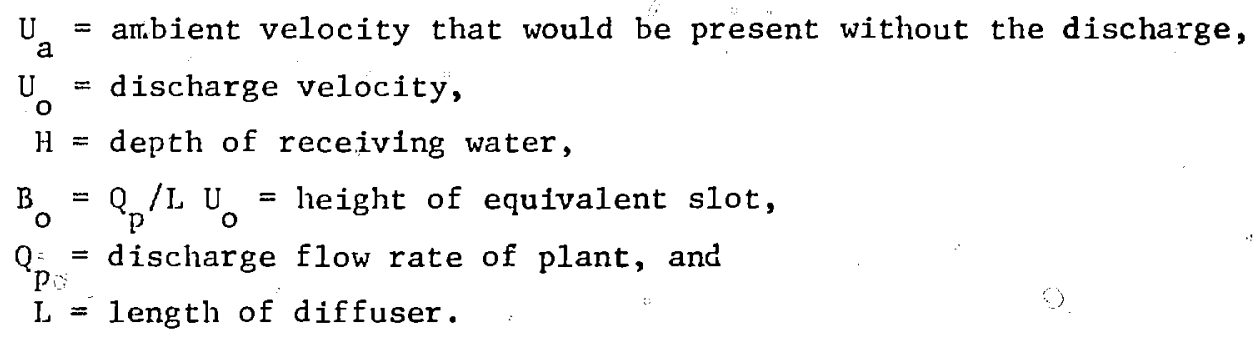

The following limitations spectfy the range of applicability of this analysis ${ }^{33}$ that is restricted to Zong diffusers in shazzow water:

$\mathrm{L} \approx 10 \mathrm{H}$

and

$$
H<\frac{1}{2} U_{\circ}\left(\frac{Q_{p}}{L\left(\frac{\Delta p_{o}}{p_{a}} g\right)^{2}}\right)^{1 / 3} .
$$

Despite the approximations and simplifylng assumptions used in the development of this estimate of the dilution attained by such a diffuser, Adams found satisfactory agreement with experimental results obtained in the laboratory. The above expression for the dilution downstream of a long diffuser in a shallow co-flowing open water body can be rearranged to yield the form: 


$$
S=\frac{\frac{H}{B_{o}}}{\sqrt{\frac{2 H}{B_{o}}+\left(\frac{U_{a}^{H}}{U_{o} B_{o}}\right)^{2}}-\frac{U_{a}^{H}}{U_{o} B_{o}}} .
$$

Substituting the definftion of the equivalent slot, this expression becomes

$$
S=\frac{U_{o} / U_{a}}{\sqrt{\frac{2 U_{o} Q_{p}}{L+U_{a}^{2}}+1}-1}
$$

The estimate of the dilution assumes that there are no lateral boundaries and, therefore, a sufficiently high discharge velocity will yield the required dilution. In a river, there are lateral boundaries and the total water available for dilution is 1 imited by the flow rate of the river. A sufficiently high discharge velocity might draw essentially the entire flow of the river over the diffuser. This would result in stagnant regions beyond the ends of the diffuser and the dilution would be 1 imited to $Q_{R} / Q_{p}$ where $Q_{R}$ is the total flow rate of the river. The restriction that less than $25 \%$ of the flow of the river be blocked by the mixing zone would not be met, whereas, if the diffuser extended only $1 / 4$ of the" way across the river, the restriction that less than $25 \%$ of the cross-sectional area of the river be blocked by the mixing zone could be met.

The Adams' expression for the dilution probably can be used for a diffuser in a river, if the diffuser is located near the middle of the river or"the main channel and if the resulting dilution is sufficiently less than $Q_{R} / Q_{p}$. Specifically, for a river of width $W$, total flow rate $Q_{R}$, and average velocity $U_{R}$, the dilution "can be expressed as:

$$
S=\frac{{U_{O} / U_{R}}^{2 U_{0} W}}{\sqrt{\frac{U_{R} L\left(Q_{R} / Q_{p}-1\right)}{P}+1}-1} .
$$

Consider a diffuser that extends $1 / 4$ of the way across the middle of a river $(\mathrm{L} / \mathrm{W}=1 / 4)$. If the river velocity $1 \mathrm{~s} 1.0 \mathrm{~m} / \mathrm{s}$ and the maximum discharge velocity reasonably attainable by such a diffuser $1 \mathrm{~s} 5.0 \mathrm{~m} / \mathrm{s}\left(U_{R} / U_{0}=0.2\right)$, a river flow rate of 9.5 times the flow rate of the plant would be required 
to produce a dilution of 3.6. This is about 2.6 times that which would be required if full mixing with the entire river were allowed. A lower river velocity would allow the diffuser to draw a larger fraction of the river flow over the diffuser and thus require a lower river flow rate to produce the same dilution. For example, a river velocity of $0.5 \mathrm{~m} / \mathrm{s}\left(U_{R} / U_{0}=0.1\right)$ would require a river flow rate of only 7.0 times the discharge flow rate of the plant. Because the diffuser extends only across $1 / 4$ of the width of the river, the restriction that less than $25 \%$ of the cross-sectional area of the river be blocked by the mixing zone will probably be met. However, more than $25 \%$ of the river flow will pass over the diffuser, therefore, it is probable that the second restriction, that less than $25 \%$ of the volume flow of the river be blocked by the mixing zone, will not be met.

"The "25\% restriction" can alternatively be interpreted in a more relaxed manner. In most cases, a diffuser is made up of many separate ports and, at least initially, separate jets emerge from these ports and expand, dilute, and cool by entraining ambient river water that flows around and between the individual jets. Therefore, there will be regions around each jet where the excess temperature is less than the appropriate temperature standard. These regions could be considered to be outside the mixing zone and, therefore, contribute to the $75 \%$ of thr cross sectional area or volume flow that must not be blocked by the mixing zone. Parr and Sayre ${ }^{34}$ have considered this interpretation in their studies of the diffuser for the QuadCities Nuclear Power Station on the Mississippi River near Cordova, Illinois. They assumed that downstream of the individual discharge ports, the excess temperature distribution at a particular downstream cross section can be approximated by an axisymmetric Gaussian distribution of the form

$$
\Delta T(r)=\Delta T_{C L} e^{-\frac{r^{2}}{2 \sigma^{2}}}
$$

where:

$$
\begin{aligned}
\Delta \mathrm{T}(\mathrm{r}) & =\text { excess temperature at radial distance } \mathrm{r} \text { from the jet centerline, } \\
\Delta \mathrm{T}_{\mathrm{CL}} & =\text { excess temperature at the jet centerline, and } \\
\sigma_{\mathrm{T}} & =\text { standard deviation of excess temperature distribution. }
\end{aligned}
$$

Both $\Delta \mathrm{T}_{\mathrm{CL}}$ and $\sigma_{\mathrm{T}}$ are functions of downstream distance. The centerline excess temperature decreases while $\sigma_{T}$ increases as the jet entrains amblent water and 
cools. If the individual jets do not significantly interfere with one another or with the river boundaries, conservation of heat energy yields:

$$
\Delta T_{C L}=\frac{\left(Q_{p} / N\right) \Delta T_{0}}{\vec{u}} \frac{1}{2 \pi \sigma_{T}^{2}}
$$

where:

$$
\begin{aligned}
Q_{\mathrm{P}}= & \text { discharge flow rate of plant, } \\
\mathrm{N}= & \text { number of ports, } \\
\Delta \mathrm{T}_{\mathrm{O}}= & \text { initial excess temperature at point of discharge, and } \\
\overline{\mathrm{u}}= & \frac{\int \mathrm{U} \Delta \mathrm{TdA}}{\int \Delta \mathrm{TdA}}=\text { the excess temperature weighted mean velocity at the } \\
& \text { downstream cross section. }
\end{aligned}
$$

Both $\sigma_{T}$ and $\bar{u}$ are functions of downstream distance. At the point of discharge, $\vec{u}$ is equal to a maximum, the discharge velocity $U_{o^{*}}$ By the time full mixing is attained, $\vec{u}$ reaches a minimum value of $U_{R}$, the ambient river velocity.

For a diffuser extending across the entire river, the fraction of the total river cross-sectional area, $f_{A}$, at a given downstream distance, exposed to-excess temperatures greater than some excess temperature standard or 1 imit, can be expressed as:

$$
\mathrm{f}_{\mathrm{A}}=\frac{\mathrm{N} \pi \mathrm{r}^{\prime 2}}{\mathrm{HL}}=\frac{-2 \pi \sigma_{\mathrm{T}}^{2} \mathrm{~N}}{\mathrm{HL}} \ln \left(\frac{2 \pi \sigma_{\mathrm{T}}^{2} \mathrm{Nu} \Delta \mathrm{T}_{\max }}{\mathrm{Q}_{\mathrm{p}} \Delta \mathrm{T}_{\mathrm{o}}}\right)
$$

where:

$$
\begin{aligned}
\mathbf{r}^{\prime} & =\text { radial distance at which } \Delta \mathrm{T}(\mathrm{r})=\Delta \mathrm{T}_{\max } \\
\mathrm{H} & =\text { depth of river, } \\
\mathrm{L} & =\text { length of diffuser (width of river), and } \\
\Delta \mathrm{T}_{\max } & =\text { excess temperature standard or } 1 \text { imit. }
\end{aligned}
$$

This fraction varies with distance downstream as $\sigma_{\bar{T}}$ and $\bar{u}$ vary. It reaches a maximum at some downstream cross section and then decreases as dilution continues. In order to facilitate finding the maximum value of $f_{A}$, Parr and Sayre made the simplifying assumption that the variation of $f_{A}$ depends most strongly on the variation of $\sigma_{T}$ and not on $\bar{u}$. The maximum can then be found by setting the derivative of $f_{A}$ with respect to $\sigma_{T}$ to zero, which yields:

$$
\left(f_{A}\right)_{\max }=\frac{Q_{p} \Delta T_{o}}{e^{\bar{u}} \text { HL } \Delta T_{\max }} \text {. }
$$


For a conservative estinate of the maximum value of $f_{A}$, $\bar{u}$ can be approximated by its minimum value $\mathrm{U}_{\mathrm{R}}$. The expression becomes

$$
\left(\mathrm{f}_{\mathrm{A}}\right)_{\max }=\frac{1}{\mathrm{e}} \frac{\Delta \mathrm{T}_{\mathrm{o}} \mathrm{Q}_{\mathrm{p}}}{\Delta \mathrm{T}_{\max } \mathrm{Q}_{\mathrm{R}}}
$$

where:

$$
Q_{R}=U_{R} H L=\text { volume flow rate of the river. }
$$

The requirement that the maximum value of $f_{A}$ be less than or equal to $1 / 4$ for $\Delta T_{0} / \Delta T_{\max }$ equal to 3.6 yields the following restriction on the river flow rate:

$$
\mathrm{Q}_{\mathrm{R}} \geq 5.30 \mathrm{Q}_{\mathrm{P}}
$$

This is $47 \%$ greater than the minimum river flow rate required for a dilution of 3.6 upon full mixing with the entire river flow.

Parr and Sayre also developed an expression for the fraction of the total volume flow of the river exposed to excess temperatures greater than some standard or limit. This fraction is defined as:

$$
\mathrm{f}_{\mathrm{Q}}=\frac{2 \pi \mathrm{N} \int_{0}^{\mathrm{r}} \mathrm{c} \text { ur dr}}{\mathrm{Q}_{\mathrm{R}}}
$$

The maximum value of this quantity was determined in a manner similar to the above procedure using similar approximations. The results cannot be expressed in simple analytic form but have been presented graphically by Parr and Sayre. Requiring that the maximum value of $f_{Q}$ be less than or equal to $1 / 4$ leads to the following restriction on river flow rate:

$$
\mathrm{Q}_{\mathrm{R}} \geq 5.66 \mathrm{Q}_{\mathrm{p}}
$$

This restriction is $57 \%$ greater than the minimum river flow rate required for a dilution of 3.6 upon full mixing with the entire river flow.

Parr and Sayre compared the expressions for the maximum values of $f_{A}$ and $f_{Q}$ as a function of $Q_{R} / Q_{p}$ with the results of their laboratory studies. They found that the laboratory results for the maximum value of $f_{A}$ showed an additional dependence on $U_{o} / U_{R}$. Larger values of $U_{o} / U_{R}$ produced smaller values for the maximum of $f_{A}$ for the same value of $Q_{R} / Q_{P}$. For the range of $\mathrm{U}_{\mathrm{O}} / \mathrm{U}_{\mathrm{R}}$ tested (3.8-33.8), the analytical estinate for the maximum value of $\mathbf{f}_{\mathrm{A}}$ 
was found to be conservative and overpredicted the fraction of the crosssectional area of the river blocked by the mixing zone. The laboratory results for the maximum value of $\mathrm{f}_{\mathrm{Q}}$ showed much less dependence on $U_{\mathrm{O}} / \mathrm{U}_{\mathrm{R}}$ and agreed well with the analytical prediction.

If this second, less strict interpretation of the "25\% restriction" is allowed, a diffuser can be designed that extends across essentially the entire river and a river flow rate of about 5.7 times the flow rate of the power plant is all that would be required to meet the temperature standards and mixing zone requirements. This rate is about half the river flow 'rate estimated in Sec. 6.2 for shoreline surface discharges on rivers.

Table 10 summarizes the estimates of minimum river flow rates required to achieve a mixing zone (dilution of 3.6 ) that blocks 1ess than $25 \%$ of the cross-sectional area of the river for the four typical power plants described in Sec. 3 (Table 6). Shoreline surface discharges, multiport diffusers that extend $1 / 4$ of the way across the center of the river (Adams analysis), and multiport diffusers that extend across the entire river but are subject to the relaxed interpretation of the "25\% restriction" (Parr and Sayre analysis) are considered. While the efficacy of surface discharges as a control technology for waste heat disposal appears 1 imited, the application of submerged multiport diffusers for this purpose seems feasible for a larger range of rivers. Depending on the interpretation of the restriction that the mixing zone not encroach upon more than $25 \%$ of the river cross-sectional area and flow, river flow rates required to meet standards range from 9.5 to as $10 \mathrm{w}$ as 5.7 times the cooling water flow rate of the plant. 
Table 10. Estimated Minimum River Flow Rates Based on Limiting the Mixing Zone (Dilution of 3.6 ) to $25 \%$ of the Cross-Sectional Area of the River, Except as Noted

\begin{tabular}{|c|c|c|c|c|c|c|}
\hline \multirow[b]{3}{*}{$\begin{array}{l}\text { Type of } \\
\text { Power Plant }\end{array}$} & \multirow{3}{*}{$\begin{array}{c} \\
\text { P1ant } \\
\text { Flow Rate, } \\
Q_{p}\left(\mathrm{~m}^{3} / \mathrm{s}\right)\end{array}$} & \multicolumn{5}{|c|}{ Minimum River Flow Rate, $\mathrm{Q}_{\mathrm{R}}\left(\mathrm{m}^{3} / \mathrm{s}\right)$} \\
\hline & & \multirow{2}{*}{$\begin{array}{l}\text { Shoreline } \\
\text { Surface } \\
\text { Discharge }\end{array}$} & \multicolumn{2}{|c|}{$1 / 4$ River Width } & \multirow{2}{*}{$\begin{array}{l}\text { Multiport } \\
\text { Diffuser } \\
\text { (Relaxed) }\end{array}$} & \multirow[b]{2}{*}{$\begin{array}{l}\text { Fully } \\
\text { Mixed }\end{array}$} \\
\hline & & & $\begin{array}{c}\text { Multiport } \\
\text { Diffuser } \\
\mathrm{U}_{\mathrm{R}} / \mathrm{U}_{\mathrm{O}}=0.2\end{array}$ & $\begin{array}{c}\text { Multiport } \\
\text { Diffuser } \\
\mathrm{U}_{\mathrm{R}} / \mathrm{U}_{\mathrm{O}}=0.1\end{array}$ & & \\
\hline 500-MW Fossil & 16.5 & 185 & 157 & 116 & 94 & 59 \\
\hline 500-MW Nuclear & 23.5 & 263 & 223 & 165 & 134 & 85 \\
\hline 1000-MW Fossil & $=33.0$ & 370 & 313 & 232 & 188 & 119 \\
\hline 1000-MW Nuclear & $\begin{array}{l}47.0 \\
=\end{array}$ & $\begin{array}{c}526 \\
(11.2)^{c}\end{array}$ & $\begin{array}{l}446 \\
(9.5)\end{array}$ & $\begin{array}{c}330 \\
(7.0)^{c}\end{array}$ & $\begin{array}{c}268 \\
(5.7) c\end{array}$ & $\begin{array}{l}169 \\
(3.6)^{c}\end{array}$ \\
\hline
\end{tabular}

aiscounting areas surrounding jets in $25 \%$ calculation.

${ }^{b}$ Ignoring $25 \%$ restriction, full mixing with entire river flow.

${ }^{c}$ Multiple of plant cooling water flow rate. 


\section{ONCE-THROUGH COOLING ON LAKES}

\subsection{GENERAL FEATURES}

The major characteristics of a lake that are important in assessing its effectiveness as a receiving water body for the purposes of once-through cooling are: (1) large, essentially unlimited, lateral extent, (2) currents that

are variable in both magnitude and direction, and (3) no significant tidal variation of currents or water depth. Large lateral extent implies that only the shore boundary near the power plant can affect the behavior of the discharge and the resulting thermal plume. For the lakes considered, the heat added by the power plant is small compared to the total heat budget of the lake; therefore, the measurable physical effect of the discharge is confined to the vicinity of the power plant and does not extend over a significant fraction of the entire water body. Impoundments for which this is not true should be treated as cooling ponds or lakes. The variability of the ambient currents implies that, although they clearly will affect the dispersal of the waste heat, they cannot be relied upon to have a uniform, consistent effect on the thermal plume. Other features of the ambient receiving water that affect dispersal of the heated effluent include: water depth, bottom topography, current shear in both the horizontal and vertical directions, and thermal (density) structure in the horizontal and vertical directions. These features are site specific and may be transient. Velocity and thermal structures may vary over time periods ranging from hours to months, depending on such things as solar heating, lake-wide circulation, and local and lakewide meteorological conditions.

The previous discussion of typical temperature standards for lakes and typical discharge temperatures indicates that a dilution of at least 6.0 is required for lakes. Typical mixing zone limitations require that this dilution be accomplished within a zone with a surface area of $2.6 \times 10^{4} \mathrm{~m}^{2}$ (area equivalent to a circle of $300 \mathrm{ft}$ radius) to $2.9 \times 10^{5} \mathrm{~m}^{2}$ (1000-ft radius circle).

\subsection{SHORELINE SURFACE DISCHARGES}

Until the early to mid 1970s, most power plants sited on large lakes used shoreline surface discharges to dispose of waste heat. The outfalls generally consist of open channels that terminate at or near the shoreline. 
The depth of the channel at the point of discharge is usually 1 imited by the water depth at that point to $1.5-4.0 \mathrm{~m}$. Discharge velocities are small, usually in the $0.5-1.0 \mathrm{~m} / \mathrm{s}$ range. The resulting discharge jets are of ten characterized, in fluid mechanical terms, by $a$ discharge densimetric Froude number defined as:

$$
F_{0}=\frac{U_{o}}{\sqrt{\frac{\Delta \rho_{0}}{\rho_{a}} g h_{0}}}
$$

where:

$$
\begin{aligned}
U_{0}= & \text { discharge velocity, } \\
\Delta \rho_{0}= & \text { initial density difference between discharge and ambient receiving } \\
& \text { water, } \\
\rho_{\mathrm{a}}= & \text { density of ambient receiving water, } \\
\mathrm{g}= & \text { acceleration due to gravity, and } \\
\mathrm{h}_{\mathrm{o}} & =\text { depth at point of discharge. }
\end{aligned}
$$

The Froude number is as a ruie in the range 2-8 for typical shoreline surface discharges. Initial mixing with the ambient receiving water is governed primarily by the outfall configuration and the discharge densimetric Froude number, but, lake currents, especially strong shore-parallel currents, can influence initial mixing. By the time a dilution of 5-6 has taken place, velocities and densities within the heated plume are only slightly different from those in surrounding ambient water; therefore, currents and turbulence associated with the ambient receiving water dominate the plume dispersal processes.

Because surface discharges on lakes have been used for a number of years, a considerable amount of data from field measurements exists in the form of horizontal isotherm areas of the plume as a function of excess temperature and depth. Early in 1971, Asbury and Frigo ${ }^{35}$ examined the literature and identifled sets of published lake-plume data from six different lake sites that they considered useful for their attempt to find a phenomenological correlation between plume surface area and excess temperature. They only included measurements for which discharge flow rate, discharge temperature, and ambient temperature were reported. In addition, they required that the plume appear to be adequately defined by the measurements and that no strong thermal gradients were present 
in the ambient receiving water. The final data set used by Asbury and Frigo consisted of 23 plume measurements at six different power plants with discharge flow rates ranging from $3-53 \mathrm{~m}^{3} / \mathrm{s}$. They found that, for the parameters available to them, the best correlation occurred when the excess-temperature ratio, $\Delta \mathrm{T} / \Delta \mathrm{T}_{\mathrm{o}}$, of a given surface isotherm was plotted against the surface area of the isotherm, A, divided by the discharge flow rate of the plant, $Q_{p}$. The excess-temperature ratio is defined as:

$$
\frac{\Delta \mathrm{T}}{\Delta \mathrm{T}_{\mathrm{o}}}=\frac{\mathrm{T}-\mathrm{T}_{\mathrm{a}}}{\mathrm{T}_{\mathrm{o}}-\mathrm{T}_{\mathrm{a}}}
$$

where:

$$
\begin{aligned}
\mathrm{T} & =\text { temperature of isotherm, } \\
\mathrm{T}_{\mathrm{a}} & =\text { ambient receiving water temperature, and } \\
\mathrm{T}_{0} & =\text { initial discharge temperature. }
\end{aligned}
$$

If the ambient receiving water is of a uniform temperature, the dilution attained within a given isotherm is simply the reciprocal of the excesstemperature ratio. For the purposes of this study, the surface area of the zone required to lattain a dilution of 6.0 (or an excess-temperature ratio of 0.17 ) is of interest. The data compiled by Asbury and Frigo were used to estimate the surface area associated with a dilution of 6.0 . These surface areas, denoted as $A_{6.0}$, are listed in the first part of Table 11 . In particular instances, when the field measurements were not adequate to make a reasonable estimate of $\mathrm{A}_{6.0}$, the survey was omitted from the table.

Since the time of the Asbury-Frigo analysis, Argonne National Laboratory has collected additional data at sites of shoreline surface discharges on Lake Michigan. 36-39 In particular, studies were conducted at the Point Beach Nuclear Power Plant, the Palisades Nuclear Power Plant, and the Waukegan Generating Station. Those measurements for which sufficient data are available to estimate the surface area associated with a dilution of 6.0 have been included in Table 11. Elliot and Harkness 40 have also reported measurements of the thermal plume from the Lakeview Generating station on Lake Ontario and results based on those measurements have also been included in the table. Following the suggestion of Asbury and Frigo, the ratio $A_{6.0} / Q_{p}$ has been included in the table. It is evident that the size of the plume varies with discharge flow rate and that the parameter $A_{6.0} / Q_{p}$ exhibits significantly less variation than 
Table 11. Summary of Thermal Plume Surface Area Data Corresponding to a Dilution of 6.0 for Shoreline Surface Discharges on Lakes

\begin{tabular}{|c|c|c|c|c|c|}
\hline Pouer Plant & $Q_{p}\left(m^{3} / s\right)$ & $A_{6.0}\left(\mathrm{~m}^{2}\right)$ & $A_{6.0} / Q_{p}$ & $p \times 10^{-4}$ & $+(s / m)$ \\
\hline Waukeran" & 53.0 & $5.4 \times 10^{5}$ & & 1.02 & \\
\hline Wauke:an" & 53.0 & $8.6 \times 10^{5}$ & & 1.62 & \\
\hline Weukegan" & 49.0 & $2.3 \times 10^{6}$ & & 4.69 & \\
\hline Weukegen" & 49.0 & $3.3 \times 10^{6}$ & & 6.73 & \\
\hline Weukegen ${ }^{a}$ & 46.0 & $2.5 \times 10^{6}$ & & 5.43 & \\
\hline Weukegan" & 53.0 & $1.8 \times 10^{6}$ & & 3.36 & \\
\hline B1. Rock Point & 3.2 & $1.7 \times 10^{5}$ & & 5.52 & \\
\hline M1111ken" & 7.2 & $3.1 \times 10^{5}$ & & 4.26 & \\
\hline Michigan City & 15.2 & $1.6 \times 10^{5}$ & & 1.04 & \\
\hline Alen s. King & 18.7 & $5.3 \times 10^{5}$ & & 2.83 & \\
\hline Allen S. King & 18.7 & $2.8 \times 10^{5}$ & & 1.50 & \\
\hline Allen S. KIns & $12: 9$ & $5.6 \times 10^{5}$ & & 4.34 & \\
\hline Allen s. KIng & 18.1 & $2.0 \times 10^{5}$ & & 1.13 & \\
\hline Allen s. King & 17.7 & $5.6 \times 10^{5}$ & & 3.16 & \\
\hline Douglas Point" & 11.2 & $7.2 \times 10^{5}$ & & 6.43 & \\
\hline Douglas Point" & 11.2 & $1.1 \times 10^{5}$ & & 1.01 & \\
\hline Point Beach, Unit 1 & 25.1 & $4.8 \times 10^{5}$ & & 1.91 & \\
\hline Point Baxch, Un1t 1 & 25.1 & $5.1 \times 10^{5}$ & & 2.03 & \\
\hline Foint Beach, Unit 1 & 24.7 & $7.6 \times 10^{5}$ & & 3.08 & \\
\hline Point Baech, On1t 1 & 25.1 & $9.0 \times 10^{5}$ & & 3.59 & \\
\hline Point Beach, Unit 1 & 25.1 & $3.8 \times 10^{5}$ & & 1.51 & \\
\hline Potat Beach, Unit 1 & 25.1 & $5.6 \times 10^{5}$ & & 4.25 & $-\therefore$ \\
\hline Point waech, Unte 1 & 25.1 & $3.6 \times 10^{5}$ & $w$ & 2.73 & \\
\hline
\end{tabular}

\begin{tabular}{|c|c|c|c|c|c|c|}
\hline Power Plar & ant & $Q_{p}\left(m^{3} / s\right)$ & $A_{6.0}\left(\mathrm{~m}^{2}\right)$ & $A_{6.0} / Q_{p}$ & $\times 10^{-4}$ & $4(\mathrm{~s} / \mathrm{m})$ \\
\hline Point Beach, & Unit 1 & 25.1 & $5.8 \times 10^{5}$ & & 4.40 & \\
\hline Point Beach, & Unit 1 & 25.1 & $3.6 \times 10^{5}$ & & 2.73 & \\
\hline Palisades & & 25.6 & $8.1 \times 10^{5}$ & & 3.16 & $\because$ \\
\hline Palisades & & 25.6 & $.2 .0 \times 10^{6}$ & & 7.81 & \\
\hline Palisades & & 25.6 & $1.7 \times 10^{6}$ & 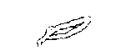 & 6.64 & \\
\hline Palísades & & 25.6 & $4.8 \times 10^{5}$ & & 1.88 & \\
\hline Palisades & & 25.6 & $2.4 \times 10^{5}$ & . & 0.94 & \\
\hline Palisades & & 25.6 & $3.7 \times 10^{5}$ & $\because$ & 1.45 & . \\
\hline Palisades & & 25.6 & $7.6 \times 10^{5}$ & & 2.97 & \\
\hline Waukegan & : & 45.9 & $1.1 \times 10^{6}$ & & 2.40 & \\
\hline Waukegan & & 44.4 & $1.3 \times 10^{6}$ & & 2.93 & \\
\hline Lakeview & & 49.6 & $2.3 \times 10^{6}$ & & 4.64 & \\
\hline Lakeview & & 49.6 & $8.6 \times 10^{5}$ & & 1.73 & \\
\hline Lakeview & & 49.3 & $1.5 \times 10^{6}$ & & 3.04 & . \\
\hline Lakeview & & 49.8 & $2.1 \times 10^{6}$ & & 4.30 & \\
\hline Lakeview & $:$ & 48.7 & $2.6 \times 10^{6}$ & & 5.32 & \\
\hline Lakeview & $=$ & 60.6 & $1.2 \times 10^{6}$ & & $1.91=$ & \\
\hline Lakeview & & 57.5 & $1.6 \times 10^{6}$ & & 2.75 & \\
\hline Lakeview & & 29.7 & $9.3 \times 10^{5}$ & & 3.13 & \\
\hline Lakeview & & 69.1 & $1.9 \times 10^{6}$ & & 2.75 & \\
\hline Lakeview & & 56.1 & $1.6 \times 10^{6}$ & & 2.82 & \\
\hline Lakev iew & & $62.3=$ & $2.5 \times 10^{6}$ & & 3.98 & \\
\hline Lakevlew & & 55.5 & $2.4 \times 10^{6}$ & & 4.23 & \\
\hline Lakeview & & 56.1 & $2.2 \times 10^{6}$ & $\therefore$ & 3.83 & \\
\hline
\end{tabular}

Tron data eat compiled by Asbury and Frigo, Ref. 35. 
either $A_{6.0}$ or $Q_{p}$ separately. However, it is also evident that while the size of the isotherm corresponding to a dilution of 6.0 depends on the details of the outfall such as flow rate, depth, discharge velocity, and Froude number, it also depends on the characteristics of the ambient recelving waters that are more difficult to identify and measure. This feature can be noted in the variation of $A_{6.0}$ for different surveys at the same power plant with essentially the same outfall conditions.

The quantity $A_{6.0} / Q_{p}$ is hardly satisfactory from a fundamental viewpoint as the near-field behavior of the plume clearly depends on the detalls of the discharge geometry and the discherge velocity as well as the discharge flow rate. Also, the behavior of the plume in the region corresponding to a dilution of 6.0 is very much dependent on far-field or ambient processes. However, at least for the nine power plants listed in Table 11, the quantity $A_{6.0} / Q_{p}$ appears, to first order, to be independent of the detalls of the outfall for the limited but typical range of shoreline surface outfall designs considered. The average value of $A_{6.0} / Q_{p}$ for all the thermal plume surveys listed in Table 11 is $3.15 \times 10^{4} \mathrm{~s} / \mathrm{m}$ with a standard deviation of $1.70 \times 10^{4} \mathrm{~s} / \mathrm{m}$.

Several analytical models have been developed to predict the behavior of the jet and the size of the resulting thermal plume from surface discharges. Many of these have been reviewed and evaluated by Policastro and Tokar, 16 Jirka et al., 19 and Dunn et al. 18 Most of the models are based on an Integral analysis of the discharge jet. By the time a dilution of 6.0 has been reached, the jet velocity has usually diminished markedly and the model assumptions begin to break down. In an attempt to determine whether such models might be useful in estinating the size of the mixing zone, two models that have often been cited in environmental impact evaluations and that are easy to use have been applied to four of the power plants Iisted in Table 11 for which significant amounts of field data are avallable. The four power plants are Point Beach Nuclear Power Plant (Unit 1)", Palisades Nuclear Power Plant, Waukegan Generating Station, and Lakeview Generating Station. The two models are those of Pritchard $d^{12}$ and ShIraz1 and Davis ${ }^{15}$ (prepared for the U.S. EPA). The Pritchard model is semi-empirical and based on a synthesis of previous theoretical and physical modeling results of buoyant and nonbuoyant jets, complemented with results Pritchard gleaned from fleld data obtained at some existing power plant sites. The Shiraz1-Davis model is based on the integral model of Prych $^{41}$ modifled by means of calibration with existing laboratory 
and field data. This model is easy to apply because results have been presented as a collection of nomograms in a workbook. Table 12 lists values of the parameters that describe the discharges of the four power plants. They represent average values for the surveys 1isted in Table 11. When significant variation exists, the standard deviation is also listed. The cooling water discharge flow rate is denoted $Q_{p}$, and the average discharge velocity is denoted $U_{0}$. The average depth and width of the outfall at the point of discharge are denoted by $h_{0}$ and $b_{0}$, respectively. The discharge densimetric Froude number is also included in this table. Figure 3 represents the model predictions along with the average results of the field surveys. Varlations among the field measurements at a given power plant are indicated by horizontal bars that represent one standard deviation on either side of the mean. The Shirazi-Davis model is quite sensitive to the discharge densimetric Froude number and the horizontal bars on these predictions represent the effects of the variations of input parameters indicated in Table 12 . In addition, the Shirazi-Davis model runs into difficulty when the jet velocity and, therefore, the local densimetric Froude number become small. The nomograms do not extend to a dilution of 6.0 when there is no ambient current present. Therefore, the predictions presented in Fig. 3 are for an ambient cross current that is $30 \%$ of the discharge velocity in magnitude and directed at right angles to the discharge. This cross current is the smallest shown on the nomograms for which results extend to a dilution of 6.0 . Smaller current would presumably

Table 12. Summary of the Discharge Parameters for Four Power Plants with Shoreline Surface Discharges on Large Lakes

\begin{tabular}{lccccc}
\hline \multicolumn{1}{c}{ Power Plant } & $Q_{\mathrm{p}}\left(\mathrm{m}^{3} / \mathrm{s}\right)$ & $\mathrm{U}_{\mathrm{o}}(\mathrm{m} / \mathrm{s})$ & $\mathrm{h}_{\mathrm{o}}(\mathrm{m})$ & $\mathrm{b}_{\mathrm{o}}(\mathrm{m})$ & $\mathrm{F}_{\mathrm{o}}$ \\
\hline Point Beach, Unit 1 & 25.1 & 0.56 & 4.2 & 10.7 & $\begin{array}{l}2.27 \\
\end{array}$ \\
& \pm 0.1 & & & & \pm .24 \\
Palisades & 25.6 & 0.43 & 2.1 & 28.3 & 2.33 \\
& & & & & \pm .11 \\
Waukegan & 49.2 & 1.08 & 1.5 & 30.5 & 7.87 \\
& \pm 3.3 & \pm .07 & & & \pm 2.08 \\
Lakeview & 53.4 & 0.44 & 3.0 & 39.6 & 3.1 \\
& \pm 9.0 & \pm .07 & & & \pm .7 \\
\hline
\end{tabular}




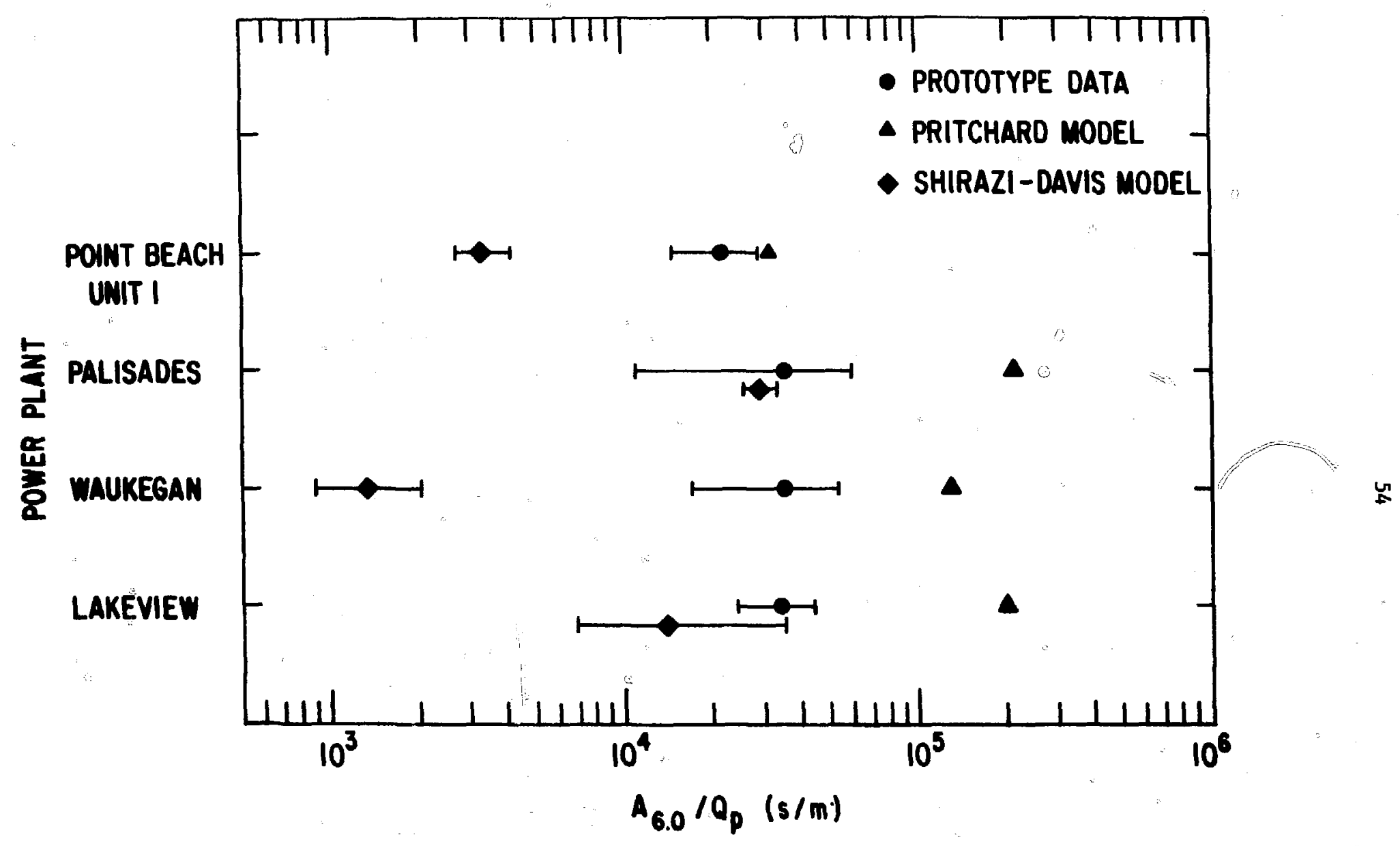

F1g. 3. Comparison of Selected Analytical Model Predictions with Average Results of Field Measurements 
result in significantly larger surface areas but specific predictions are not available. Neither model predlcts the surfuce areas correctly; indeed, the predictions are generally off by an order of magnitude. These results and, in fact, the more detailed comparisons of predictions and data by Dunn et al., 18 indicate that analytical models cannot be used to make reliable predictions of plume surface areas. For the purposes of this generallzed assessinent of oncethrough cooling water technology, the simple correlation of the surface area with plant discharge flow rate, while not theoretically satisfying and presumably not entirely general, is probably sufficient.

Based on this simple correlation, a 500-MW fossil-fueled plant $Q_{p}=$ $16.5 \mathrm{~m}^{3} / \mathrm{s}, \Delta \mathrm{T}_{\mathrm{o}}=10 \mathrm{C}^{\circ}$ ) would require a mixing zone with a surface area of $2.4-8.0 \times 10^{5} \mathrm{~m}^{2}$ to attain a dilution of 6.0 using a typlcal shoreline surface discharge. Such a plant might, under certain condttions, meet the less stringent mixing zone surface area restriction of $2.9 \times 10^{5} \mathrm{~m}^{2}$ (area equivalent to a circle of $1000 \mathrm{ft}$ radius). However, it is very unlikely that the more stringent mixing zone surface area restriction of $2.6 \times 10^{4} \mathrm{~m}^{2}$ (300-ft radius circle) could be met by such a plant. It appears that power plants, either fossil-fueled or nucltar, with capacity greater than $500 \mathrm{MW}$, will not be able to meet thermal standards on lakes using once-through cooling and a conventional surface discharge.

\subsection{OFFSHORE SUBMERGED DISCHARGES}

Only recently have submerged discharges been used by power plants on large lakes for the disposal of waste heat. Subme :ged discharges have generally higher outfall velocities than surface discharges, and, because of discharge at depth, can result in substantial dilution of the effluent by the time it reaches the surface. The Increased dilution due to mixing results in correspondingly smaller plume areas at the surface where mixing zone limitations usually apply. The configuration of submerged discharge systems vary, but, in general terms, they can be put into two categories: single structures with a few discharge opentngs and multiport diffusers with numerous discharge ports.

Submerged single structures seem to have unique designs and generalizations about their performance are few. of course, as is the case with all submerged discharges, Increased relative submergence (ratio of the water depth 
above the discharge opening to the characteristic vertical dimension of the discharge opening) leads to increased dilution at the surface. Two submerged single-structure type discharges on lakes at which field measurements of the thermal plume have been made are the Zion Nuclear Power Station 42,43 and the D.C. Cook Nuclear Power Plant, 44,45 both on Lake Michigan. The results of these field measurements are discussed briefly as examples of submerged single-structure type discharges.

The Zion Nuclear Power Station is made up of two separate 1100-MW units with two similar cooling-water discharge structures about $100 \mathrm{~m}$ apart in the longshore direction. Each structure consists of a rectangular box $23 \mathrm{~m}$ long, $9 \mathrm{~m}$ wide, and $1 \mathrm{~m} \mathrm{high}$, oriented with the long axis perpendicular to the shoreline. The boxes are on the bottom in $4.5 \mathrm{~m}$ of water. The outlet from each discharge structure consists of 14 ports, each of which is roughly $1.6 \mathrm{~m}$ wide by $0.9 \mathrm{~m} \mathrm{high}$, formed by louvers set at $45^{\circ}$ angles on the offshore end and one side (the side away from the other structure) of the box. In this way, the effluent is directed away from the shore and away from the other discharge structure. The resulting relative submergence of the discharges is about 4.2. The normal cooling-water flow rate for each unit is about $50 \mathrm{~m}^{3} / \mathrm{s}$ yielding a discharge velocity of $2.4 \mathrm{~m} / \mathrm{s}$. Eight surveys of the thermal plume were made when only one unit was in operation. 42 These surveys show that the minimum surface dilution (i.e., dilution corresponding to the maximum surface excess temperature) is only 1.4-2.0. Additional mixing once the plume has reached the surface is needed in order to meet typical temperature standards. The size of the plume was found to depend strongly on the presence and direction of an ambient lake current. For operation of only one unit, the surface area corresponding to a dilution of 6.0 was found to be $6-8 \times 10^{4} \mathrm{~m}^{2}$ when the discharge was in the same direction as the ambient current and 1-6 $\times 10^{5} \mathrm{~m}^{2}$ when the discharge was into an oncoming current. Measurements when both units were in operation ${ }^{42,43}$ demonstrated that significant interaction can occur between the adjacent thermal plumes. It can be concluded that the size of the plume at Zion is strongly influenced by the availability of cold dilution water brought in by the ambient current. Such a discharge could meet thermal standards under certain circumstances, but its ability to do so depends on ambient lake currents that are highly variable. 
The D.C. Cook Nuclear Power Plant will eventually conslst of two 1100-WW units, each with its own discharge structure. Only Unit 1 is presently in operation. The Unit 1 discharge structure consists of two adjacent horizontal slots, each $9.1 \mathrm{~m}$ wide and $0.6 \mathrm{~m} \mathrm{high}$, near the bottom in about $5.7 \mathrm{~m}$ of water. One slot is directed offshore whlle the other is at a $75^{\circ}$ angle with respect to the first. The resulting relative submergence of the discharge is 8.1 . The normal cooling-water flow rate is $46 \mathrm{~m}^{3} / \mathrm{s}$, resulting in a discharge velocity of $4.1 \mathrm{~m} / \mathrm{s}$. The results of seven surveys of the thermal plume at the D.C. Cook site 45 show that the minimum surface dilution is about 2.2-3.3. Again, additional mixing once the plume has surfaced is necessary in order to meet typical temperature standards. The surface area corresponding to a dilution of 6.0 was found to be $9-20 \times 10^{4} \mathrm{~m}^{2}$ for most surveys. However, on two occasions, the surface area was substantially larger, about $1 \times 10^{6} \mathrm{~m}^{2}$. In one case, the large surface area appeared to be due to the heated surface water being pushed in the offshore direction by a surface current caused by the offshore component of the wind, which resulted in a plume with larger than usual horizontal extent at the surface but with smaller than usual vertical extent. In the second case, a current reversal that occurred just prior to and during the plume mapping survey apparently brought the plume back upon itself, resulting in less effective dilution because the plume was entraining heated water. As in the case of the Zion discharge, this discharge could meet thermal standards under certain circumstances. However, the size of the plume is again strongly dependent upon the ambient current and ambient current structure and, as such, can be highly varlable.

In order that once-through cooling be an acceptable alternative for power-plant condenser cooling, the discharge structure should be designed so that thermal standards will be met for the complete range of normally expected receiving water conditions. To accomplish this, most of the dilution must take place near the outfall where mixing is governed primarily by the characteristics of the discharge, such as densimetric Froude number and relative submergence, rather than by the characteristics of the ambient receiving water, such as currents, ambient turbulence, and density stratification. Because of the large quantities of cooling water required and the relatively shollow receiving water available in the near-shore region of lakes, high-velocity submerged discharges with significant lateral extents will be necessary. A multiport diffuser with a number of openings or ports spread along a pipe or tunnel on 
or under the lake bottom is the most 1ikely candidate. The individual ports are usually smaller than the openings in single-structure type submerged discharges resulting in larger relative submergence and greater surface dilution for the same receiving water depth.

The J.A. FitzPatrick Nuclear Power Plant on Lake Ontario has such a multiport diffuser. The plant has one 850-MN unit and discharges cooling water at a rate of $23.4 \mathrm{~m}^{3} / \mathrm{s}$. The diffuser consists of six pairs of ports spread along a 236-m long diffuser tunnel oriented approximately parallel to the shoreline. The ports direct the effluent horizontally in a generally offshore direction. A feeder tunnel, under the lake bottom, carries the cooling water from the plant to the center of the diffuser tunnel. This configuration is referred to as a "tee" diffuser (Fig. 2). Each port has a diameter of $0.76 \mathrm{~m}$, and the velocity at the point of discharge is $4.3 \mathrm{~m} / \mathrm{s}$. The ports are located about $1.5 \mathrm{~m}$ above the lake bottom in about $9-10 \mathrm{~m}$ of water, resulting in a relative submergence of about 10. Field surveys of the thermal plume have been reported by Tsai and Burris. ${ }^{46}$ Based on the highest observed surface temperature excess, the minimum surface dilution attained by this diffuser is in the range of 6-14. Although there is, again, apparently significant dependence on ambient receiving water conditions, the initial dilution induced by the multiport diffuser is such that, over a range of conditions, considerable dilution at the surface is achieved in close proximity to the diffuser.

Multiport diffusers appear to be the most promising method (within the physical constraints assumed for this study) of disposing of large quantities of waste heat from once-through cooling systems on large lakes. Because the dilution attained at the surface above a multiport diffuser depends on water depth, port diameter, port orientation, number of ports, diffuser length (or port spacing), discharge velocity, and ambient current, several design options are available to achieve the required surface dilution. Various methods exist that can be used to determine, in general terms, the circumstances under which it would be reasonable to attempt to design a multiport diffuser capable of meeting a given set of thermal standards. A first approach might be to consider the diffuser as made up of a number of separate ports. If the plume from each port attains the required dilution at the surface, the diffuser will meet the standards if the ports are suffictently far apart so that no significant interference occurs among them. This approach may be conservative in 
that it does not take into account any additional dilution that may occur at the surface within some specifled surface mixing zone. If this additional mixing were taken into account, smaller diffusers might be adequate.

Several researchers have reported results of laboratory-scale experiments involving single round buoyant jets discharging horizontally near the bottom into quiescent recelving water of uniform temperature. In general, minimum surface dilution was measured as a function of discharge densimetric Froude number, $F_{0}$, and relative water depth, $H / D_{0}{ }^{.}$The discharge densimetric Froude number is defined by:

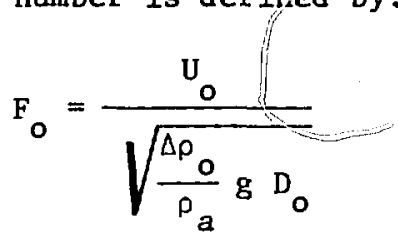

where:

$$
\begin{aligned}
U_{0}= & \text { discharge velocity, } \\
\Delta \rho_{0}= & \text { initial density difference between discharge and ambient receiving } \\
& \text { water, } \\
\rho_{\mathbf{a}}= & \text { density of amblent recelving water, } \\
\mathrm{g}= & \text { acceleration due to gravity, and } \\
D_{0}= & \text { discharge port diameter. }
\end{aligned}
$$

The relative water depth is the ratio of the total receiving water depth, $H$, to the diameter of the discharge port. Relative water depths are often small (1ess than 10-15) for typlcal submerged outfalls due to the shallowness of the near-shore regions of most receiving water bodles and due to the large port sizes needed to accommodate large cooling water flows. The influence of the recelving water bottom and surface on the thermal plume may have a large effect on the dilution attained by a submerged discharge, especially when the relative water depth is small. The presence of an ambient cross current will, In general, increase the surface dilution attained by a single submerged round port, 23 but in the case of a multiport diffuser, interaction among the plumes from the individual ports may occur resulting in smaller effective dilution. The orientation of the individual ports with respect to the diffuser, the orientation of the diffuser with respect to the anbient current, and the magnitude of the ambient current clearly affect the extent of interaction. The details of the effect of currents on the behavior of multiport diffusers are not well understood; they are considered later. 
Parthentades et a1.47,48 carrled out more than 100 1aboratory, scale experiments designed to measure the maximum surface temperature (minimum surface dilution) resulting from a discharge of heated water horizontal- $y$ from a single round port located near the bottom of a relatively shallow experimental basin. Their results were presented as contours of specific values of dilution on a plot of relative water depth versus discharge densimetric Froude number. By interpolation, the contour corresponding to a minimum surface dilution of 6.0 has been estimated from their results and is plotted in Fig. 4. Results of similar laboratory experiments have been reported by Koester, 49 Hafetz, 50 and Balasubramanian and Jain. ${ }^{1}$ Again, by interpolation, estimates of the discharge densimetric Froude number needed to achieve a minimum surface dilution : of 6.0 for a given relative" water depth have been "plotted in the figure. In addition, Shiraz1 and Davis ${ }^{23}$ have developed a series of nómograms based on an integral analysis of the equations of motion that describe the gross characteristics of deeply submerged, round buoyant jets. The results for the situation analogous to the laboratory experiments already discussed (horfzontal discharge into a quiescent receiving water of uniform temperature) are plotted on the figure. This analytical model does not take into account the effects on jet dilution of interaction of the plume with the bottom or the free sirface. However, the results appear to be in good agreement with the experimental results for large Froude numbers and somewhat conservative for small Froude numbers. Figure 4 shows that in order for a single horizontal round jet to attain a minimum surface dilution of at least 6.0 , there exists a minimum discharge densimetric Froude number for a given relative water depth. Lárger Froude numbers, at a given water depth, will give larger dilutions and smaller Froude numbers will yield dilutions less than 6.0.

In order to demonstrate the effect of the Froude number/relative depth relation on multiport diffuser design, Table 13 has been constructed for the ca'se of a typical 1000-MW nuclear power plant with a discharge flow rate, $Q_{p}$, of $47 \mathrm{~m}^{3} / \mathrm{s}$ and an initial temperature $\mathrm{rise}, \Delta \mathrm{T}_{0}$, of $10 \mathrm{C}^{\circ}$. The maximum port diameter, $D_{0}$, and associated minimum number of ports, $N$, has been determined for a series of recelving water depths $(H=2.5,5.0,10.0$, and $15.0 \mathrm{~m})$ and a series of discharge velocities $\left(U_{0}=2,3,4\right.$, and $\left.5 \mathrm{~m} / \mathrm{s}\right)$. The curve resiling from the experiments by Partheniades et al. was used for relative water depths less than 4.5 and the curve based on the Shirazi-Davis nomograms was used for relative water depths greater than 4.5. These two curve segments should lead 


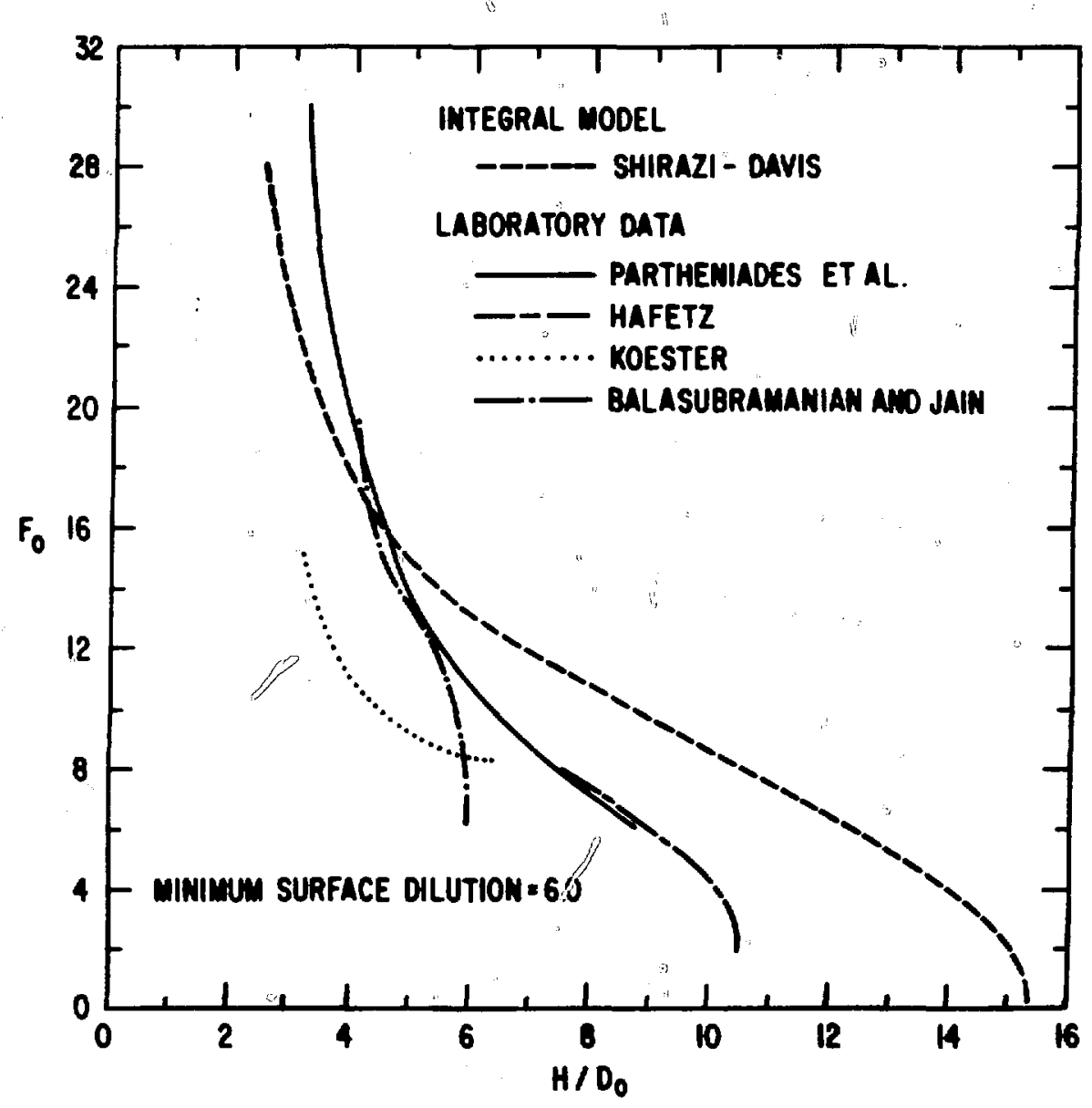

Pig. 4. Minimum Discharge Densimetric Froude Number Needed for the Plume from a Single Submerged Round Port to Attain a Centerline Dilution of 6.0 at the Surface vs Relative Water Depth 
Table 13. Estimated Multiport Diffuser Parameters for a Typical 1000-MW Nuclear Power Plant when a Dilution of 6.0 is Required (Quiescent Receiving Water)

\begin{tabular}{rcrrrrr}
\hline$H(\mathrm{~m})$ & $\mathrm{U}_{0}(\mathrm{~m} / \mathrm{s})$ & $\mathrm{D}_{0}(\mathrm{~m})$ & $\mathrm{N}$ & $\mathrm{L}(\mathrm{m})$ & $\mathrm{L} / \mathrm{N}(\mathrm{m})$ & $\mathrm{W}(\mathrm{m})$ \\
\hline 2.5 & 2.0 & 0.60 & 82 & 677 & 8 & 7 \\
2.5 & 3.0 & 0.72 & 39 & 451 & 12 & 9 \\
2.5 & 4.0 & 0.79 & 24 & 338 & 14 & 11 \\
2.5 & 5.0 & 0.89 & 15 & 271 & 18 & 14 \\
5.0 & 2.0 & 0.95 & 33 & 338 & 10 & 10 \\
5.0 & 3.0 & 1.24 & 13 & 226 & 17 & 14 \\
5.0 & 4.0 & 1.37 & 8 & 169 & 21 & 17 \\
5.0 & 5.0 & 1.41 & 6 & 135 & 23 & 20 \\
10.0 & 2.0 & 1.41 & 15 & $169^{\mathrm{a}}$ & 11 & 14 \\
10.0 & 3.0 & 2.00 & 5 & 113 & 23 & 20 \\
10.0 & 4.0 & 2.23 & 3 & $85^{\mathrm{b}}$ & 28 & 26 \\
10.0 & 5.0 & 2.45 & 2 & $68^{\mathrm{b}}$ & 34 & 31 \\
15.0 & 2.0 & 1.73 & 10 & $113^{\mathrm{a}}, \mathrm{b}$ & 11 & 16 \\
15.0 & 3.0 & 2.23 & 4 & $75^{\mathrm{b}}$ & 19 & 24 \\
15.0 & 4.0 & 2.74 & 2 & $56^{\mathrm{b}}$ & 28 & 32 \\
15.0 & 5.0 & 3.46 & 1 & $45^{\mathrm{b}}$ & 45 & 40 \\
\hline
\end{tabular}

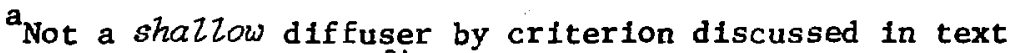
for Adams analysis. 24

$b_{\text {Not }}$ a long diffuser by criterion discussed in text for Adams analysis. 24

to conservative predictions of maximum port diameter. It can be seen from the table that, except for low-velocity discharges in very shallow water, a dilution of 6.0 can be attained with reasonable port sizes and reasonable numbers of ports. It should be noted that larger numbers of smaller diameter ports can be substituted for the arrangement listed in the table as that would result in even higher Froude numbers and relative water depths and, therefore, possibly better dilution. For example, for the case of $H=10.0$ and $U_{0}=4 \mathrm{~m} / \mathrm{s}$, the three $2.23-\mathrm{m}$ dlaneter ports could be replaced by 15 ports, 1.0 in in diameter. If the 15 ports are separated sufficiently so that 
interference is unlikely, a surface dilution of 12 would result according to both the laboratory data of Hafetz and the Shirazi-Davis nomograms.

An estimate of the total diffuser length, $L$, is also sought because total length, as well as the number of ports and port diameter, will enter into the determination of whether it is reasonable to expect to be able to design an adequate diffuser under a given set of circumstances:. Adams 24 has applied a one-dimensional momentum analysis to a long diffuser in shallow, quiescent water. He assumed that the momentum of the diffuser induces a flow of ambient water over the diffuser resulting in an average dilution, $\overline{\mathrm{S}}$, downstream upon complete mixing that is given by:

$$
\bar{s}=\sqrt{\frac{H}{2 B_{0}}}
$$

where:

$$
B_{0}=Q_{p} / L U_{0}=\text { equivalent slot width. }
$$

Adams and Stolzenbach ${ }^{33}$ suggest that the applicability of the analysis is restricted by the following limitations on diffuser length and water depth:

$\mathrm{L} \geq 10 \mathrm{H}$,

and

$$
H<\frac{1}{2} U_{0}\left(\frac{Q_{p}}{L\left(\frac{\Delta \rho_{o}}{\rho_{a}} g\right)^{2}}\right)^{1 / 3},
$$

that is, Zong diffusers in shallow water. The diffuser length required to achieve a given average dilution is then given by:

$$
L=\frac{2 Q_{p} \bar{s}^{2}}{H U_{o}}
$$

The length of the diffuser needed to yleld an average dilution of 6.0 , according to this analysis, has been included in Table 13 for the various receiving water depths and discharge velocities. The ratio $\mathrm{L} / \mathrm{N}$, an est Imate of the required port spacing, is also included in the table. As a check on whether this spacing is reasonable, the widths, $W$, of the individual jets at the surface, as estimated from the Shirazi-Davis nomograns, are included in 
the table. The width is defined as twice the radial distance from the fet centerline to the radius at which the excess temperature has dropped to $1 / \mathrm{e}^{2}$ (13.5\%) of the centeriline value. These widths are comparable to the port spacing prevlously estimated and, therefore, indicate significant interference between adjacent jets w11l be indeed unllkely.

The estimates given in Table 13 are for a 1000-MW nuclear power plant with a discharge flow rate of $47 \mathrm{~m}^{3} / \mathrm{s}$. For different capacities and discharge flow rates, the number of ports and the total length of the diffuser would change while maximum port diameter, port spacing, and fet width would remain unchanged. For example, a 500-MW nuclear plant with a discharge flow rate of $23.5 \mathrm{~m}^{3} / \mathrm{s}$ would require one-half the number of ports along a diffuser of only one-half the length of those specified in Table 13.

The above estimates are based on discharges into a quiescent receiving water body. In a lake situation, ambient currents are often present and are shore parallel. These currents will vary in magnitude and direction. If the individual ports are oriented perpendicular to the diffuser and the diffuser is oriented so that the ambient flow is in the same direction as the diffuser flow, intial dilution will probably be somewhat enhanced. However, if the ambient current and diffuser discharge flow are opposed, dilution will be significantly inhibited. ${ }^{33}$ If the diffuser is oriented approximately parallel to the shore with the Individual ports directed offshore "a "tee" diffuser), the ambient current will most likely be along the axis of the diffuser. For sufficlently large currents, this cross flow will cause increased interference among individual jets and àlso inhibit the flow of dilution water over the diffuser, thus reducing the overall dilution. Adams and Stolzenbach ${ }^{33}$ have suggested the following relationship between the dilution when no ambient current is present; $s_{0}$, and the dilution, $s$, in "the presence of a current $U_{a}$ along the axis of a "tee" diffuser:

$$
s_{0} / S=\left(1+\frac{\alpha v_{a}^{2}}{U_{0}^{2} B_{0}}\right)^{1 / 2}
$$

Adams and Stolzenbach chose $\alpha=5$ based on 1 imited laboratory and fleld observations that show a wide range of varlability. Figure 5 is a plot of the variation of dilution with amblent current observed during laboratory model studies of the J.A. FitzPatrick diffuser reported by Gunwaldsen et al.52 


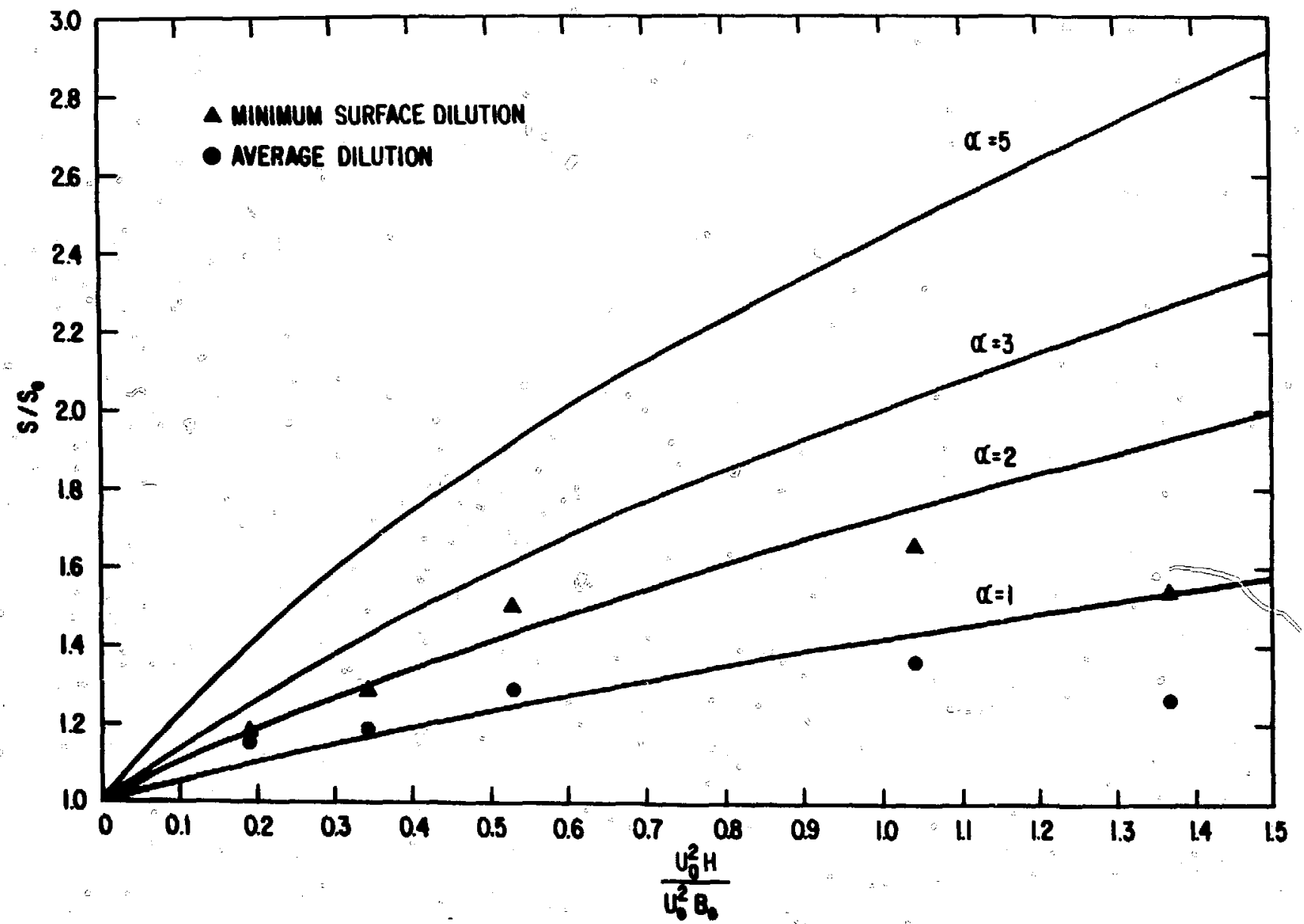

$\sigma^{\prime}$

Fig. 5. Effect of Cross Currents on the Dilution Attained by the Physical Model of the J.A. FitzPatrick Diffuser 
The results are presented in a format consistent with the Adams-Stolzenbach relation. Two values of the ratio $s_{o} / S$ are plotted for each amblent current value, one for the minimum surface dilution and one for the average dilution. The Adams-Stolzenbach relation is also plotted in the figure for various "values of the parameter $\alpha$. The plot suggests that a value of 1 or 2 for $a$ would be more appropriate than 5 , at least for this particular case.

In order to compensate for the reduction in dilution caused by a cross current, the length of the diffuser would have to be increased for a fixed water depth and discharge velocity. This increase can be estimated by applying the Adams-Stolzenbach expression to the equation ysed to estimate diffuser length based on Adams' momentum analysis, 24 resulting in

$$
L^{\prime}=\frac{L}{1-2 \alpha\left(\frac{\mathrm{S} \mathrm{U}_{\mathrm{a}}}{\mathrm{U}_{\mathrm{o}}}\right)^{2}}
$$

where:

$$
\begin{aligned}
L^{\prime} & =\text { diffuser length need when no current is present, and } \\
L^{\prime} & =\text { diffuser length when a cross current } U_{a} \text { is present. }
\end{aligned}
$$

The larger the discharge velocity with respect to the ambient current, the smaller the effect on the dilution and the length of the diffuser. For example, for $\alpha=5$, the length of a diffuser with a discharge velocity of $2 \mathrm{~m} / \mathrm{s}$ would have to be increased tenfold to maintain a dilution of 6.0 in a smal1 cross current of $0.1 \mathrm{~m} / \mathrm{s}$, while the length of a diffuser with a dischargevelocity of $5 \mathrm{~m} / \mathrm{s}$ would only have to be increased 15-20\% to maintain the same dilution under the same cross current. Clearly, large discharge velocities are desirable; however, pumping power costs and enviromental considerations near the discharge ports place a practical limit on the discharge velocity. The proper choice for the value of $\alpha$, as noted earlier, is not wel1-determined and may be site-dependent. It has a large effect on the estimate of the required diffuser length in a cross current. For example, for a discharge velocity of $5 \mathrm{~m} / \mathrm{s}$ and a current of $0.25 \mathrm{~m} / \mathrm{s}$, which $1 \mathrm{~s}$ a reasonable upper limit on the currents normally expected in the near-shore region of large lakes, a value of 5 for $\alpha$ indicates that a tenfold increase in diffuser length is necessary to maintain a dilution of 6.0 , while a value of 2 Indicates that only a 50-60\% increase in length is needed. 
The simple analyses and arguments presented in this section on submerged multiport diffusers in large lakes are not refined or precise enough to be used as a basis for diffuser design. They are meant only as a guide to estimate the size of the diffuser that might be required to meet thermal standards. Other types of diffusers have been considered for the disposal of waste heat. Diffusers with vertical ports or horizontal ports on alternate sides of the diffuser pipe rely on submergence and buoyancy to produce the required dilution because they introduce no net horizontal momentum of their own. Such diffusers are not adversely affected by ambient currents but require significantly longer lengths, especially in shallow water, than diffusers with net horizontal momentum. 33

A staged diffuser is another alternative that is being considered more frequently. The diffuser pipe is oriented perpendicular to the shoreline and ports are located on alternate sides of the pipe directed in the general offshore direction (Fig. 2). A flow is induced along the axis of the diffuser in an offshore direction. Individual jets interfere significantly with one another requiring a diffuser that is three or four times longer than if the individual jets did not interfere. 33 However, the dilution is not expected to be highly influenced by ambient currents, and the heated water tends to be swept away from the shallow near-shore regions.

The selection of a particular diffuser type and the detailed design of the diffuser will have to be done on a case-by-case basis using site-specific data. Bottom topography, natural lake currents, construction costs, local thermal standards, and local environmental concerns will have to be taken into consideration. In many cases, physical models will have to be constructed to aid in the design of an appropriate multiport diffuser and to demonstrate that applicable thermal standards will be met. However, it can be concluded from this simple analysis that, under most circumstances, it should be possible to design a submerged multiport diffuser that will attain the required dilution and meet the thermal standards discussed in Secs. 4 and 2, respectively. Therefore, in terms of meeting typical thermal standards, once-through cooling using submerged multiport diffusers has the possibility of being an acceptable alternative for waste heat disposal for large power plants sited on large lakes. 


\section{ONCE-THROUGH COOLING ON ESTUARIES}

\subsection{GENERAL FEATURES}

Estuaries are water bodies in which both saline tidal waters and fresh water runoff produce diverse physical and biological processes. Circulation is often a complex function of seasonally varying river inflow and of periodic ocean tides modified by geometric features such as 1slands, peninsulas, embayments, and tidal flats. Complex density structures exist due to both temperature and salinity differences between the river water and the ocean water. Estuaries usually also support a wide variety of benthic and free-swiming aquatic organisms as well as water fowl and certain mamals. Anadromous species rely on passage through estuarine regions to reach their natural spawning grounds. The complexity of the physical and blological systems in estuaries has made if difficult to determine the diverse potential effects of the addition of waste heat. Consequently, strict temperature standards are often established, especially for the summer months when natural water temperatures are already high. Also, standards of ten require that zones of passage be maintained so that the mixing zone must not extend across the entire cross-sectional area of the estuary.

The physical characteristics of estuaries vary widely, and classifications such as "saline-wedge," "partially-mixed," and "well-mixed" have been used to differentiate among estuarine enviroments. For the purposes of this study, it is sufficient to note that near the mouth of an estuary currents are predominantly tidally driven and saline ocean water makes up the greatest part of the flow. Depending on the geometry, the characteristics may resemble those of an ocean embayment. Near the head, the fresh water river flow may make up a significant portion of the total flow, and the characteristics may closely resemble those of a river. Thus, no single set of characteristics is generally applicable to all waste heat discharge situations on estuaries. For the purposes of this study, the major features that are important in governing the dispersal of the effluent from a once-through cooling system discharge on an estuary are (1) limited lateral extent, (2) bi-directional flow, and (3) significant variation (t1da1) in current magnitude. Changes in water depth may also be significant at some sites and the outfall may have to be designed to operate effectively at mean-low-water conditions. Limited lateral extent implies that both the near and far shores may influence the 
behavior of the effluent. Tidal variations of the current result in periods of large current (flood or ebb tide) followed by periods of very small current (slack tide), followed again by large currents in the opposite direction. This reversal of the flow continually returns some fraction of the waste heat discharged during a previous part of the tidal cycle. of course, mixing occurs during unidirectional tidal excursions so that excess temperatures will be lower when the heated water returns. Also, part of the heat will be flushed out of the area due to the net river flow (especially near the head of the estuary) and/or the coastal currents of the ocean (especially near the mouth of the estuary). An additional complication that must be considered in the design of a once-through cooling system at an estuarine site is the selection of a location for the cooling water intake. Designs usually attempt to avold significant recirculation of the heated effluent back into the system intake to achieve the lowest practical cooling water temperature. The perfodic reversals of the current tend to cause the thermal plume to be swept both upstream and downstream making it difficult to find a location that is not influenced by the plume at least during part of each tidal cycle.

Prediction of the fate of waste heat from a power plant sited on an estuary is extremely difficult due to the complexities described above. Analytical models for thermal plumes usually cannot handle the complicated geometries and flow patterns often present at such sites. Numerical modeling techniques have been applied to estuarles; however, it is difficult to treat realistically the near-field behavior of the thermal plume where outfall geometry and initial discharge momentum are important. Numerical models can be used to predict far-field plume behavior where transport and mixing are governed primarily by ambient currents and turbulence. Such models may be particularly helpful in estimating the quantity of heat returned to the outfall site during a current reversal. The effect of the return of heat due to current reversals can also be treated analytically based on the results of fleld measurements involving the tracking of dye releases over several tidal cycles.19 Physical (hydraulic) models often cannot be made large enough to include enough of the estuary so that they may be operated over several tidal cycles and still include the effect of return heat. Even if the model were large enough, hydraulic scaling laws are different for near-field effects such as jet-induced mixing and jet-current interaction and for far-field effects such as buoyant spreading, natural turbulent mixing, and surface heat 
1oss." Thus the complete thermal field cannot be simulated in one physical model. The approach most often used to design discharges for estuarine application is to construct a physical model of the near- and intermed late-field regions and operate it over different critical segments of the tidal cycle. In this way, the mixing that can be expected in the vicinity of the outfall due to the discharge jet itself and the immediate interaction with the local currents can be determined. Far-field mixing and the effect of the return of heat due to current reversals must then be treated independently.

A general analysis of thermal discharges at estuarine sites is not possible due to the wide range of site-specific factors that can influence the thermal plume. Therefore, most of these factors will not be treated in the following general assessment of once-through cooling at estuarine sites. In the design or evaluation of a proposed once-through cooling system at a specific site, all the local characteristics of the estuary that might affect the thermal plume or that might be affected by the thermal plume should be considered.

\subsection{SHORELINE DISCHARGES}

Conventional shoreline surface outfalls (open channels) do not appear to be acceptable alternatives for once-through cooling for large power plants on estuaries due to the large initial dilution that is required. Based on the typical thermal standards and the typical temperature rise at the point of discharge discussed in Secs. 2 and 3, a dilution of 4.5 would have to be attained within the mixing zone during the cooler months, while a dilution of 12 would be needed during the summer. In order to operate on a year-round basis, a once-through cooling system would have to be designed to meet the more restrictive sumer standards.

In contrast to the situation for lakes, not many field data exist for surface discharges on estuaries. Measurements at the Surry Nuclear Power Plant on the James River estuary in Virginia have been reported by Parker and Fang. 53 The Surry plant is located about $50 \mathrm{~km}$ upstream of Chesapeake Bay and consists of two 822-MW units. The two units share a common discharge canal that extends about $300 \mathrm{~m}$ beyond the shoreline. The cooling water flow rate is normally about $100 \mathrm{~m}^{3} / \mathrm{s}$ and, at full capacity, the temperature rise across the condensers is about $8 \mathrm{c}^{\circ}$. The cooling water intake is $9.2 \mathrm{~km}$. 
downstream of the outfall; therefore, the salinity of the effluent is significantly greater than the salinity of the receiving water. The decrease in density due to the addition of heat by the plant is partially cancelled out by the increase in density due to salinity. Measurements of the thermal plume at the Surry site were made during à varlety of conditions due to frequent changes in plant load and to tidal and seasonal changes in the ambient receiving water conditions. Resulting data are therefore difficult to interpret in detail; however, the surface area, $A_{12}$, enclosed within the isotherm corresponding to a dilution of 12 was generally about $2-7 \times 10^{6} \mathrm{~m}^{2}$ and the isotherm extended about 30-50\% of the way across the estuary near the surface." This mixing zone appears to be notably larger than the limit of ten placed on mixing zones. Using the same type of correlation between plume surface area and plant discharge flow rate, $Q_{p}$, discussed in Sec. 7 with regard to surface discharges on lakes, the observations at the Surry plant yield $A_{12} / Q_{p}=2-7 \times 10^{4} \mathrm{~s} / \mathrm{m}$. This range of values appears to be typical of shoreline surface discharges. The Asbury-Frigo correlation $^{35}$ based on field measurements at sites of shoreline surface discharges on lakes yielded $7 \times 10^{4} \mathrm{~s} / \mathrm{m}$ with the results of individual measurements ranging from $2 \times 10^{4} \mathrm{~s} / \mathrm{m}$ to larger than $10 \times 10^{4} \mathrm{~s} / \mathrm{m}$. Lakes and estuaries clearly exhibit different receiving water characteristics; however, the results from measurements at lake sites should at least give an order-of-magnitude estimate of the size of the mixing zone needed by shoreline surface discharges to attain a dilution of 12 . Based on a value of $7 \times 10^{4} \mathrm{~s} / \mathrm{m}$ for $A_{12} / Q_{p}$, only power plants with capacities of less than $10 \mathrm{MW}$ could meet the mixing zone limitations of $2.6 \times 10^{4} \mathrm{~m}^{2}$ (equivalent to a circle of $300-\mathrm{ft}$ radius) and on $1 \mathrm{y}$ plants of less than $100 \mathrm{MW}$ could meet the 1imitation of $2.9 \times 10^{4} \mathrm{~m}^{2}$ (1000-ftradius circle) for the typlcal summer temperature standard at estuarine sites. Power plants with capacities of 500-1000 MW would require mixing zones 10-100 times larger and, therefore, conventional shoreline surface outfalls would probably not be acceptable in terms of meeting the typical thermal standards.

Shoreline discharges, other than operr surface channels, have also been used at estuarine sites. The IndIan Point Nuclear Generating Station uses a slde-channel discharge with large submerged ports. The station, operated by Consolidated Edison, is located about $70 \mathrm{~km}$ up the Hudson River estuary near Peeksk111, New York. At this point the river is about $1.5 \mathrm{~km}$ wide with a maximum depth of about $15 \mathrm{~m}$. Tidal currents are present with a maximum velocity of about $0.5 \mathrm{~m} / \mathrm{s}$. There are three units at the site with a total gross 
generating capacity of $2100 \mathrm{MW}$. The total discharge flow rate of the plant can be as high as $190 \mathrm{~m}^{3} / \mathrm{s}$ when all three units are in full operation. The discharge, common to all three units, consists of a 150-m long open channel parallel to the east bank of the river. The channel is separated from the river by steel sheet pilings with a series of 12 rectangular ports spaced along the last $75 \mathrm{~m}$ of the channel. These ports are $1.2 \mathrm{~m}$ high by $4.6 \mathrm{~m}$ wide, with their centers located about $3.7 \mathrm{~m}$ below the water surface. The number of ports in use is varied dependent upon the total discharge flow rate of the plant so as to maintain a discharge velocity of $3 \mathrm{~m} / \mathrm{s}$.

Routine monitoring surveys of the thermal plume are conducted to fulfill regulatory requirements. The results of these surveys are difficult to interpret in general terms due to the intricate thermal structure that is present in that region of the river. The temperature structure is due not only to the Indian Point power plant but also to two other power plants in the area (one $1.7 \mathrm{~km}$ downstream and one $8.1 \mathrm{~km}$ downstream), the reversing tidal flows that return heat to the region from previous tidal cycles, and a shallow tidal pond that releases stored solar energy during flood tide. The high-velocity submerged discharge ports produce initial mixing and dilution within 50-100 of the discharge that would not be attained by a surface discharge. The highekt initial dilution, about 2.5, is observed during" flood tide. Inttial dilutions of about 2.0 are observed durlng slack tide and dilutions of only about 1.2, during ebb tide. Inftial dilution is important in that it reduces the excess temperature of the water returned to the area of the outfall following a tidal reversal.

It is evident that the surface area of the thermal plume is dependent upon the tidal phase, even though a detailed analysis is not possible due to the difficulty in determining an appropriate ambient temperature because of the complicated temperature structure. The largest measured plumes exist during ebb tide when the heat previously released during slack and flood tides is carried down the river along with the heat being discharged at that time. It also appears that the most critical situation probably occurs during the pertod of flow reversal when the plume is swept from 1ts upstream (downstream) position to its downstream (upstream) position. There is a tendency during this small fraction of the tidal cycle for the plume to exhibit its largest penetration across the width of the river. This tendency would be true not only for this particular outfall system but also for most shoreline outfalls located on narrow reaches 
of estuaries. The restriction that the mixing zone not encroach upon more than a certain fraction of the width and/or cross-sectional area of an estuary is probably the most limiting environmental constraint during such an occurrence.

\subsection{SUBMERGED MULTIPORT DIFFUSERS}

Submerged multiport diffusers offer the opportunity of designing oncethrough cooling system outfalls that produce rapid complete mixing with at least a portion of the flow of the estuary. Dilutions on the order of 12 can then be attained within mixing zones of smaller lateräl extent than those produced by shoreline discharges. Rapid dilution not only yeduces the size of the mixing zone during a given phase of the tidal cycle but also tends to reduce the excess temperature associated with heat returned to the site during subsequent tidal phases. Again, as in the case of a river site, the diffuser cannot extend across the entire estuary so that a zone of passage, free from large excess temperatures, is maintained.

A co-flowing diffuser (Fig. 2), such as is of ten considered for riverine applications, will usually not be appropriate in an estuary where the flow is bi-directional. When the estuary flow is in the same direction as the flow of the diffuser discharge, or when the " $\mathrm{flow}$ is large, the diffuser may perform satisfactorily. However, when the flow is small and opposed to the direction of the discharge, the effective dilution will decrease sharply. ${ }^{3}$

A "tee" diffuser (Fig. 2), such as has been used in some lake applications, could be considered for an estuary, if only small tidal currents are present. This type of diffuser has its main axis essentially parallel to the shoreline with the ports oriented in the offshore direction. In order to estimate the length of the diffuser and the size and number of ports necessary to produce the required dilution, the same procedure used for submerged discharges in lakes, discussed in Sec. 7, can be followed. The diffuser is considered to be made up of a series of ports sufficiently separated so that no significant interference occurs among the jets from individual ports when no cross current is present. The discharge densimetric Froude number of the individual ports, $F_{0}$, must exceed some minimum value for $a_{\unlhd}$ given relative water depth, $H / D_{0}$, in order that the plumes from the individual ports attain the required dilution by the time they reach the surface. The discharge 
densimetric Froude number is defined by:

$$
F_{0}=\frac{U_{o}}{\sqrt{\frac{\Delta \rho_{0}}{\rho_{a}} g D_{o}}}
$$

where:

$$
\begin{aligned}
U_{0}= & \text { discharge velocity, } \\
\Delta \rho_{0}= & \text { density difference between discharge water and ambient receiving } \\
& \text { water, } \\
\rho_{\mathrm{a}}= & \text { ambient receiving water density, } \\
\mathrm{g}= & \text { acceleration due to gravity, and } \\
\mathrm{D}_{\mathrm{o}}= & \text { discharge port diameter. }
\end{aligned}
$$

The relative water depth is the ratio of the total receiving water depth, $H$, to the diameter of the discharge ports. An estimate of the minimum Froude number required to yield a minimum surface dilution of "12 can be made based on the results of laboratory scale experiments ${ }^{4}, 50$ and analytical model predictions. 23 These results and predictions are plotted in Fig. 6. Shallower relative water depths require larger Froude numbers to achieve a dilution of 12.

In order to demonstrate the effect of the Froude number/relative depth. relation on multiport diffuser design, Table 14 has been constructed for the case of a typical 1000-MW nuclear power plant with a discharge flow rate, $\mathrm{Q}_{\mathrm{p}}$, of $47 \mathrm{~m}^{3} / \mathrm{s}$ and an initial temperature rise, $\Delta \mathrm{T}_{\mathrm{o}}$, of $10 \mathrm{C}$. The maximum port diameter, $D_{0}$, and associated minimum number of ports, $N$, has been determined for a series of receiving water depths $(2.5,5.0,10.0$, and $15.0 \mathrm{~m})$ and a series of discharge velocities $(2,3,4$, and $5 " \mathrm{~m} / \mathrm{s})$. The curve based on the Shirazi-Davis nomograms was used because it appears to be consistent with the laboratory results or on the conservative side of them. An estimate of the total diffuser length, $\mathrm{L}$, "is included in the table based on Adams' onedimensional momentum analysis ${ }^{24}$ discussed in Sec. 7.3. Also included in the table is $\mathrm{L} / \mathrm{N}$, which is an estimate of the required port spacing. Again, as a check on whether this separation is reasonable, the width; $\mathrm{W}$, of the individual jets at the surface, as estimated from the Shirazi-Davis nomograms, is included in the table. The results show that except for high-velocity discharges $(24 \mathrm{~m} / \mathrm{s})$ in deep water $(z 10 \mathrm{~m})$, long diffusers $(500-1000 \mathrm{~m})$ 


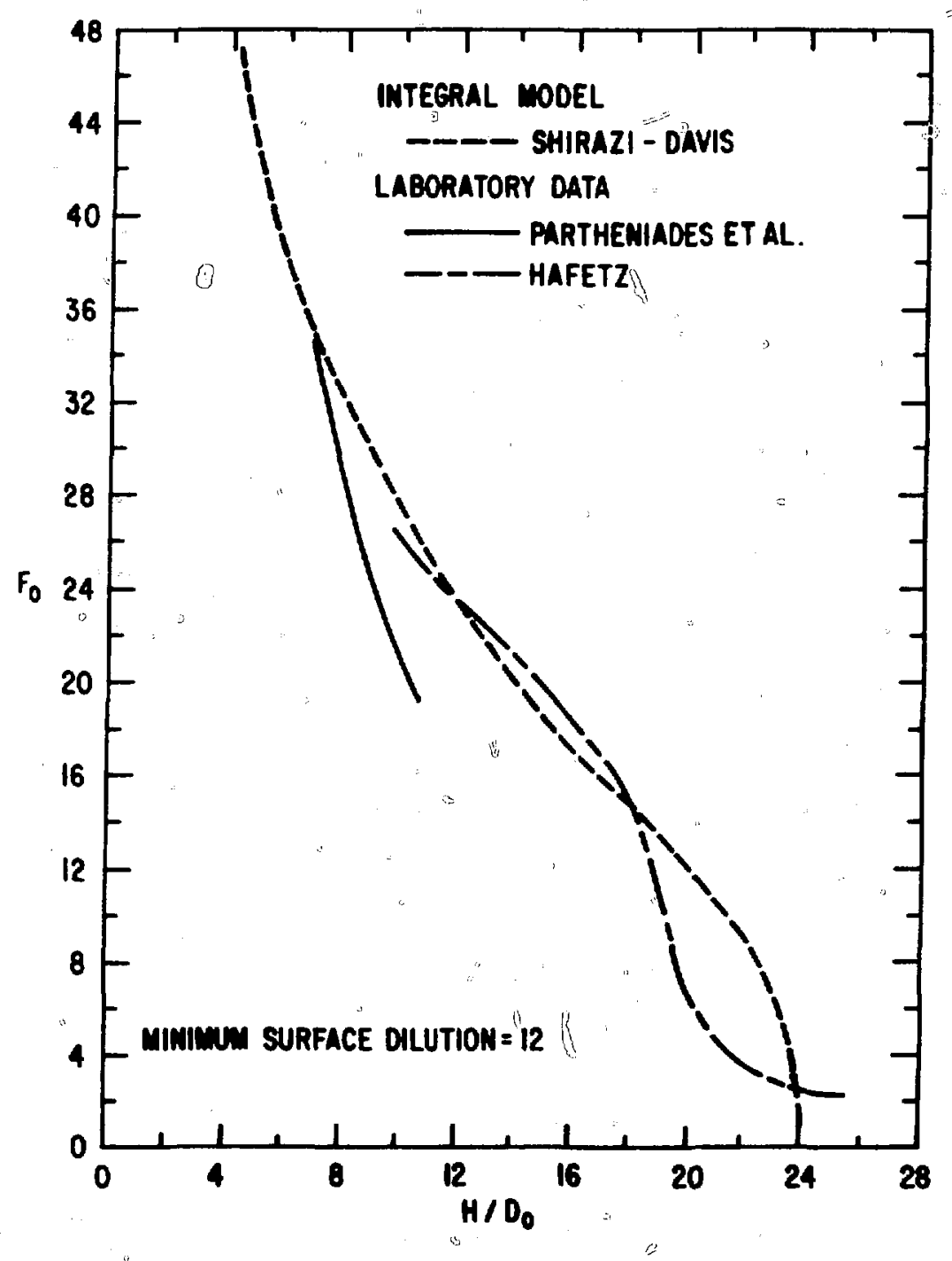

Fig. 6. Minimum Discharge Densimetric Froude Number Needed for the Plume from a Single Submerged Round Port to Attain a Centerline Dilution of 12 at the Surface vs Relative Water Depth 
Table 14. "Estimated Multiport "Tee" Diffuser Parameters for a Typical 1000-MW Nuclear Power Plant: when a Dilution of 12 is Required (Quiescent Receiving Water)

\begin{tabular}{rrrrrrr}
\hline$H(m)$ & $U_{0}(\mathrm{~m} / \mathrm{s})$ & $\mathrm{D}_{\mathrm{O}}(\mathrm{m})$ & $\mathrm{N}$ & $\mathrm{L}(\mathrm{m})$ & $\mathrm{L} / \mathrm{N}(\mathrm{m})$ & $\mathrm{W}(\mathrm{m})$ \\
\hline 2.5 & 2.0 & 0.26 & 460 & 2707 & 6 & 5 \\
2.5 & 3.0 & 0.36 & 153 & 1805 & 12 & 7 \\
2.5 & 4.0 & 0.47 & 69 & 1354 & 20 & 10 \\
2.5 & 5.0 & 0.57 & 37 & 1083 & 29 & 12 \\
5.0 & 2.0 & 0.40 & 191 & $1354^{\mathrm{a}}$ & 7 & 7 \\
5.0 & 3.0 & 0.53 & 70 & 902 & 13 & 11 \\
5.0 & 4.0 & 0.68 & 32 & 677 & 21 & 14 \\
5.0 & 5.0 & 0.84 & 17 & 541 & 32 & 17 \\
10.0 & 2.0 & 0.64 & 73 & $677^{\mathrm{a}}$ & 9 & 11 \\
10.0 & 3.0 & 0.82 & 30 & $451^{\mathrm{a}}$ & 15 & 15 \\
10.0 & 4.0 & 1.00 & 15 & 338 & 23 & 20 \\
10.0 & 5.0 & 1.22 & 8 & 271 & 34 & 25 \\
15.0 & 2.0 & 0.84 & 42 & $451^{\mathrm{a}}$ & 11 & 14 \\
15.0 & 3.0 & 1.08 & 17 & $301^{\mathrm{a}}$ & 18 & 19 \\
15.0 & 4.0 & 1.29 & 9 & 226 & 25 & 24 \\
15.0 & 5.0 & 1.55 & 5 & 180 & 36 & 31 \\
& & & & & &
\end{tabular}

${ }^{a}$ Not a sholzow diffuser by criterion discussed in Sec. 7.3 for Adams analysis. 24

will be needed to produce a minimum surface dilution of 12 , even in the absence of a cross current.

The estimates given in Table 14 are for a 1000-MW nuclear power plant with a cooling water flow rate of $47 \mathrm{~m}^{3} / \mathrm{s}$. For different capacities and cooling water flow rates, the maximum port diameter, port spacing, and "jet width will remain unchanged while a number of ports and total diffuser length will change in direct proportion to the flow rate.

The above estimates are based on discharges into a quiescent receiving water body. In an estuary, tidal currents will be present and, in general, will be along the axts of the "tee" diffuser. Such currents will tend to 
reduce the effective dilution attained by causing interference between jets from adjacent ports and by promoting entrainment of heated water by downstream jets. Based on the empirical correlations suggested by Adams and: Stolzenbach ${ }^{33}$ and discussed in Sec. 7.3 on submerged discharges in lakes, an estimate can be made of the increased diffuser length needed to compensate for this reduction in dilution caused by cross currents. Using a value of 5 for the parameter $\alpha$ in the correlation as suggested by Adams and Stolzenbach, a current of more than $0.1 \mathrm{~m} / \mathrm{s}$ would completely negate the possibility of designing a "tee" diffuser that would result in a dilution of 12 . For $\alpha=2$, as suggested by the laboratory model studies for the J.A. FitzPatrick diffuser (see Sec. 7.3 , a current of $0.2 \mathrm{~m} / \mathrm{s}$ would require a 13-fold increase in the length of the diffuser, even for the case of a discharge velocity of $5 \mathrm{~m} / \mathrm{s}$. These results indicate that the "tee" diffuser concept" is probably not appropritate in estuaries where large dilutions are required in the presence of significant tidal cross currents.

An alternative diffuser design concept is that of the alternating diffuser (Fig. 2). Discharge ports are directed normal to the diffuser pipe or tunnel in both directions so that no net horizontal momentum is introduced. The diffuser pipe or tunnel is usually oriented perpendicular to the direction of the ambient current if present. When no ambient current is present, the dilution is governed by a density-driven exchange flow. 25 Such a diffuser would be located across a portion of the estuary, perpendicular to the tidal flow. In this way, the dilution would actually increase in the presence of currents in either direction.

According to studies by Jirka and Harleman 25 and by Adams and Stolzenbach, 33 the dilution directly above the diffuser, attained by an alternating diffuser in stagnant receiving water, is given by:

$$
S=\left(\frac{2 F_{H}}{F_{S}}\right)^{2 / 3} \frac{H}{B_{0}}
$$

where:

$$
\begin{aligned}
& F_{H}=\text { densimetric Froude number of the exchange flow system, } \\
& F_{S}=\text { densimetric Froude number of the equivalent slot, }
\end{aligned}
$$




$$
\begin{aligned}
& =\frac{\mathrm{U}_{0}}{\sqrt{\frac{A_{0}}{B_{\mathrm{O}}} g B_{O}}}, \text { and } \\
\mathrm{B}_{O} & =\text { equivalent slot width } \\
& =Q_{\mathrm{p}} / \mathrm{U}_{\mathrm{O}} \mathrm{L} .
\end{aligned}
$$

This result can be rearranged" to glve the following estimate of the required diffuser length:

$$
L=\frac{S^{3 / 2} Q_{P}}{\left(2 F_{H}\right)\left(\frac{\Delta O}{P_{a}} g\right)^{1 / 2} H^{3 / 2}}
$$

According to Adams and Stolzenbach, the parameter $F_{H}$ is a function of interfacial friction and ranges from 0.25 for no friction to less than 0.15 for large frictional effects. Predictions of the diffuser length required to produce a dilution of 12 , under stagnant receiving water conditions, are given in Table 15 for various receiving water depths for a typical 1000-MW nuclear power plant with a discharge flow rate of $47 \mathrm{~m}^{3} / \mathrm{s}$ and an initial excess temperature of $10 \mathrm{C}^{\circ}$. The predicted lengths are significantly longer than those of Table 14 for a "tee" diffuser in quiescent receiving water. However, in the case of an alternating diffuser, currents will increase the dilution, ${ }^{3}$

Table 15. Estimated Diffuser Length to Attain a Dilution of 12, Under Stagnant Conditions,

\begin{tabular}{|c|c|c|}
\hline $\begin{array}{l}\text { Nater Depth } \\
H(\mathrm{~m})\end{array}$ & $\mathrm{F}_{\mathrm{H}}=0.25$ & $\begin{array}{l}F_{H}=0.15 \\
L(m)\end{array}$ \\
\hline 2.5 & 6,960 & 11,600 \\
\hline 5.0 & 2,460 & 4,100 \\
\hline 10.0 & 870 & 1,450 \\
\hline 15.0 & 470 & 790 \\
\hline
\end{tabular}
for a 1000-MW Nuclear Power Plant Using an Alternating Diffuser Design 
while in the case of a "tee" diffuser, cross currents tend to decrease dilution and could require significantly longer diffusers than are 1 isted in Table 14 to compensate for the decrease in diiution.

Recently, staged diffusers (Fig. 2) have received considerable attention as a possible means of disposing of waste heat at shallow lake, estuary, and coastal sites. The diffuser pipe or cunnel is oriented perpendicular to the shore and the ports are located on alternate siaes of the pipe directed in the general offshore direction. A jet-like flow is induced along the axis of the diffuser in an fffshore direction and water is entrained primarily from the sides. The forientation of the individual ports is such that significant interference occurs among individual jets. Therefore, in the case of quiescent receiving waters, a significantly longer staged diffuser would be needed to yield the same dilution as, a "tee" Qiffuser. However, staged iffusers have the distinct advantage that cross currents tend to enhance the dilution rather than hinder it, in contrast to the case of a "tee" diffuser.

- Almquist and Stolzenbach ${ }^{26}$ have carried out an approximate analysis of the behavior of a long staged diffuser in shallow quiescent receiving water. They suggest that the minimum surface dilution near the offshore end of the diffuser can be estimated by an expression of the following form:

$$
S=f(H / L) \sqrt{\frac{H}{B_{O}}}=f(H / L) \sqrt{\frac{H U_{o} L}{Q_{p}}} .
$$

The symbols used in the above expression are tile same as those used throughout this discussion of submerged multiport diffusers. Almquist and Stolzenbach found that for values of $\mathrm{H} / \mathrm{L}$ in the range corresponding to typical prototype situations (0.01-0.07), the function $f(H / L)$ is not strongly dependent upon $\mathrm{H} / \mathrm{L}$ and has a numerical value of about 0.38 . The following limitations specify the range of applicability of the analysis, ${ }^{26}$ which is restricted to Zong diffusers in shallow water:

$\mathrm{L} \geq 15 \mathrm{H}$

and

$$
H<0.56 U_{o}\left(\frac{Q_{p}}{L\left(\frac{\Delta \rho_{o}}{\rho_{a}} g\right)^{2}}\right)^{1 / 3} .
$$


Almquist and Stol zenbach carrled out a series of 10 laboritory-scale experiments tomeasure dflution as a function of $\sqrt{ } / 1 / \mathrm{P}_{0}$ and $H / \mathrm{I}$. The results are ploted in $F y .7$ in the form of $\frac{1}{5} \sqrt{H / B}$, versis $H / h$. Although a considerable amount of scatter exlsts, the results appear to indicate a monotonic relationship between $\frac{1}{S} / / / B_{0}^{-}$and $H / L$, which is approximately linear, thus implying that $1 / \mathrm{f}(\mathrm{H} / \mathrm{L})$ Is a lincar function of $\mathrm{H} / \mathrm{L}$. A linear least-squaresfit to the data yields:

$$
\frac{1}{f(\mathrm{H} / \mathrm{L})}=3.2-15 \mathrm{H} / \mathrm{L} .
$$

"This function is ploted as a solid line on the figure. For the range of $H / 1$. studied $(0.02-0.067)$, this fit implies that $f(H / L)$ varies from $0.35-0.45$.

Brocard ${ }^{5}$ reported on unother series of laboratory scale experintents conducted at Alden Rescarch laboratories during design studies for a stabed diffuser contemplated for use near charlestown, khode Island. Animum surfit dilution was measured for a variety of diffuser lenrths under several crossflow conditions. The discharge velocity, ${ }_{0}$, was fixed at $5.5 \mathrm{~m} / \mathrm{s}$. (me series of experiments corresponds to a uniform cross-flow velocity, $u_{a}$, of $0.1 .5 \mathrm{~m} / \mathrm{s}\left(\mathrm{U}_{\mathrm{a}} / \mathrm{U}_{\mathrm{o}}=0.028\right)$. In addition, a single experintent was conducted at a cross flow of $0.3 \mathrm{~m} / \mathrm{s}\left(U_{a} / u_{0}=0.056\right)$. The results of these measurements are plotted on fig. 7 along with the Almquist-Stol\%cnbach results. Although the measurements were not carried ont over a very wide range of $\mathrm{h} / \mathrm{L}$, the results indicate that the dilution is significantly increased over that expected from the Almquist-Stolzenbach results for no current. Measurements were also miade for the transient condition of no current during the reversal of a current that originally was constant at $0.15 \mathrm{~m} / \mathrm{s}$. These experiments were meant to simulate diffuser behavior during periods of slack tide. The results also are plotted in Fig. " 7 . It is apparent that even though the instantaneous current is zero, the dilution is less than expected from the Almquist-Stolzenbach results. The process of reversing the current apparently causes part of the heated water previously discharged to be reentrained by the diffuser jet reducing the effective dilution. Dashed lines are drawn through the data reported by Brocard with the same slope as the fit to the Almquist-Stolzenbach data. Although there is not sufficient data to confirm that these slopes should be the same, the data do not refute this trend. Based on the linear fit to the Almquist-Stolzenbach data and the functional form suggested by Almquist and Stolzenbach, an estimate can be made of 


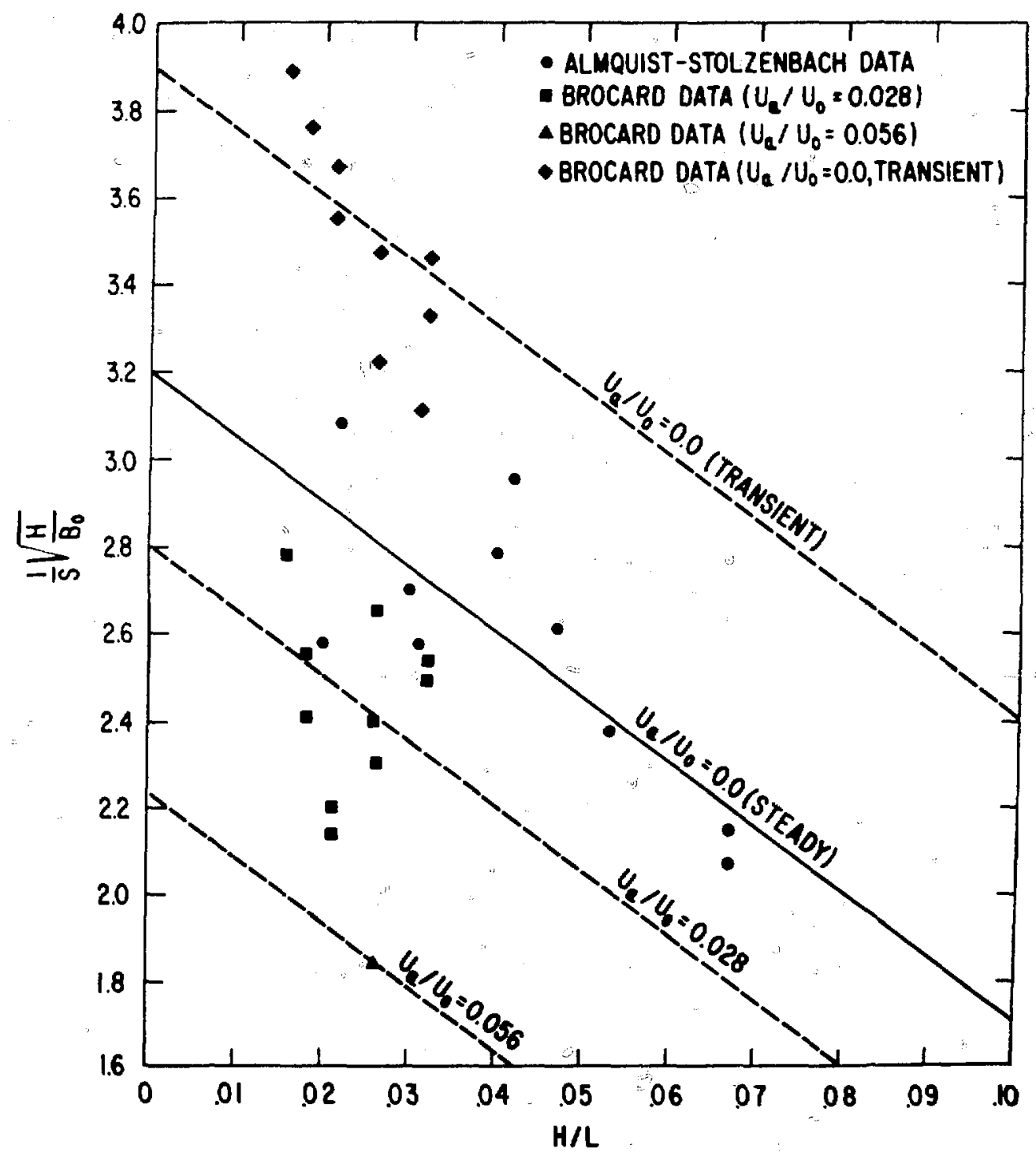

Fig. 7. Parametric Representation of the Minimum Surface Dilution Attained by a Staged Diffuser -- Physical Model Results 
the leneth of the stared diffuser required to proderce a minimum surfat a di]utlon "of 12, in the absence of an ambient current. Tible 16 lists the required diffuser lensth, designated $L$, for various recefving water depths and dischare velocitjes for a typical $1000-M b$ nuclear puwer plant with a discharge flow rate of $47 \mathrm{in}^{3} / \mathrm{s}$. The length needed to yield a minimum surface dilution of 12 is very larse in most cases. It showld be noted that these: corresiond $t o$ a quiescent recelving water. Jurlng a current reversal (i...., slack tide), the effective dilution may be less than 12 as noted from the results of the Charlestown physical model study. Table 17 contains an equlvalent set of predictions for a typical 500-MW fossil-fueled plant with a discharge flow rate of $16.5 \mathrm{~m} \% \mathrm{~s}$. This second compilation has becn iarluded because the predtetions are not simply linearly related to discharge flow rates. The estimated diffuser lengths, al though smaller than for the lojp-idw: plant, are still quite large except for the case of deep ( $/ 15$ mo receiving water. However, according to Nlmulist and Stolzenbarh, the analysis brcaks down for short diffusers in dees wator.

The preceeding estimales of the required length of a staged diffuser are probably more conservative than necessary to meet typjcal thermal standards. Usually the temperature standards and, therefore, the dilution requirements must be met beyond some specificd mixing zone. Mixing zones are generally specified in terms of surface areas and typical values are $2.6 \times 10^{4} \mathrm{~m}^{2}$ (equivalent to a circle of $300-\mathrm{ft}$ radius) and $2.9 \times 10^{5} \mathrm{~m}^{2}$ (equivilent to a $1000-\mathrm{ft}$ radius). Therefore, dilution at the edge of a mixing zonc of finfte areal extent at the surface, not the minimum surface dilution, is the limiting factor.

Almquist and Stolzenbach 26 have developed a simple analytical model for the jet-1ike flow produced by a staged diffuser. The model can predict surface areas within isotherms of a given excess temperature corresponding to a particular dilution. Using a simple top-hat shape to represent lateral excess-temperature and velocity profiles (assumed to be self-similar along the axis of the jet), they find that the surface area, ${ }_{A}$, corresponding to a particular dilution $S$, can be expressed as:

$$
A_{S} / L^{2}=\text { function }\left(\frac{1}{S} \sqrt{\frac{H}{B_{0}}}, \frac{H}{\mathrm{~L}}\right) \text {. }
$$


Table 16. Estimated Staged Diffuser length for a Typical 1000-M Nuclear Power Plant When a Dilution of 12 is Required

\begin{tabular}{|c|c|c|c|c|}
\hline$H(m)$ & $U_{0}^{(\mathrm{II} / \mathrm{s})}$ & $L(m)^{a}$ & $L_{1}(m)^{b}$ & $\mathrm{~L}_{2}(\mathrm{~m})^{\mathrm{C}}$ \\
\hline 2.5 & 270 & $13,840^{\mathrm{d}}$ & $13,800^{\mathrm{d}}$ & $13,350^{\mathrm{d}}$ \\
\hline 2.5 & 3.0 & 9,220 & 9.170 & 8,070 \\
\hline 2.5 & 4.0 & 6,910 & 6,840 & 5,130 \\
\hline 2.5 & 5.0 & 5,520 & 5,420 & 3,520 \\
\hline 5.0 & 2.0 & $6,880^{d}$ & $6,810^{\mathrm{d}}$ & $5,150^{d}$ \\
\hline 5.0 & 3.0 & 4,750 & 4,480 & 2,600 \\
\hline 5.0 & 4.0 & 3,420 & 3,190 & 1,510 \\
\hline 5.0 & 5.0 & 2,750 & 2,430 & 930 \\
\hline 10.0 & 2.0 & $3,370^{\mathrm{d}}$ & $3,150^{d}$ & $1,510^{\mathrm{d}}$ \\
\hline $10.0^{-*}$ & 3.0 & $2,210^{\mathrm{d}}$ & $1,840^{\mathrm{d}}$ & 580 \\
\hline 10.0 & 4.0 & 1,630 & 1,150 & $\$ 150^{\mathrm{e}}$ \\
\hline 10.0 & 5.0 & 1,290 & 780 & $<150^{\mathrm{e}}$ \\
\hline 15.0 & 2.0 & $2,160^{\mathrm{d}}$ & $1,840^{\mathrm{d}}$ & 560 \\
\hline 15.0 & 3.0 & $1,390^{\mathrm{d}}$ & $930^{d}$ & $\leqslant 225^{\mathrm{e}}$ \\
\hline 15.0 & 4.0 & $1,000^{d}$ & $560^{d}$ & $<225^{e}$ \\
\hline 15.0 & 5.0 & 760 & 350 & $<225^{e}$ \\
\hline
\end{tabular}

${ }^{\text {a }}$ Length required to produce a minimum surface dilution of 12 .

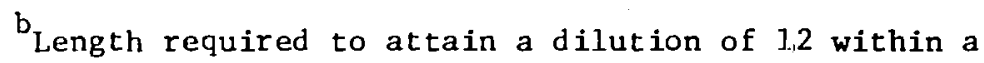
mixing zone with a surface area equivalent to a 300-ft radius circle.

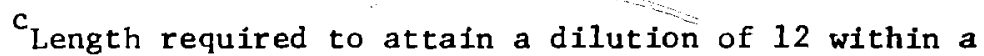
mjxing zone with a surface area equivalent to $a$ 1000-ft radius circle.

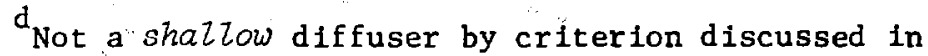
text for Almquist-Stolzenbach analysis. 26

eAlmquist-Stolzenbach analysis limited to long dif fusers, $\mathrm{L} \geq 15 \mathrm{H} .26$ 
Table 17. Estimated Staged Diffuser Length for a Typical 500-MW Fossil-Fueled Power Plant When a Minimum Surface Dilution of 12 is Required

\begin{tabular}{|c|c|c|c|c|}
\hline $\mathrm{H}(\mathrm{m})$ & $U_{0}(m / s)$ & $L(m)^{a}$ & $L_{1}(m)^{b}$ & $\mathrm{~L}_{2}(\mathrm{~m})^{\mathrm{c}}$ \\
\hline 2.5 & 2.0 & 4,843 & 4.708 & 2,836 \\
\hline 2.5 & 3.0 & 3,221 & 3,040 & 1,315 \\
\hline 2.5 & 4.0 & 2,409 & 1,988 & 675 \\
\hline 2.5 & 5.0 & 1,923 & 1,388 & $30^{5}$ \\
\hline 5.0 & 2.0 & $2,386^{\mathrm{d}}$ & $1,987^{\mathrm{d}}$ & $52 b$ \\
\hline 5.0 & 3.0 & 1,574 & 1,028 & $\leqslant 75^{e}$ \\
\hline 5.0 & 4.0 & 1,168 & 610 & $<75^{e}$ \\
\hline 5.0 & 5.0 & 925 & 403 & $<75^{\mathrm{e}}$ \\
\hline 10.0 & 2.0 & $1,117^{\mathrm{d}}$ & $614^{\mathrm{d}}$ & $5150^{e}$ \\
\hline 10.0 & 3.0 & $707^{d}$ & $265^{d}$ & $<150^{\mathrm{e}}$ \\
\hline 10.0 & 4.0 & 499 & $\$ 150^{\mathrm{e}}$ & $<150^{e}$ \\
\hline 10.0 & 5.0 & 372 & $<150^{\mathrm{e}}$ & $<150^{e}$ \\
\hline 15.0 & 2.0 & $643^{d}$ & $265^{d}$ & $<225^{e}$ \\
\hline 15.0 & 3.0 & $340^{d}$ & $<225^{\mathrm{e}}$ & $<225^{e}$ \\
\hline 15.0 & 4.0 & $\leq 225^{\mathrm{e}}$ & $<225^{\mathrm{e}}$ & $<225^{e}$ \\
\hline 15.0 & 5.0 & $<225^{\mathrm{e}}$ & $<225^{\mathrm{e}}$ & $<225^{\mathrm{e}}$ \\
\hline \multicolumn{5}{|c|}{$\begin{array}{l}b_{\text {Length required to attain a dilution of } 12 \text { with- }} \\
\text { in a mixing zone with a surface area equivalent } \\
\text { to a } 300-\mathrm{ft} \text { radius circle. }\end{array}$} \\
\hline \multicolumn{5}{|c|}{$\begin{array}{l}\text { cength required to attain a dilution of } 12 \text { with- } \\
\text { in a mixing zone with a surface area equivalent } \\
\text { to a } 1000-\text { ft radius circle. } \\
\text { Not a shallow diffuser by criterion discussed in } \\
\text { text for Almquist-Stolzenbach analysis. } 26\end{array}$} \\
\hline \multicolumn{5}{|c|}{$\begin{array}{l}\text { Almquist-Stolzenbach analysis limited to Zong } \\
\text { diffusers, } L \geqslant 15 \mathrm{H}^{26}\end{array}$} \\
\hline
\end{tabular}


This conclusion is the result of a near-field model and is probably valid only near the diffuser where $A_{S} / L^{2} \leqslant 1$.

Almquist and Stolzenbach show that, according to their model, the dependence of plume surface area on $H / L$ is small for $A_{S} / L^{2} \approx 0.1$ and essentially nonexistent for $A_{S} / L^{2} \geq 0.2$. Although the details of this functional relationship are predicted by the model, the results have not been well verified and are not used here. Instead, the results of the laboratory scale experiments reported by Brocard ${ }^{55}$ have been plotted in Fig. 8 in the form of $\frac{1}{\mathrm{~S}} \sqrt{\mathrm{H} / \mathrm{B}_{\mathrm{o}}}$ vs $\mathrm{A}_{\mathrm{S}} / \mathrm{L}^{2}$. The circles represent the results for a uniform cross current of $0.15 \mathrm{~m} / \mathrm{s}\left(U_{a} / U_{0}=0.028\right)$ and the squares indicate the results for the case where the instantaneous current is zero following a current reversal representing slack tide. Any dependence on the parameters $\mathrm{H} / \mathrm{L}$ is not noted on the figure because, if present, it appears to be less than the scatter due to experimental uncertainties and experimental reproduciability. However, a significant systematic difference in the observed surface area is apparent between the two different current cases. As noted earlier, in the discussion of minimum surface dilution, the case of discharge into a quiescent receiving water resulted in initial dilutions that were intermediate between the two cases studied by Alden Research Laboratories (see Fig. 7). It therefore seems reasonable to assume that the quiescent receiving water case should fall between the two sets of results'plotted in Fig. 8 . The solid lines drawn on the figure can therefore be considered to be reasonable estinates of a functional relationship between $\frac{1}{\mathrm{~S}} \sqrt{\mathrm{H} / \mathrm{B}_{\mathrm{O}}}$ and $\mathrm{A}_{\mathrm{S}} / \mathrm{L}^{2}$ for a staged diffuser in quiescent receiving water. The limiting value of the parameter $\frac{1}{\mathrm{~S}} \sqrt{\mathrm{H} / \mathrm{B}}$, corresponding to the minimum surface dilution and thus a surface area of zero, has previously been established based on the fit to the data of Almquist and Stolzenbach presented in Fig. 7. This limiting value was shown to be dependen' on the parameter $\mathrm{H} / \mathrm{L}$ and was used as a guide when drawing the solid lines on Fig. 8.

Estimates of the staged diffuser length needed to produce a dilution of 12 within a mixing zone with a specifled surface area can be made based on the surface area predictions of the solid curves in Fig. 8. Tables 16 and 17 contain such estimates for a typical 1000-MW nuclear power plant and a typical 500-MW fossil-fueled power plant, respectively, for mixing zone surface areas of $2.6 \times 10^{4} \mathrm{~m}^{2}$ (equivalent to a $300-\mathrm{ft}$ radius circle), designated $\mathrm{L}_{1}$, and 


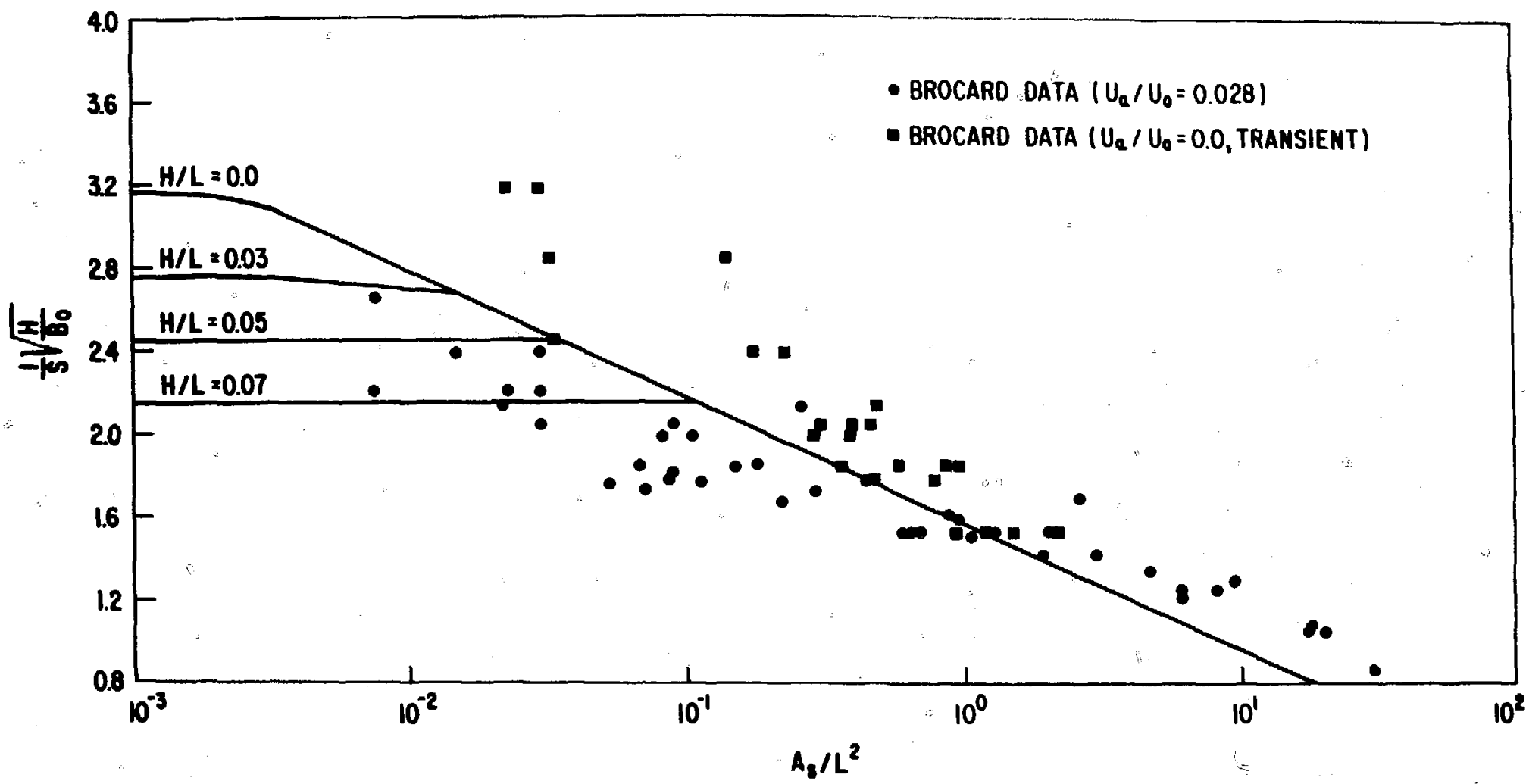

Fig: 8. Parametric Representation of Plume Surface Area as a Function of Dilution for a staged Diffuser 
$2.9 \times 10^{5} \mathrm{~m}^{2}$ (1000-ft radius circle), designated $\mathrm{L}_{2}$. These results show that substantially shorter diffuser lengths can be utilized for high-velocity discharges $(4-5 \mathrm{~m} / \mathrm{s})$ in receiving waters of greater than 5-m depth than are possible when requiring a minimum surface dilution of 12 .

It can be concluded from the above discussion of thermal discharges into estuaries that some type of high-velocity submerged discharge structure will probably have to be used to dispose of the waste heat from large power plants. The design of a specific discharge structure for use at a specific site will require that many complicating factors be taken into account. These factors include: the requirement of a large initial dilution, the limited lateral extent of the receiving water, the complex temperature, density, and current structures that are typically present in an estuary, and the return and reentrainment of previously discharged heat following a current reversal.

The decision as to whether once-through cooling will be an acceptable method for disposing of waste heat from a steam-electric generating station located on an estuary will have to be made on a case-by-case basis. The decision process will have to include analysis of site-specific data and may have to include laboratory-scale physical model studies to estimate the effects of complex site-specific geometric constraints and currents, and field experiments to establish local heat return and flushing rates. However, it appears that, at least under certain circumstances, submerged multiport diffusers of reasonable length can be designed that will produce the large dilutions that are required in an estuarine environment. 
9 ONCE-THROUGH COOLING ON OPEN COASTAL WATERS

\subsection{GENERAL FEATURES}

Open coastal waters, by their very nature, offer a large sink for the disposal of waste heat. Large quantities of heat can be accomodated with little or no effect on the overall thermal regime of the water body. The only physical environmental concern is limited to the local increase in water temperature in the immediate vicinity of the outfall and possibly the impact on close-by, shallow, nearshore areas. Currents are generally shore parallel and may be predominantly in one direction. While these currents may help to bring in cool dilution water, care must be taken that cooling system structures extending from the shore do not interfere with natural littoral transport. In general, open coastal waters should serve well as receiving water bodies for once-through-cooling waste heat discharges.

Certain regions of very large lakes such as the Great Lakes might be classified as open coastal waters. Yet, larger induced excess temperatures are usually allowed than in marine waters due to the larger natural temperature variations that occur in lakes. Use of the Great Lakes for disposal of waste heat has been discussed in Sec. 7 .

Bays and inlets may not fall, directly into any of the preceding classes of water bodies. Exchange flow with the open ocean may be limited by the geometry of the connecting passage, especially when stratification exists. 19 , Complex density and current structures may require that a specific bay or inlet be treated as an estuary in terms of establishing the applicability of once-through cooling. Larger bays with significant tidal flushing may as a rule be treated as open costal waters.

An interest in using offshore waters for the disposal of waste heat has developed due to several novel concepts that can be applied to the conventional steam-electric generating process. One is offshore power generation on a floating barge or artificial island and another is the nuclear energy center (NEC). An offshore plant would allow the generating station to be located near the load center without requiring the dedication of large land areas that might be better utilized. An NEC is a group of many ( $\geq 10)$ large nuclear generating units located at one site;' Such a center could be located somewhat Inland to avoid using valuable shoreline land, and the center could 
use common pipes or tunnels to bring in cooling water from of fshore intakes and return it to offshore outfalls. ${ }^{56}$ "The use of once-through cooling by such centers rather than evaporative cooling towers would eliminate such disadvantages of large cooling tower installations as large land use, decreased thermal efficiency, and local atmospheric and meteorologica impacts. Deep offshore intakes would take advantage of lower intake temperatures due to natural thermal stratification, and deep of fhore submerged outfalls would take advantage of increased dilution due to greater submergence.

The shallow slope of the continental shelf off the Atlantic coast of the U.S. precludes reaching very deep water without going far of fshore. For example, the proposed Atlantic Generating Station (ACS), a floating nuclear plant, is tentatively sited about $5 \mathrm{~km}$ off the coast of New Jersey, yet is in only about $10-13 \mathrm{~m}$ of water. The proposed plant has two separate 1150-MW units moored inside a breakwater. The cooling water flow rate will be $65.7 \mathrm{~m}^{3} / \mathrm{s}$ for each unit with a temperature rise of $8.9 \mathrm{C}^{\circ}$. Three different discharge schemes have been considered for this installation. 57 Each would be an integral part of one section of the breakwater and have a discharge velocity of about $3.6 \mathrm{~m} / \mathrm{s}$. The first design consists of two sets of six closely spaced round ports. The ports are $2.0 \mathrm{~m}$ in diameter spread along two $13.2-\mathrm{m}$ sections of the breakwater just below the water level at mean low water. The second design is also a near-surface discharge but with only two ports (one" per unit), each $4.5 \mathrm{~m}$ in diameter. The third design, a submerged discharge, is similar to the first except that the ports are located near the bottom of the breakwater. Physical model studies conducted by MIT ${ }^{57}$ showed very little differences in the temperature and velocity fields beyond $150 \mathrm{~m}$ from the outfall induced by these three designs.

Another example of an offshore discharge on the Atlantic coast is the one planned for the Seabrook Station near Seabrook, New Hampshire. 58,59 The plant will consist of two 1150-MW units. However, the cooling water flow rate will be only $25.8 \mathrm{~m}^{3} / \mathrm{s}$ for each unit, but will have a temperature rise of $21.7 \mathrm{C}^{\circ}$. Compared to the proposed AGS with the same capacity, the cooling water flow rate is $2-1 / 2$ times smalier, while the temperature rise is $2-1 / 2$ times larger. The lower flow rate is an attempt to reduce pumping costs associated with the extremely long intake tunnel $(4.0 \mathrm{~km})$ and discharge tunnel $(4.6 \mathrm{~km})$ " that are to be used. The long tunnels, each $5.5 \mathrm{~m}$ in diameter and 
abcitt $60 \mathrm{~m}$ below sea level, will allow the plant to be located about $3.1 \mathrm{~km}$ inland of the open coast and the intakes and discharges to be located $0.9 \mathrm{~km}$ and $1.5 \mathrm{~km}$ of fshore, respectively. Even with the long tunnels, the discharge will be in only about $15 \mathrm{~m}$ of water. The proposed discharge structure is a 305-m long diffuser with 22 ports directed in a general offshore direction. Each port is $0.8 \mathrm{~m}$ in diameter and the resulting discharge velocity is $4.6 \mathrm{~m} / \mathrm{s}$.

As with the design of any outfa11, the process of selecting an out fall design to be used at an open coastal site will have to take into consideration local currents and bottom topography. A large dilution will be required ( 12 for the typical summer thermal standard and typical outfall excess temperature discussed earlier).

\subsection{SHORELINE SURFACE DTSCHARGES}

Based on the discussion in Sec. 8 on estuaries, conventional shoreline surface outfalls usually will not be adequate at marine coastal sites. Even a 500-MW fossil-fueled plant would require, in general, a mixing zone with a surface area $21 \times 10^{6} \mathrm{~m}^{2}$ to attain a dilution of 12 . However, specific ambient conditions at certain sites may produce greater mixing and result in smaller mixing zones. For example, the shoreline surface outfall at the Pilgram Nuclear Power Station produces a thermal plume that is somewhat smaller than might be expected based on the average of plumes from other surface outfalls. The Pilgrim station is located on the western shore of Cape Cod Bay near Plymouth, Massachusetts, and consists of a single 650-i w unit. Cooling water is discharged at a rate of $20.4 \mathrm{~m}^{3} / \mathrm{s}$ through an open channel with an inverted trapezoidal cross section. The bottom of the channel is at mean low water so that changes in water level with tidal phase produce significant changes in the water depth at the point of discharge, in the discharge velocity, and, therefore, in the discharge densimetric Froude number. According to field measurements reported by Pagenkopf et al., 60 the Froude number varies from less than 2 to greater than 16 with tidal cycle. Based on the results of field measurements of the thermal plume, ${ }^{60}$ the surface area contained within the isotherm corresponding to a dilution of 12 is about 3-15 $\times 10^{5} \mathrm{~m}^{2}$. This area is generally smaller than the $1.4 \times 10^{6} \mathrm{~m}^{2}$ predicted by the correlation between surface area and plant discharge flow rate discussed in Sec. 8.2. Apparently the non-steady nature of the discharge (due to tidal 
variations in water level) and the complex ambient current structure (due to tidal and wind-induced components) result in increased mixing. However, the mixing zone is still larger than the limits often imposed by thermal standards.

\section{3 SUBMERGED MULTIPORT DIFFUSERS}

High-velocity submerged discharges will be necessary to produce the large dilutions needed to meet typical thermal standards for marine waters. The essentially infinite offshore extent of the receiving waters and the shore parallel orientation of typical coastal currents makes staged diffusers one of the most promising discharge design concepts for use at open coastal sites. Other diffuser designs such as the "tee" diffuser or the diffuser with the discharge direction parallel with the shore have the disadvantage that currents tend to decrease the effective dilution. Kon et a1. 1 have conducted physical model studies to evaluate various diffuser designs for use with Units 2 and $3(1100 \mathrm{MW}$ each) at the San Onofre Nuclear Power Plant on the coast of Southern California. Each unit is expected to have a cooling water flow rate of $52.4 \mathrm{~m}^{3} / \mathrm{s}$ with a temperature rise of $11.1 \mathrm{C}^{\circ}$. They concluded that a staged diffuser design would best meet the requirements at that site. Each unit would have its own diffuser about $768 \mathrm{~m}$ long with 63 ports. Each port would be about $0.6 \mathrm{~m}$ in diameter resulting in a discharge velocity of $4.0 \mathrm{~m} / \mathrm{s}$. One diffuser would be in 9-13 $\mathrm{m}$ of water and the other, farther offshore, in 13-17 in of water. Results of the physical model studies indicated that the momentum of the discharge produces an offshore drift of the diluted warm water plume. The maximum temperature rise at the surface in the model was obscrved to decrease with increasing longshore current speed (minimum surface dilution varied from 7.1 for no current to 14.7 for a $0.26 \mathrm{~m} / \mathrm{s}$ current). Beyond $1000 \mathrm{ft}(305 \mathrm{~m})$ from the outfall the dilution at the surface ranged from 8.6 for no current to 22.2 for a $0.26 \mathrm{~m} / \mathrm{s}$ current. These results appear to be characteristic of staged diffusers. Typical diffuser lengths that mighi he needed for a staged diffuser to attain a dilution of 12 were estimated in Sec. 8.3 and presented in Tables 16 and 17 in connection with their application to estuarine sites.

As in the estuarine case, it appears that multiport diffusers can be designed so as to make once-through cooling an acceptable alternative at many open coastal sites, at least in terms of typical thermal standards. 


\section{SUMMARY AND CONCLUSIONS}

Once-through-cooling-water control technology has been reviewed to determine the circumstances under which forms of this technology might provide acceptable allernatives for the disposal of waste heat from large steamelcctric power plants. The final determination of the acceptability or oncethrough cooling at a particular site must be made on a case-by-case basis. Many factors enter into the evaluation process, including: (1) the heat rejection rate of the plant, (2) the size and type of the receiving water body, (3) local physjcal characteristics of the water body, (4) the existence of other nearby sources of heat, (5) the character and distribution of indigenous populations of shellfish, fish, and wildlife, (6) the physical exicnt of the resulting thermal plume, (7) the impact of the thermal plumic on aquilic: organisms, (8) the impact of the cooling water intake on aquatic organisms, and (9) the costs and impacts of alternative waste heat disposal technolorics. This study was $1 \mathrm{imited}$ to assessing the efficacy of once-through cooljng in terms of the restrictions on the physical extent of the thermal plume produced. Typical water quility standards and guidelines were used as measures of the acceptability of once-through cooling systems and as the means of comparing the various ontfall design concepts. Thjs use of such standards and guidelines is, in one sense, arbitrary in that all of the other factors mentioned above are a]so taken into accounc in the actual evaluation of a proposed oncethrough cooling system. However, it does allow an assessment of the feasibility, in general terms, of using once-through cooling for various combinations of power plant generating capacities, receiving water types, and outfall design concepts.

Four generic classes of receiving water bodies (rivers, lakes, estuaries, and open coastal waters) and four typical large power plants (500-y fossi]-Fueled, 500-MN nuclear, 1000-MW fossil-fueled, and 1000-MN nuclear) were used to form a framework for the assessment. Typical thermal standards for each of the four classes of water bodies were identifie?. These standards are usually expressed in terms of upper limits on the allowed increase in water temperature above the natural ambient temperature. A region near the outfall within which the 1 init on excess temperature does not apply, referred to as the mixing zone, is often allowed. Restrictions on the physical size of this mixing zone, usually in terms of maximum surface area and maximum lateral extent, are imposed by the thermal standards or on a case-by- 
case basis. Estimates of cooling water flow rates and initiai excess temperatures were made for each of the four typical power plants. Because the initial excess temperature at the point of discharge is usually larger than that specified by thermal standards, a certain amount of mixing of the heated effluent with cooler ambient water must take place within the mixing zone. Estimates of the dilution required within the mixing zone were made for each of the classes of water bodies based on the initial excess temperature and the appropriate temperature standard.

Various outfall designs ranging from conventional, 1ow-velocity, shoreline, surface discharges to long, high-velocity, offshore, submerged multiport diffusers were considered. The mixing and dilution characteristics of these outfall designs were examined to determine the circumstances under which they could produce the required dilution within the appropriate mixing zone limits. The results of prototype measurements, analytical model predictions, and laboratory physical model studies were used to make this determination. Many of the results are subject to numerous qualifications and limitations. Many times, however, orle or two parameters characteristic of the outfall and/or the receiving water were identified and used to quantify the results, thus allowing a few general conclusions to be drawn.

The initial dilution attained by a shoreline surface discharge, and therefore the size of the mixing zone, is strongly influenced by the physical characteristics of the ambient receiving water. In the case of rivers, the surface area and lateral extent of the mixing zone are primarily determined by the average river velocity. The requirement that the mixing zone not extend across the entire river and the fact that available dilution water is limited by the finite flow rate of the river place limits on the minimum river flow rate for which typical thermal standards can be met. For example, a 500- W fossil-fueled plant would require a river flow rate of about $180 \mathrm{~m}^{3} / \mathrm{s}$ and a 1000-MW nuclear plant would require $520 \mathrm{~m}^{3} / \mathrm{s}$. Only the major river systems in the U.S. have flow rates that are consistently this large. In large lake applications, surface discharges might be acceptable for power plants with capacities $\$ 500$ MW if a mixing zone with a surface area of $2.9 \times 10^{5} \mathrm{~m}^{2}$ (equivalent to a circle with a 1000-ft radius) or larger were allowed. Larger power plants. with surface discharges would require mixing zones that would exceed most standards and guidelines. The large dilution 
typically required at estuarine and marine sites essentially precludes the use of shoreline surface discharges for large power plants.

The initial dilution attained by submerged outfalls, especially highvelocity multiport diffusers, is governed primarily by the characteristics of the discharge rather than the characteristics of the receiving water. Therefore, water depth, rather than the magnjtude and direction of ambient currents, is generally the most important characteristic of the receiving water body, except in riverine and certain estuarine cases where the total natural flow past the diffuser site is often the factor that limits dilution. It appears to be possible to design a multiport diffuser with a reasonable discharge velocity that will result in full mixing of the effluent with the total river flow. If full mixing is assumed, excess temperature standar $1 \mathrm{~s}$ place an extreme lower limit on the river flow rate necessary to support oncethrough cooling. However, the restriction that a zone of passage equivalent to three-quarters of the cross-sectional area of the river be maintained, requires larger river flow rates. For example, a 500-MW fossil-fueled plant would prodably require a river flow rate of $100-150 \mathrm{~m}^{3} / \mathrm{s}$ and a 1000-MW nuclear plant would require $300-400 \mathrm{~m}^{3} / \mathrm{s}$. Multiport diffusers appear to be very promising for use in large lakes. Even in fairly shallow water $(\approx 5 \mathrm{~m})$, a diffuser of reasonable length $(<350 \mathrm{~m})$ and discharge velocity $(>2 \mathrm{~m} / \mathrm{s})$ should be able to produce the dilution required for a power plant as large as $1000 \mathrm{MW}$ to meet typical thermal standards. Multiport diffusers for use at estuarine and marine open coastal sites must be designed to produce large dilutions $(\approx 12)$. In estuaries, complex density and current structures and other complicating factors make a general analysis of submerged multiport diffusers impossible. The need for large dilutions, the presence of bi-directional tidal currents, limited flushing, and the need to maintain a zone of passage requires that much care be taken in selecting the type of diffuser to be used at a specific site. Open coastal sites are less restrictive in that only the initial dilution in the vicinity of the outfall is critical. Coastal currents are often present to carry away the diluted effluent and the lack of a far boundary and the offshore location of the outfall preclude the need of a zone of passage. In general, diffusers will have to be at least 3-5 times longer than those needed for lake sites where comparable water depths are available. 
It has been shown in this study that once-through cooling water systems for single plants or generating units may be designed to operate, in some circumstances, within typical thermal standards. However, the cumulative effects of $a$ number of power plants on the same receiving water body have not been discussed. The degree of physical interactions among plants on the same water body depends on the relative magnitudes of heat advection and heat exchange to the atmosphere -- far-field processes. Large lakes and open coastal waters may, of course, accommodate greater heat loadings than other receiving waters. Envirommental inpacts of multiple plants with oncethrough cooling, obviously, include more than physical impacts. The cumulative effects of impingement and entrainment, potential disruption of coastal migration patterns, and the like must be considered. Estimates of physical thermal impacts of multiple plants can be made, and such studies should be a part of the first steps of an assessment extending over an entire water body. A useful prototype for such studies was carried out by Paily et al. 4 They used a numerical model of the thermal regimes of the upper Mississippi and Missouri Rivers to identify the number, distribution, and capacity of potential waste-heat disposal sites where steam-electric generating stations using once-through cooling might be installed. 


\section{ACKNOWLEDGMENTS}

This study was supported by the Division of Environmental Control Technology, Assistant Secretary for Environment, U.S. Department of Energy. The authors acknowledge the assistance of A.A. Frigo and D.L. McCown of the Argonne Fnergy and Environmental Systems Division in portions of this study. 
REFERENCES

1. Federal Power Commission, 1974 Annual Report, U.S. Government Printing Office, Washington, D.C. (1975).

2. Federal Energy Regulatory Commission, Steam-EZectric Plant Air and Water Quality Control Data for the Yexr Ended Decerber 31, 1974, Report DoE/ FERC-0018, Washington, D.C. (Sept. 1978).

3. Job, C.A., R.M. Bohne, K.H. Clemens, T. Gross, J.R. Hall, J.A. Johansen, W.E. Skimin, and D.M. Staples, Energy Eacility Siting in the Great Lakes Coastal Zone: Analysis and Folicy Options, Sreat Lakes Basin Commission, ann Arbor, Mich. (Jan. 1977).

4. Paily, P.P., T.-Y. Su, A.R. Giaquinta, and J.F. Kennedy, The Thermal Regimes of the Upper Mississippi and Mi.ssoumi Rivers, Institute of Hydraulic Research Report No. 182, Univ, of Iowa, Iowa City (Oct. 1976).

5. Parker, F.L., and P.A. Krenkel, Physical and Engineering Aspects of Thermal PolZution, CRC Press, Cleveland, Ohio (1970).

6. Samuels, G., Assessmert of Water Resources for Nuclear Energy Centers, Oak Ridge National Laboratory Report ORNL-5097, Oak Ridge, Tenn. (Sept. 1976).

7. Thermal Control Cust Factors, prepared for the Utility Water Act Group by National Economic Research Associates, Inc, and Stone \& Webster Engineering Corp. (May 1978).

8. United Engineers \& Constructors, Inc, Comercial Electric Power Cost Studies, Vol. 7, Cooling Systems Addendum: Capitol and Total Generating Cost Studies, prepared for U.S. Nuclear Regulatory Commission and the U.S. Department of Energy, Report No. NUREG-0247 (Sept. 1978).

S. Spigarel1i, S.A., Cesiwn-137 Activities in Fish Residing in Themal Discharges to Lake Michigan, Health Physics, 30:411-413 (1976).

10. National Technical Advisory Committee, Water Quality Critemia, Federal Water Pollution Control Administration, U.S. Dept. of Interior, Washington, D.C. (Apr. 1968).

11. U.S. Environmenta1 Protection Agency, Interagency 316(a) Technical Guidance Manual and Guide for Thermal Effects Sections of Nuclear Facilities Environmental Impact Statements, office of Water Enforcement, Permits Division, Industrial Permits Branch, Washington, D.C. (Draft, May 1, 1977).

12. Pritchard, D.W., Design and Siting Criteria for Once-Through Cooling Systems, presented at 68 th Annual Meeting, American Institute of Chemical Engineers, Houston (Mar. 2, 1971). 
REFERENCES (Cont'd)

13. P.itchard, D.W., Fate of and Effect of Excess Heat Discharged into Lake Mchigan with Specific Application to the Condenser Cooling Water Discharge from the Zion Nuclear Power Station, testimony at AEC Licensing Hearings for Zion Operating Permit, Chicago (June 1973).

14. Stolzenbach, K.D., and D.R.F. Harleman, An Analytical and Expemimentuj Investigation of Surface Discharges of Heated Water, Ralph M. Parsons Laboratory for Water Resources and Hydrodynamics Report No. 135, Massachusetts Institute of Technology, Cambridge, Mass. (Feb. 1971).

15. Shirazi, M.A. and L.R. Davis, Workbook of Thermal Plume Prediction, Volume 2, Surface Discharge, National Environmental Research Center Report EPA-R2-72-005b U.S. Environmental Protection Agency, Corval1is, Oregon (May 1974).

16. Policastro, A.J., and J.V. Tokar, Heated-Effluent Dispersion in Large Lakes: State-of-the-Art of Analytical Modeling, Argonne National Laboratory Report ANL/ES-11, Argonne; I11. (Jan. 1972).

17. Benedict, B.A., J.L. Anderson, and E.L. Yandel, Jr., Analytical Modeling of Thermal Discharges - A Review of the State of the Art, Argonne National Laboratory Report ANL/ES-18, Argonne, I11. (Apr. 1974).

18. Dunn, W.E., A.J. Policastro, and R.A. Paddock, Surface Thermal Plumes: Qvaluation of Mathematical Models for the Near and Complete Fiezd, Argonne National Laboratory Report ANL/WR-75-3 Parts One and Two, Argonne, I11. (May and Aug. 1975).

19. Jirka, G.H., G. Abraham, and D.R.F. Harleman, An Assessment of Techniques for Hydrothermal Prediction, Ralph M. Parsons Laboratory for Water Resources and Hydrodynamics Report No. 203, Massachusetts Institute of Technology, Cambridge, Mass. (July 1975).

20. Fan, L.-N., and N.H. Brooks, Numerical solutions of Turbulent Buoyant jet Problems, W.H. Keck Laboratory of Hydraulics and Water Resources Report No. KH-R-18, California Institute of Teshnology, Pasadena, Calif. (1969).

21. Hirst, E.A., Analysis of Round, Turbulent, Buoyant Jets Discharged to Flowing Stratified Ambients, Oak Ridge National Laboratory Report ORNL4685, Oak Ridge, Tenn. (June 1971).

22. Koh, R.C.Y., and L.-N. Fan, Mathematical Models for the Prediction of Temperature Distributions Resuiting from the Discharge of lleated Water into Large Bodies of Water, Water Pollution Control Research Series Report No. 16130 DWO 10/70, U.S. Environmental Protection Agency (Oct. 1970). 


\section{REFERENCES (Cont'd)}

23. Shirazi, M.A., and L.R. Davis, Workbook of Thermal Plume Prediction, Volume 1, Submerged Discharge, National Environmental Research Center Report EPA-R2-72-005a, U.S. Environmental Protection Agency, Corvallis, Oregon (Aug. 1972).

24. Adams, E.E., Submerged Multiport Diffusers in shalzow Water with Current, S.M. thesis, Department of Civil Engineering, Massachusetts Institute of Technology, Cambridge, Mass. (June 1972).

25. Jirka, G.H., and D.R.F. Harleman, The Mechanies of Submerged Multiport Diffusers for Buoyant Discharges in ShaZzow Water, Ralph M. Parsons Laboratory for Water Resources and Hydrodynamics Report No. 169 , Massachusetts Institute of Technology, Cambridge, Mass. (Mar. 1973).

26. Almquist, C.W., and K.D. Stolzenbach, Staged Diffusers in ShaZzow Water, Ralph M. Parsons Laboratory for Water Resources and Hydrodynamics Report No. 213, Massachusetts Institute of Technology, Cambridge, Mass. (June 1976).

27. Ditmars, J.D., R.A. Paddock, and A.A. Frigo, Observations of Thermal Plumes from Submerged Discharges in the Great Lakes ancine The Implication for Modeling and Monitoring, Waste Heat Management and Utilization, S.S. Lee and S. Sengupta, eds., Hemisphere Pub1. Corp., Washington, D.C., Vo1. 2, pp. 1307-1328 (1979).

28. Edinger, J.E., and E.M. Polk, Jr., Intermediate Mixing of Thermal Discharges into a Uniform Current, Water, Air, and Soil Pollution, 1:7-31, D. Reidel Publishing Company, Dordrecht, Holland (1971).

29. Parker, F.L., B.A. Benedict, and E.M. Polk, Mixing Zones below Thermal Power PZants, Proc. 1971 Intersociety Energy Conservation Engineering Conf., Boston, pp. 722-727 (1971).

30. Binkerd, R.C., Thernal Plumes at Vemont Yankee Nuclear Power Station, presented at Anerical Society of Civil Engineers National Convention, Denver (Nov. 3-7, 1975).

31. Stefan, H., G.R. Lake, and C.V. Nguyen, Mixing and Heat Transfer of CooIing Water Discharges from the Monticelzo Nuclear Power Generating Plant into the Mississippi River, St. Anthony Falls Hydraulic Laboratory Report No. 158, Univ. of Minnesota, Minneapolis (Mar. 1976).

32. Argue, I.R. and W.W. Sayre, The Mixing Characteristics of Sumerged Multiple-Port Diffusers for Heated Effluents in Open Channel Flow, Iowa Institute of Hydraulic Research Report No. 147, Univ. of Iow3, Iowa City, (July 1973). 
REFERENCES (COnt'd)

33. Adams, E.E., and K.D. Stolzenbach, Comparison oj Altemative Diffucer Designs for the Discharge of Heated iater into Shazlow Receiving Water, Proc. of the Conf. on Vaste Heat Hanagement and Utilization, Miami Beach, Fla., Vol. I, pp. 2C-171 - 2C-189 (Hay 9-11, 1977).

34. Parr, A.D., and W.W. Sayre, Prototyle and Model studies of the DiffuserPive Jystem for Discharging condenser cooling iater at the Quad-Citios Niclear Power Station, Iowa Institute of Hydraulic Research Report No. 204, Univ. of Iowa, Iowa City (June 1977).

35. Asbury, J.G., and A.A. Frigo, A Phenomenological Relationship for Tredicting the Surface Areas of Thermal Plumes in Lakes, Argonne National Laboratory Report ANL/ES-5, Argonne, I11. (Apr. 1971).

36. Frigo, A.A., and D.E. Frye, Physical Measurements of Triemat. Discharges into Lake lichigan: 1971, Argonne National Laboratory Report ANL/ES-16. Argonne, I11. (Oct. 1972).

37. Frigo, A.A., D.E. Frye, and J.V. Tokar, Fieid Investigations of Heated Discharges from Nuclear Power Plants on Lake Michigan: 1972, Argonne Natjona1 Laboratory Report ANL/ES-32, Argonne, Il1. (Mar. 1974).

38. Tokar, J.V., S.M. Zivi, A.A. Frigo, L.S. Van Loon, D.E. Frye, and C.Tome, heasurements of Physical Phenomena Related to power Plant Waste Heat Discharges: Laile Michigan, 1972 and 1974, Argonne National Laboratory Report ANL/WR-75-1, Argonne, I11. (Mar. 1975).

39. Kyser, J.M., R.A. Paddock, and A.J. Policastro, Analysis of Three Years of Complete-Field Temperature Data from Different Sites of Heated Surface Discharges into Lake Wichigan, Argonne National Laboratory Report ANL/WR-75-2, Argonne, I11. (Aug. 1974).

40. Elliott, R.V., and D.G. Harkiness, A Phenomenological Modei for the Prediction of Thermal Piumes in Large Lakes, The Hydro-Electric Power Commission of Ontario, Report No. TP-2, Toronto (Apr. 1972).

41. Prych, E.A., A Warm Water Effuent Analyzed as a Buoyant Surface Jet, Swedish Meteorological and Hydrological Institute Report No. 21, Stockholm, Sweden (1972).

42. Paddock, R.A., A.A. Frigo, and L.S. Van Loon, Thermal Dlumes from Submerged Discharges at Zion Nuclear Power Station: Prototype Measurements and Comparisons with Model Predictions, Argonne National Laboratory Report ANL/WR-76-5, Argonne, I11. (July 1976).

43. Paddock, R.A., A.A. Frigo, and J.D. Ditmars, ThermaZ Plumes from Submerged Discharges at Zion Nuclear Power Station: Additional Protoiype Measurements of Interacting Plumes, Argonne Nationai Laboratory Report ANL/WR-77-3, Argonne, I11. (July 1977). 
44. Frigo, A.A., R.A. Paddock, and D.L. McCown, Field Studies o: the Themal Plume fron the D.C. Cook Submerged Discharge witi Comparisoris to HydrauZic-Model Results, Argonne National Laboratory Report ANL/WR-754, Argonne, I11. (June 1975).

45. Paddock, R.A., J.D. Ditmars, and A.A. Frigo, Argonne National Laboratory, unpublished information.

46. Tsai, T.J., and B.E. Burris, Submerged Mutipori Diffuser Themaz Discharges from Conceptual Design to Postoperational Survey, Proc. of the Conf. on Waste Heat Management and Utilization, Miami Beach, Fla., Vol. III, pp. 10B-49 - 10B-70 (May 9-11, 1977).

47. Partheniades, E., B.C. Beechley, and Y. Jen, Wear Field Temperotures Distribution in Shallow Waters the to Submerged Heated Water Jets, Proc. 15th Congress of the International Association for Hydraulic Research, Vol. 2, pp. 137-144 (Sept. 1973).

48. Parthenıades, E., B.C. Beechley, and Y. Jen, A Parametric Study for Surface Temperature Concentration Due to Submerged Heated Water jets in Ghallow Water, Coastal and Oceanographic Engineering Laboratory Technical Peport No. 17, University of Florida, Gainesville, Fla. (May 1973).

49. Koester, G.E., Experimental Study of Sulmerged Single-Port Thermaz Discharges, Battelle Pacific Northwest Laboratory Report BN-SA-398, Richland, Washington (1974).

50. Hafetz, L.I., An Experimental Study of the Romd Buoyant det, Ph.D. thesis, University of Connecticut, Hartford, Conn. (1975).

51. Balasubramanian, V., and S.C. Jain, Horizontal Buoyant ejets in ariescent Shallow Water, Jour. Envir. Eng. Div., Proc. Amer. Soc. Civil Engr., 104 (EE4): 717-730 (Aug. 1978).

52. Gunwaldsen, R.W., B. Brodfeld, and G.E. Hecker, Cooling rater Struetrres for FitzPatrick Nuclear Plant, Jour. Power Div., Proc. Amer. Soc. Civil Engr., 97 (PO4):767-781 (Dec. 1971).

53. Parker, G.C., and C.S. Fang, Thermal Effects of the Surry Nuclear Eower Plant on the James River, Virginia, Part V. Results of Monitoming Physical Parameters during the First Two Years of Flant operation, Virginia Institute of Marine Sciences Report No. 92, Gloucester Point, Va. (June 1975).

54. Consolidated Edison Company of New York, Inc., Indian Point Vuclear Generating Station Thermal Sumey Program - Routine Honthiy Thema? Monitoring, May 1977 Sumey - Report No. 2, New York (Feb. 1978). 
RFFERERTS (cint'y)

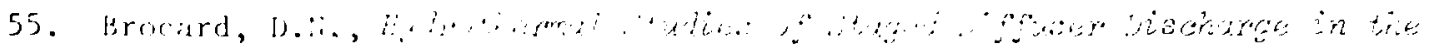

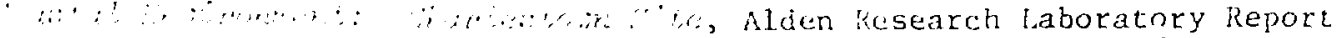

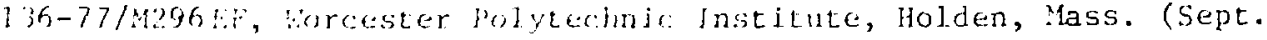
1977).

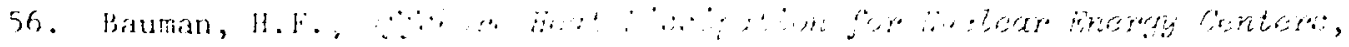
Wak Ridge fational laboratery Report ORal-TM-6435, Jak Ridge, Tenn. (Sept. 1978).

57. Harleman, D.R.F., FE. Adans, and G. Koester, Heromontal and findy-

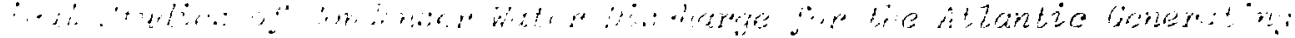
$\therefore$ Alire, Ralph 4 . Parsons laboratory for water Resources and llydrndynatires Report in. 173, Massachusetts Institute of Technology, Cambridge, liasis. (Junce 1973).

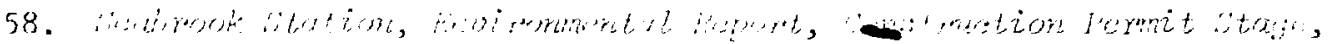
fublic Service Company of ivew llampshire, Seabrook, N.H. (June 1973).

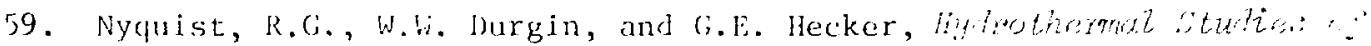

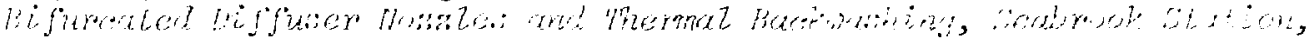
Alden Research laboratory Report 101-77/M296BF, Worchester Polytechnic: Institute. Holden, Mass. (Ju]y 1977).

60. Pagenkopf, I.R., D.R.F. Harleman, A.T. Ippen, and B.R. Pearce, pur.

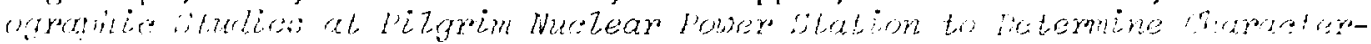

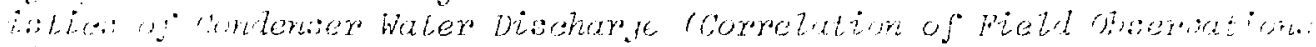
$\therefore(h$ (row $)$, Ralph M. Parsons Laboratory for Water Resources and llydrodynamics Report No. 183, Massachusetts Institute of Technology, Cambridge, Mass. (Jan. 1974).

61. Kol, R.C.Y., N.H. Brooks, E.J. L.ist, and E.J. Wolanski, Hydrauzie

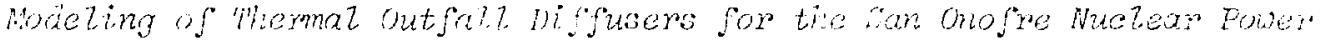
l'zent, W.M. Keck Laboratory of Hydraulics and Water Resources Report No. KH-R-30, California Institute of Technology, Pasedena, Calif. (Jan. $15,1974)$. 


\section{Distribution for ANL/WR-78-5}

Internal:
E. J. Croke
J. D. Ditmars
R. D. Flotard
A. A. Frigo
B. I. Graves
P. F. Gustafson
W. Harrison
A. B. Krisciunas

\author{
K. S. Macal \\ G. J. Marmer \\ W. E. Massey \\ D. I. Mc Cown \\ R. A. Paddock (25) \\ A. J. Poliustro \\ L. A. Raphaelian \\ J. J. Roberts \\ W. K. Sinclair
}

\author{
S. A. Spigarelli \\ V. C. Stamoudis \\ C. Tome \\ Y. H. Tsai \\ L. S. Van Loon \\ ANL Contract Copy \\ ANL Libraries (5) \\ TIS Files (6)
}

\section{Externa1:}

DOE-TLC, for distribu:ion per UC-11 and UC-12 (399)

Manager, Chicago Operations and Regional Office, DOE

Chief, Office of Patent Counsel, DOE-CORO

President, Argonne Universities Association

Energy and Environmental Systems Division Review Committee:
E. E. Angino, U. Kansas
R. F. Ciordon, U. Notre Dame
W. W. Hogan, Harvard U.
L. H. Roddis, Jr., Charleston, S.C.
(.) A. Rohlich, U. Texas at Austin
R. A. Schmidt, Electric Power Research Institute

E. E. Adams, Massachusetts Inst. Technology

R. A. Benedict, U. So. Carolina

N. H. Brooks, California Inst. Technology

R. B. Code11, U.S. Nuclear Regulatory Commission, Washington, D.C.

M. J. Crickmore, Hydraulic Research Station, Wallingford, England

G. T. Csanady, Woods Hole Oceanographic Inst.

A. A. Ezra, National Science Foundation, Washington, D.C.

H. B. Fischer, U. Celifornia, Berkeley

J. H. Gibbons, Office of Technology Assessment, U.S. Congress

T. Green III, U. Wisconsin, Madison

C. Grua, Division of Environmental Control Technology, DoE, Washington, D.C.

D. R. F. Harleman, Massachusetts Inst. Technology

T. Hayashi, Chuo U., Tokyo

G. E. Hecker, Alden Research Lab., Holden, Mass.

E. R. Holley, U. Texas, Austin

G. H. Jirka, Corne11 U.

L. D. Kannberg, Battelle Pacific Northwest Lab.

D. E. Kash, USGS, Reston, Va.

R. C. Y. Koh, California Inst. Technology

Librarian, Iowa Institute for Hydraulic Research, U. Iowa

W. Murphy, Illinois Inst. for Natural Resources, Chicago

A. Okubo, State U. of New York at Stony Brook

M. Palmer, Ministry of Environment, Toronto

A. Pinsak, National Oceanic and Atmospheric Admin., Ann Arbor

D. W. Pritchard, State U. of New York at Stony Brook

P. Reed, U.S. Nuclear Regulatory Commission, Washington, D.C.

R. R. Rumer, State U. of New York at Buffalo

N. S. Shashidhara, Envirosphere Co., New York 
W. C. Sonzogni, Great Lakes Basin Commission, Ann Arbor

H. Stefan, U. of Minnesota

G. E. Stout, U. Illinois, Urwana

T. W. Sturm, Georgia Inst. of Technology

T. I. Tsai, Stone and Webster Engzneering Corp., Boston

W. Waldrop, Tenncssec Valley Authority, Norris

H. Zar, U.S. Environmental Protection Agency, Chicago 